Published in final edited form as:

Compr Physiol. 2014 April 1; 4(2): 851-887. doi:10.1002/cphy.c130041.

\title{
Vestibulo-Sympathetic Responses
}

\author{
Bill J Yates ${ }^{1}$, Philip S. Bolton ${ }^{2}$, and Vaughan G. Macefield ${ }^{3}$ \\ ${ }^{1}$ Departments of Otolaryngology and Neuroscience, University of Pittsburgh, Pittsburgh, PA USA \\ ${ }^{2}$ School of Biomedical Sciences and Pharmacy, University of Newcastle, Callaghan, Australia \\ ${ }^{3}$ School of Medicine, University of Western Sydney, Sydney, Australia, and Neurosci Res \\ Australia
}

\section{Abstract}

Evidence accumulated over 30 years, from experiments on animals and human subjects, has conclusively demonstrated that inputs from the vestibular otolith organs contribute to the control of blood pressure during movement and changes in posture. This review considers the effects of gravity on the body axis, and the consequences of postural changes on blood distribution in the body. It then separately considers findings collected in experiments on animals and human subjects demonstrating that the vestibular system regulates blood distribution in the body during movement. Vestibulosympathetic reflexes differ from responses triggered by unloading of cardiovascular receptors such as baroreceptors and cardiopulmonary receptors, as they can be elicited before a change in blood distribution occurs in the body. Dissimilarities in the expression of vestibulosympathetic reflexes in humans and animals are also described. In particular, there is evidence from experiments in animals, but not humans, that vestibulosympathetic reflexes are patterned, and differ between body regions. Results from neurophysiological and neuroanatomical studies in animals are discussed that identify the neurons that mediate vestibulosympathetic responses, which include cells in the caudal aspect of the vestibular nucleus complex, interneurons in the lateral medullary reticular formation, and bulbospinal neurons in the rostral ventrolateral medulla (RVLM). Recent findings showing that cognition can modify the gain of vestibulosympathetic responses are also presented, and neural pathways that could mediate adaptive plasticity in the responses are proposed, including connections of the posterior cerebellar vermis with the vestibular nuclei and brainstem nuclei that regulate blood pressure.

\section{Introduction}

The role of the vestibular system in adjusting eye, head, and body position in space to compensate for linear and angular accelerations that occur during voluntary or unexpected movements has been appreciated for many decades $(117,118,120)$. In addition, the occurrence of motion sickness showed that the vestibular system influences the activity of the sympathetic and parasympathetic nervous systems and respiratory muscles, since the signs and symptoms of motion sickness include pallor, cold sweating, nausea and vomiting $(206,329)$. Consequently, the role of the vestibular system in control of autonomic functions was originally thought to be limited to the aberrant response of motion sickness, whose evolutionary significance and physiological role is still debated $(34,121,177,206,230,242$, $313)$. 
Over the past four decades, beginning with a seminal study by Doba and Reis in 1974 (89), considerable evidence has accumulated through experiments in both animal and human subjects to demonstrate that the vestibular system plays an active role in adjusting blood distribution in the body during movement and changes in posture $(22,314,317,326)$. Redistributions of blood elicited by vestibular stimulation are mainly accomplished through the actions of the sympathetic nervous system, and have been termed "vestibulo-sympathetic reflexes" (VSR). This article will outline the evidence showing that body movements in space trigger VSR, and that these responses complement baroreceptor and cardiopulmonary reflexes in assuring that blood pressure remains stable during the homeostatic challenges associated with body motion and postural alterations. In addition, current information regarding the neural pathways that mediate VSR will be described.

\section{Neural Regulation of Blood Pressure}

Both the sympathetic and parasympathetic nervous systems contribute to the regulation of blood pressure, as reviewed extensively in other Handbook of Physiology chapters (1, 33, $35,298,302)$ and many additional publications $(61,79,113,116,139,155,229,243,270$, $271,283,284)$. For both systems, preganglionic neurons located in the central nervous system provide synaptic inputs to postganglionic neurons situated in peripheral ganglia, that in turn innervate smooth or cardiac muscle cells or pacemaker cells in the heart. Sympathetic preganglionic neurons are concentrated in the thoracic and upper lumbar spinal cord, whereas parasympathetic preganglionic neurons are located in specific sites in the brainstem as well as in the sacral spinal cord. Parasympathetic postganglionic neurons release the neurotransmitter acetylcholine onto muscarinic receptors on the surface of target cells. In contrast, most (but not all) sympathetic postganglionic neurons release norepinephrine onto $a$ - or $\beta$-adrenergic receptors on the surface of target cells. An exception to this organization is the innervation of chromaffin cells in the adrenal medulla by sympathetic preganglionic neurons. Chromaffin cells resemble sympathetic postganglionic neurons, but release epinephrine and some norepinephrine into the bloodstream when activated by sympathetic preganglionic neurons. Epinephrine binds to adrenergic receptors, with a preference for $\beta$ receptors. The organization of sympathetic and parasympathetic nervous system influences on the cardiovascular system are outlined in Fig. 1.

The dogma that the sympathetic and parasympathetic nervous systems always operate in a push and pull fashion $(52,53)$ certainly does not apply to the cardiovascular system (1). While these two systems have opposite effects on heart rate through their actions on cardiac pacemaker cells, the parasympathetic nervous system contributes relatively little to adjusting peripheral blood flow or contractility of the ventricles of the heart (155). Whereas vascular smooth muscle receives rich innervation from the sympathetic nervous system, the parasympathetic nervous system is connected with only a few specific vascular beds (such as blood vessels in the genitalia)(191). In the vascular beds that receive parasympathetic innervation, the parasympathetic nervous system induces the release of nitric oxide from endothelial cells, which in turn causes vasodilation.

Pressure in the systemic arteries is related to both the amount of blood ejected from the left ventricle of the heart and the resistance present in the vasculature (249). Cardiac output is 
determined by both heart rate and the contractility of the ventricles (propensity for cardiac muscle cells to shorten). In general, the sympathetic nervous system acts to increase blood pressure, as it induces an increase in heart rate, enhanced ventricular contractility, and increases in vascular resistance. It is noteworthy, however, that blood flow through capillary beds, and not blood pressure per se, is the critical factor in maintaining the viability of peripheral tissues. Vasoconstriction of smooth muscle in arterioles diminishes blood flow to the capillary beds distal to the constricted vessels, while blood flow through capillaries distal to dilated vessels increases. Hence, the sympathetic nervous system serves to adjust the amount of blood flow to particular tissues of the body.

\section{Effects of Postural Alterations on the Cardiovascular System}

Understanding the physiological significance of VSR requires an appreciation of the effects of gravity on the cardiovascular system. When lying in the supine or prone positions, the force of gravity has approximately the same effects at the level of the feet, head, and heart $(35,135,140)$. Hence, arterial and venous blood pressures are relatively constant across the body axis, as shown in Fig. 2. However, upon standing, gravity causes great disparities in arterial and venous blood pressure in different body regions $(35,135,140)$ (see Fig. 2). Since mercury is approximately 13.6 times as dense as blood, arterial blood pressure decreases about $0.74 \mathrm{~mm} \mathrm{Hg}$ per $\mathrm{cm}$ above the heart, and increases the same amount as blood descends below the heart. Thus, if mean arterial blood pressure is $90 \mathrm{~mm} \mathrm{Hg}$ in the aorta, it would be $\sim 68 \mathrm{~mm} \mathrm{Hg}$ at $1^{\prime}(30.5 \mathrm{~cm})$ above the heart and $\sim 112 \mathrm{~mm} \mathrm{Hg}$ at $1^{\prime}$ below the heart. Furthermore, upon standing, venous pressure increases in the lower body, to $\sim 100 \mathrm{~mm}$ $\mathrm{Hg}$ in an individual with $136 \mathrm{~cm}$ of distance from the feet to the heart (see Fig 2). Thus, if no other physiological processes (e.g., skeletal muscle pumping, venoconstriction, presence of venous valves) acted to propel blood back to the heart, $100 \mathrm{~mm} \mathrm{Hg}$ of pressure would be required to translocate blood from the feet to the heart during standing.

There are a variety of physiological consequences of postural alterations. The increases in arterial and venous pressures that occur in the lower body when an individual stands from a supine position result in increased hydrostatic pressures within capillaries, and thus loss of fluid into the interstitial space $(35,135,140)$. Moreover, blood is translocated to the lower body, resulting in a reduction of venous return to the heart $(35,135,140)$. It has been established for nearly a century that cardiac output is dependent on venous return, since stretch of the ventricle (and the myocytes in its wall) results in stronger contractions (228, 274). Thus, a reduction in venous return to the heart immediately results in decreased cardiac output, and lower blood pressure.

A study in cats examined the effects of postural changes on blood pooling in the lower body, by comparing blood flow (measured using transit-time ultrasound technology) in the femoral artery and vein during passive head-up tilts of different amplitudes (331). As indicated in Fig. 3, sudden head-up rotations of the animals (delivered at a velocity of $30^{\circ} / \mathrm{sec}$ ) resulted in an immediate decrease in venous return, which was maximal $\sim 5 \mathrm{sec}$ after the tilt reached peak amplitude, but subsequently abated. However, as long as the animal was in the head-up position, venous return to the heart was lower than when the animals were prone. The effects were dependent on the amplitudes of rotations, such that $60^{\circ}$ tilts resulted in a transient, 
instantaneous 70\% decrease in femoral vein blood flow, and a sustained decrease of 30-40\% relative to when animals were prone. Simultaneously, femoral artery blood flow also decreased, presumably due to vasoconstriction in the lower body produced by the actions of the sympathetic nervous system. At $\sim 10 \mathrm{sec}$ after the tilt reached maximal amplitude, the decline in arterial and venous blood flow were almost perfectly matched, so that blood accumulation in the hindlimb (difference between the two parameters) was $\sim 0$ (331).

These data suggest that the sympathetic nervous system triggers both venoconstriction (to reduce venous compliance and aid in return of blood to the heart) and arterial vasoconstriction (to decrease blood flow to the hindlimb) during head-up rotations, to limit hindlimb blood pooling resulting from the effects of gravity on the body (331). Additional physiological mechanisms also facilitate venous return to the heart during standing, including skeletal muscle pumping and alterations in the activity of respiratory muscles (67, 245). It is noteworthy that muscle contraction associated with standing has the potential of producing a transient surge of blood to the heart, thereby momentarily offsetting the gravitational effects on the cardiovascular system (304). Thus, gravitational actions on the cardiovascular system likely differ depending on whether the postural changes are active or passive (e.g., delivered using a tilt table).

Data from human subjects have provided contradictory conclusions regarding the role of the sympathetic nervous system in ameliorating blood pooling in the lower body $(32,144,151$, $215,241,295)$. In particular, the role of the sympathetic nervous system in regulating compliance of lower body veins during postural changes is a matter of debate $(106,175$, 203). Nonetheless, it is universally agreed that sympathetic vasoconstrictor activity increases in the upper and lower body during standing, and that an absence of such increases in sympathetic nervous system activity during postural changes results in a precipitous drop in blood pressure $(107,108,136,184,292)$. Thus, a variety of physiological mechanisms, including feedforward mechanisms that are triggered before changes in blood pressure occur, are necessary to maintain stable blood pressure during postural alterations.

\section{Detection of Postural Alterations that Affect the Cardiovascular System}

A variety of feedback mechanisms serve to increase sympathetic nervous system activity when postural alterations result in decreased venous return to the heart and lowered blood pressure. Stretch receptors in the wall of the atria are activated in accordance with venous return; unloading of the atrial receptors results in increased firing in sympathetic nerves (33). In addition, baroreceptors in the aortic arch and carotid sinus respond to arterial stretch, and are unloaded when blood pressure decreases, leading to an increased firing of sympathetic vasoconstrictor neurons (251). Thus, a decline in venous return and the associated reduction in arterial blood pressure trigger two reflex systems that act in parallel to increase sympathetic vasoconstrictor drive to resistance vessels.

Although complementary reflex systems serve to increase sympathetic nervous system activity when venous return and blood pressure decrease, these reflex systems are engaged only after cardiovascular disturbances are present $(33,251)$. Atrial receptors that regulate sympathetic activity are mainly unmyelinated $(223,287)$, and most baroreceptor afferents 
are unmyelinated or thinly myelinated $(12,254,300)$. Thus, transmission of sensory signals from baroreceptors to the brainstem occurs relatively slowly. Studies involving electrical stimulation of baroreceptor afferents have shown that changes in blood pressure occur at a relatively long latency (>1 sec) following activation of the afferent fibers (160). Considering the extremely rapid changes in venous return that occur during head-up tilt (see Fig. 3), this lag in the baroreceptor reflex would allow considerable blood accumulation in the lower body. Moreover, appreciable unloading of atrial and arterial stretch receptors would only occur after a significant decline in venous return to the heart and blood pressure have transpired $(35,135,140)$. Since leg and abdominal muscle contractions during active standing propel a bolus of blood to the heart, the arterial and atrial stretch receptors could be momentarily loaded when gravitational effects are beginning to cause blood accumulation in the lower body (304). These observations indicate the physiological importance of additional mechanisms that rapidly adjust sympathetic nervous system activity during postural alterations.

As discussed in detail below (see "Characteristics of Vestibulosympathetic Reflexes in Animal Models" and "Vestibulosympathetic Reflexes in Human Subjects"), it is now established that an additional reflex system activated by inputs from vestibular system endorgans adjusts sympathetic nervous system activity during postural changes. The significance of VSR in regulating blood pressure likely rests with the exquisite sensitivity of the vestibular system in detecting changes in head orientation in space. VSR can be triggered at the onset of movements that could lead to peripheral blood pooling and a decrease in venous return to the heart, and thus have an important advantage over reflexes elicited by the unloading of atrial or arterial stretch reflexes.

Five vestibular sensory organs exist in the inner ear on each side of the head: one associated with each of the three semicircular canals, and two otolith organs located within a central area called the vestibule, which extends between the semicircular canals and the cochlea (see Fig. 4). The semicircular canals are sensitive to angular acceleration, which occurs when an individual rotates their head or is positioned on a spinning device such as a merry-go-round. In contrast, the two otolith organs, the utriculus and the sacculus, which are roughly perpendicular to each other, sense linear acceleration. The utriculus is mainly responsive to horizontal plane linear accelerations, such as those that occur when an airplane speeds down a runway. In contrast, the sacculus is mainly responsive to vertical plane linear accelerations, which occur when an individual falls downward or is suddenly hoisted upwards in an elevator. Gravity is a form of linear acceleration, and changes in head position with respect to gravity provide the major physiological stimulus for the otolith organs. Signals from the vestibular endorgans are carried via afferents in the VIII ${ }^{\text {th }}$ cranial nerve to the brainstem, mainly to the vestibular nuclei. This complex of four nuclei is located dorsolaterally within the medulla and caudal pons $(23,118,120)$.

It is noteworthy that the vestibular endorgans signal head movements and position in space, and not the location of the body in space. In order to produce physiologically-appropriate responses, additional sensory information is required. For example, both a downward nod of the head and a head-forward fall produce the same activation of vestibular endorgans. Whereas the first of these scenarios requires no limb extension through vestibulospinal 
reflexes to remain erect, the second example does. To differentiate between whole-body and head-on-body movements, vestibular nucleus neurons integrate inputs from vestibular endorgans and neck proprioceptors. These inputs are typically antagonistic, and tend to cancel each other $(96,310,311)$. Hence, a vestibular nucleus neuron whose firing rate increases during a head-forward shift in body position may not respond to a downward nod of the head, since the latter entails stimulation of both neck proprioceptors and receptors in the vestibular endorgans $(40,166)$. In addition, proprioceptive inputs from throughout the body affect the activity of vestibular nucleus neurons (163), and recent studies have suggested that at least some vestibular system neurons encode movement with respect to the body and not the head (183). Furthermore, recent data have also shown that vestibular nucleus neurons respond differently to active and unexpected movements of the head, showing that higher brain regions that control movement affect the processing of signals within the vestibular system (74).

Although some changes in posture that affect venous return to the heart are unexpected, such as a cat falling from a tree, most are voluntary movements. Consequently, it would seem appropriate to proactively adjust sympathetic nervous system activity as movements are planned and executed. The notion that higher brain centers regulate the firing rate of brainstem neurons that control sympathetic nerve activity is supported by research on "central command" (97, 186, 197, 298, 305). Experiments monitoring cardiovascular responses in human and animal subjects showed that adjustments in these responses necessary during exercise are initiated before exercise begins $(97,298)$. For example, paralyzed human subjects exhibit increases in blood pressure and heart rate that are graded to the intensity of imagined exercise (110). In decerebrate or anesthetized cats, stimulation of regions of the lateral and caudal hypothalamus, fields of Forel, and midbrain ventral tegmental area elicit parallel changes in motor activity and cardiovascular responses (186, 213, 298). Central command entails in part resetting the gain of baroreceptor reflexes, which allows blood pressure and heart rate to increase $(97,186,197,298,305)$. However, there has been no demonstration through neurophysiological recordings in conscious animals that planning of movement affects the activity of brainstem neurons that control blood pressure.

\section{Characteristics of Vestibulo-Sympathetic Reflexes in Animal Models}

\section{Responses Elicited by Electrical Stimulation of Vestibular Afferents}

Accelerations of the head that activate vestibular endorgans also have the potential of stimulating other receptors in the body. In particular, linear accelerations including those produced by gravity during body tilts can result in fluid shifts that affect stretch receptors in the atria and large arteries. To circumvent this problem, a number of studies have used stimulating electrodes secured near branches of the VIII ${ }^{\text {th }}$ cranial nerve to selectively activate vestibular afferents, without stimulus spread to adjacent nerves (the auditory portion of the VIII ${ }^{\text {th }}$ nerve or the VII ${ }^{\text {th }}$ nerve). In addition, the stimulus is synchronous, and thus latencies of responses can be calculated accurately. A limitation of the use of electrical vestibular stimulation is that vestibular afferents signaling head movements in different directions are activated at the same time. Thus, whereas electrical vestibular stimulation can 
be used to determine whether a response is produced by the vestibular system, the technique does not provide insights regarding the physiological properties of the response.

A large number of studies conducted in a variety of laboratories have shown that delivery of electrical stimuli to vestibular nerve branches elicits changes in sympathetic nerve activity, as illustrated in Fig. 5 (62, 145, 146, 170, 202, 276, 286, 288, 289, 323, 328). These responses could be excitatory, inhibitory, or consist of a combination of excitation and inhibition. Furthermore, VSR elicited by electrical stimulation have been recorded from sympathetic nerves innervating many regions in the body, including the cardiac nerve, cervical sympathetic nerve, abdominal sympathetic chain, splanchnic nerve, renal nerve, celiac nerve, superior mesenteric nerve, hypogastric nerve, lumbar colonic nerve, and external cardiac nerve. Many of the studies included controls such as lesioning the ipsilateral vestibular nuclei to demonstrate that the responses were due to activation of vestibular afferent fibers, and not to current spread to other afferents. The latencies of VSR elicited by electrical stimulation typically ranged from 50-100 msec, depending on the recording location.

One study examined the effects of electrical stimulation of vestibular afferents on the firing rate of physiologically-identified muscle constrictor fibers in the face, forelimb, and hindlimb (171). Muscle vasoconstrictor fibers in all three regions responded to vestibular stimulation. Some of the efferents were inhibited by the stimulus, whereas others were mainly excited. Curiously, muscle vasoconstrictor fibers that were inhibited by vestibular stimulation tended to be located in the leg, whereas those that were mainly excited were located in the upper body. These findings suggest that VSR are anatomically patterned, and differ between body regions (see "Patterning of Vestibulosympathetic Reflexes" below).

Other studies have demonstrated that delivery of a train of electrical stimuli to vestibular nerve fibers produces a decrease in blood pressure $(145,146,168,192,268,269,289)$, as well as a large increase in blood flow to the lower body (168), as shown in Fig. 6. Electrical stimulation of vestibular afferents also produced a slight decrease in forelimb blood flow (168), as illustrated in Fig. 6. Since the magnitude of the forelimb hemodynamic response was smaller than that of the hindlimb response, the decline in blood pressure was likely due to a decline in total peripheral resistance associated with the increase in lower body perfusion.

\section{Responses Elicited by Natural Stimulation of Vestibular Afferents}

The use of electrical stimulation of vestibular afferents demonstrated that the vestibular system influences sympathetic nervous system activity. However, studies using natural vestibular stimulation (movement of the animal's body in space) were required to provide insights into the physiological role of VSR. As noted above, use of natural vestibular stimulation is problematic, as body movements can activate receptors outside the inner ear, including cardiopulmonary and baroreceptor afferents if the movements produce fluid shifts. To address this limitation, two approaches have been used. In the first, extensive denervations were conducted in animals to eliminate inputs from nonlabyrinthine afferents. In the second, responses were compared before and after removal of vestibular inputs, usually by bilateral destruction of the inner ear or transection of the VIII ${ }^{\text {th }}$ nerves. 
In one study (327), splanchnic nerve activity was recorded in decerebrate cats during rotation of the head on a fixed body, following a cervical dorsal root rhizotomy (to eliminate inputs from neck receptors activated by head movement) and transection of the IX ${ }^{\text {th }}$ and $X^{\text {th }}$ cranial nerves in the neck (to eliminate inputs from cardiopulmonary receptors and baroreceptors). The maximal rotation amplitude was $20^{\circ}$. Since only the head of the animals was moved, and extensive denervations were conducted, it was presumed that vestibular receptors were selectively activated. This was confirmed by demonstrating that lesions placed in the vestibular nuclei eliminated the sympathetic nerve responses to head rotation.

During sinusoidal rotations of the head in vertical planes, splanchnic nerve activity was highest when the nose was tilted upwards, and lowest when the nose was tilted downwards, as shown in Fig. 7. Roll tilts (ear-down rotations) of the head had little effect on splanchnic nerve activity, and neither did horizontal (yaw) rotations. Responses to clockwise and counterclockwise rotations of the head in vertical planes were used to determine the response vector orientation, or the plane of head tilt that produced maximal sympathetic nerve activation. For most animals, the response vector orientation was near nose-up pitch of the head (327).

After the response vector orientation was determined, sinusoidal head rotations were delivered in this plane at a variety of frequencies to determine the dynamics of responses to vestibular stimulation (327). A sine wave was fitted to responses, and two parameters were calculated: the amplitude of the sine wave (response gain) and the phase shift between the stimulus and response sine waves (response phase). These parameters are plotted in Fig. 8 for each stimulus frequency tested. Response gains were typically consistent across stimulus frequencies, and response phases were near stimulus position or lagged stimulus position slightly. These response characteristics are similar to those of afferents innervating the vestibular otolith organs $(7,101,165)$, suggesting that inputs from the otolith organs elicited the changes in sympathetic nerve activity (327).

Another study using the same preparation tested whether $50^{\circ}$ rotations of the head produced changes in blood pressure (312). Head-up tilts elicited an increase in blood pressure with a mean magnitude of $18 \mathrm{~mm} \mathrm{Hg}$ and a mean latency of $1.3 \mathrm{sec}$ from the onset of the movement. The rise in blood pressure occurred without an appreciable change in heart rate, suggesting that the blood pressure response was caused by an increase in peripheral vasoconstriction. Ear-down tilts did not produce a significant change in blood pressure. Therefore, increases in blood pressure were elicited by the direction of vestibular stimulation (head-up tilt) that ordinarily signals body movement that diminishes venous return to the heart. The increases in blood pressure triggered by head-up tilts were abolished by transection of the VIII ${ }^{\text {th }}$ cranial nerves, demonstrating that they were the result of activation of labyrinthine afferents. However, several caveats must be considered when interpreting the results of the study. First, it was assumed that if neck receptors were intact, neck and vestibular inputs to the vestibular nuclei would have cancelled, and no changes in blood pressure would have occurred. This assumption was supported by a later study showing that rotation of the head upwards produced changes in sympathetic nerve activity only following an upper cervical dorsal rhizotomy to eliminate neck inputs (and not when neck inputs were 
present) (37). In addition, the responses recorded in this study would likely have been attenuated if baroreceptors were intact.

Other studies compared cardiovascular responses to whole-body movements before and after bilateral destruction of the inner ear or transection of the VIII ${ }^{\text {th }}$ nerves, to ascertain which components of the responses were related to activation of labyrinthine receptors. The earliest of these studies, conducted by Doba and Reis (89), was paramount in establishing the physiological significance of VSR. These investigators showed that transection of the VIII $^{\text {th }}$ nerves in anesthetized, paralyzed cats resulted in significantly larger decreases in blood pressure during $30^{\circ}$ and $60^{\circ}$ head-up tilts than when vestibular inputs were present. Complementary findings were subsequently obtained through experiments on conscious cats (162), although it was noted that the effects of the lesions dissipated over time. The transience of effects of vestibular system lesions on the regulation of blood pressure is discussed below (see "Recovery of Cardiovascular Responses Following Vestibular System Lesions"). Lesions placed bilaterally in the caudal aspect of the vestibular nucleus complex also resulted in larger decreases in blood pressure during head-up tilts (207). Similarly, studies in rats showed that rearing causes a drop in blood pressure that is exacerbated following vestibular lesions or baroreceptor denervation (2).

Subsequent studies considered the effects of elimination of labyrinthine inputs on peripheral blood flow during head-up tilts $(307,331)$. As illustrated in Fig. 9, $60^{\circ}$ head-up tilts in conscious cats resulted in a decrease in both forelimb and hindlimb blood flow and a marked increase in vascular resistance. However, the changes in hindlimb blood flow and vascular resistance were strongly attenuated following a bilateral vestibular neurectomy. Over time, however, there was recovery in adjustments of hindlimb blood flow during postural changes. In contrast, removal of vestibular inputs resulted in little change in forelimb blood flow. These findings complement those from studies using electrical stimulation of vestibular afferents in showing that VSR are anatomically patterned, and differ between body regions $(168,169)$.

The effects of removal of labyrinthine inputs on carotid artery blood flow to the head have also been assessed in conscious animals (306). Unlike limb blood flow, blood flow to the head measured when animals were in the prone position increased appreciably after bilateral transection of the VIII ${ }^{\text {th }}$ nerves. As a result, even when posturally-related lability in carotid blood flow occurred after removal of vestibular inputs, blood supply to the head was not lower than when labyrinthine inputs were present. These data show that the vestibular system may have different roles in regulating cerebral blood flow and blood flow to other regions of the body, in that it modulates the baseline levels of perfusion of the head. In addition, the findings support the notion that VSR are anatomically patterned.

Another group of experiments examined the role of the vestibular system in generating cardiovascular responses during gravitational stress resulting from centrifugation (3-G hypergravity) in rodents $(3,124,185)$. In animals lacking both baroreceptor and vestibular inputs, blood pressure dropped during short exposures to hypergravity. In baroreceptorintact animals lacking vestibular inputs, blood pressure increased during hypergravity exposures. It was concluded that the VSR serve to increase blood pressure during 
gravitational stress, and that any overshoots in blood pressure were corrected by baroreceptor reflexes $(4,124,185)$. Other experiments showed that microgravity associated with free-fall resulted in an increase in blood pressure in intact rats, but that the response was attenuated in rats with bilateral peripheral vestibular lesions (3-5). The pressor responses to free-fall were also attenuated in animals with 2 weeks exposure to centrifugation. Furthermore, in centrifuged rats with subsequent bilateral vestibular lesions, the pressor responses were significantly smaller than in other conditions. These data provide additional evidence that the vestibular system contributes to cardiovascular regulation.

Summary-The combination of approaches used in animal models support the conclusion that VSR complement baroreceptor and cardiopulmonary reflexes in maintaining stable blood pressure during changes in posture. In addition, VSR are rapid enough to limit blood pooling at the onset of movement, before appreciable blood accumulation occurs in the periphery. Loss of vestibular inputs results in disturbances in blood pressure during postural alterations, likely due to impairments in the capacity to raise peripheral resistance in the lower body. However, long-term experiments showed that deficiencies in cardiovascular responses during postural changes following vestibular lesions are temporary, suggesting that other mechanisms can substitute for the loss of VSR. These mechanisms are described below (see "Recovery of Posturally-Related Cardiovascular Responses Following Vestibular System Lesions".)

\section{Recovery of Posturally-Related Cardiovascular Responses Following Vestibular System Lesions}

Studies assessing the effects of removal of vestibular inputs on the regulation of blood pressure and peripheral blood flow showed that impairments in the cardiovascular responses dissipated over time $(306,307,331)$. It thus appears that alternate mechanisms can at least partially replace VSR. Postural stability recovers over the same time period that compensatory cardiovascular responses return following peripheral vestibular lesions, which has been attributed to substitution of nonlabyrinthine for labyrinthine sensory inputs within the central nervous system (190).

Several possible mechanisms of sensory substitution have been discussed, which are not mutually exclusive. Placement of lesions bilaterally in the caudal aspect of the vestibular nucleus complex resulted in permanent deficits in adjusting blood pressure during head-up tilts, suggesting that the recovery of the ability to make such adjustments following bilateral VIII ${ }^{\text {th }}$ nerve transections required the processing of neural signals within the vestibular nuclei (207). Other studies demonstrated that neurons in the caudal portions of the vestibular nuclei receive appreciable inputs from somatosensory receptors in the neck, trunk, and limbs $(161,163)$, and that the number of vestibular nucleus neurons that responded to these signals increased following the elimination of labyrinthine inputs $(163,189)$. The firing rate of a small fraction of vestibular nucleus neurons was modulated by head-up tilts following bilateral transection of the VIII ${ }^{\text {th }}$ nerves, which raised the following possibility: substitution of nonlabyrinthine for labyrinthine signals in the vestibular nuclei restored responses that were initially lost following removal of vestibular inputs $(195,324)$. However, it remains 
unclear whether enough vestibular nucleus neurons respond to changes in body position following bilateral loss of labyrinthine inputs to account for the functional recovery that is observed (195).

A large body of physiological evidence has demonstrated that the rostral ventrolateral medulla (RVLM), a column of cells located near the ventral surface of the rostral medulla, plays a predominant role in controlling sympathetic nerve activity and blood pressure (39, 76-78). Bilateral inhibition of the RVLM causes a loss of baroreceptor reflexes $(75,126$, 244). The RVLM also provides a major pathway through which vestibular signals are conveyed to sympathetic preganglionic neurons in the spinal cord, as indicated by the observation that bilateral chemical lesions of the RVLM abolished VSR (328). In conscious cats, a significantly higher fraction of RVLM neurons exhibited cardiac-related activity, or rhythmic bursts of action potentials synchronized with the cardiac cycle, after removal of vestibular inputs (27). In addition, a bilateral labyrinthectomy resulted in a significant reduction in the spontaneous activity of RVLM neurons, including those with cardiac related activity (27). Both the higher prevalence of cardiac related activity and depressed activity of RVLM neurons subsequent to removal of vestibular inputs could be explained by an increase in the baroreceptor reflex gain. The development of enhanced baroreceptor reflexes following vestibular lesions would result in increased vasoconstriction during head-up tilts, which could account for the findings that instability in blood pressure during postural changes dissipates over time after a loss of VSR (162). These observations raise the hypothesis that after a bilateral labyrinthectomy, blood pressure instability during head up tilts, which is reflected in the activity of baroreceptors, triggers plastic changes in the neural circuit that produces baroreceptor reflexes, such that baroreceptor reflex gain increases.

Uvulectomy (removal of lobule IX of the posterior cerebellar vermis) prevents compensation for loss of VSR, such that blood pressure permanently remains labile during head up tilts following a bilateral labyrinthectomy (141). Furthermore, stimulation or lesions of the uvula elicit changes in sympathetic nerve activity and blood pressure $(24,43,138$, 218). Purkinje cells in the uvula provide monosynaptic inputs to the caudal aspect of the vestibular nucleus complex, which mediates VSR, and disynaptic inputs to nucleus tractus solitarius (NTS), which receives direct inputs from baroreceptor afferents $(138,226,250)$. Thus, the uvula's connections are appropriate for regulating gains of both VSR and baroreceptor reflexes. Inputs to the uvula are consistent with the hypothesis that this cerebellar region modulates cardiovascular responses when disturbances in homeostasis occur, such as during postural alterations subsequent to loss of labyrinthine inputs. The uvula receives labyrinthine and baroreceptor signals relayed through both mossy and climbing fibers $(23,41,173,217,221,267)$. This pattern of inputs is analogous to those to the cerebellar flocculus, which modifies the gain of the vestibulo-ocular reflex when it is inadequate in keeping the retinal fovea aligned with a visual target of interest during head movements $(48,90,182,194,303)$, with the exception that signals related to blood pressure are substituted for those indicating retinal slip. Consequently, the uvula may participate in producing plastic changes in the neural pathways that regulate blood pressure when disturbances in cardiovascular homeostasis ensue. This hypothesis awaits experimental verification. 


\section{Summary}

Effects of removal of vestibular inputs on the regulation of blood pressure dissipate over the same time period that the animals recover postural stability, likely because nonlabyrinthine inputs substitute for the elimination of vestibular signals. There is some evidence that the gain of the baroreceptor reflex increases following a bilateral labyrinthectomy, and that the enhanced baroreceptor responses partially compensate for the loss of the VSR. Damage to the cerebellar uvula attenuates recovery of posturally-related cardiovascular responses following the loss of vestibular inputs, raising the possibility that the cerebellum adjusts the gains of VSR and baroreceptor reflexes when these responses are inadequate in maintaining cardiovascular homeostasis. Similarly, adjustments in the gain of the vestibulo-ocular reflex to prevent retinal slip no longer occur following damage to the cerebellar flocculus.

Accordingly, the posterior cerebellum may have analogous roles in somatic and autonomic motor control, at least with regard to responses generated by the vestibular system.

\section{Patterning of Vestibulosympathetic Reflexes}

Walter Cannon proposed early concepts about the regulation of sympathetic nervous system activity. Cannon conjectured that all sympathetic nerve fibers were activated simultaneously in response to a variety of different stimuli (53). However, the development of methods to record activity from single sympathetic nervous system efferents changed this perspective. Jänig and colleagues disproved Cannon's notion by demonstrating that sympathetic efferents innervating particular tissue types responded to selective stimuli $(36,154,156)$. For example, the excitability of sympathetic efferent fibers regulating skin blood flow is selectively altered in accordance with changes in body temperature. Such findings led to the dogma that patterning of blood flow mediated by the sympathetic nervous system is in accordance with tissue type, but not the location of the tissue within the body. For instance, a stimulus might induce a decrease in the activity of sympathetic efferent fibers regulating skeletal muscle blood flow, but the activity of efferents innervating blood vessels in all muscles would be affected equally. Additional observations supported this notion. When microinjection of sodium glutamate was used in cats to activate neurons in the RVLM, no differences could be found between sites that caused vasoconstriction in forelimb and hindlimb muscles (187), despite the fact that injection sites that specifically altered blood flow to particular tissues (e.g., viscera vs. muscle or skin) were readily identifiable (80, 81, 187, 188). The dogma was also reinforced by experimental findings in human subjects. For example, mild unloading of cardiopulmonary afferents in humans resulted in an increase in the discharges of muscle vasoconstrictor fibers in both the arms and legs (241), but no change in the activity of cutaneous vasoconstrictor fibers (295). Mental stress produced parallel increases in arm and leg muscle sympathetic nerve activity (59), but variable changes in cutaneous blood flow depending on the ambient temperature (85). Furthermore, the variety of inputs evoked by head-down neck flexion in human subjects produced parallel changes in arm and leg muscle vasoconstrictor activity (204).

In contradiction to Cannon's traditional views discussed in the last paragraph, VSR in animals are patterned in accordance to tissues innervated by particular sympathetic nervous system efferents, as well as the location of the tissue in the body. A variety of sympathetic 
nerves respond to stimulation of vestibular efferents, although the responses are particularly large for the renal nerve, which is comprised almost entirely of vasoconstrictor efferents, and relatively small for the hypogastric nerve, which is comprised largely of nonvasoconstrictor efferents (170). Furthermore, VSR are strongly attenuated or abolished by increases in blood pressure (170), which selectively diminish the excitability of sympathetic efferents that innervate vascular smooth muscle $(14,15,156)$, as illustrated in Fig. 5.

In addition, vasoconstrictor efferents innervating different body regions have distinct responses to vestibular stimulation. Simultaneous recordings were performed from muscle vasoconstrictor efferents in the lower body (coursing in the peroneal nerve of the hindlimb) and the upper body (coursing in either the radial nerve of the forelimb or the facial nerve) (169). Most hindlimb muscle vasoconstrictor efferents were inhibited by electrical stimulation of vestibular afferents, whereas most forelimb and facial muscle vasoconstrictor efferents exhibited a response consisting of early, powerful excitation followed by weak prolonged inhibition. Accordingly, delivery of a train of electrical stimuli to the vestibular nerve elicited an increase in hindlimb blood flow but a decrease in forelimb blood flow (168), as illustrated in Fig. 6. These findings indicate that vestibular signals can trigger distinct changes in blood flow to the upper and lower body.

As discussed previously, a bilateral vestibular neurectomy attenuated the decrease in hindlimb blood flow that ordinarily occurs during head-up rotations $(307,331)$ (see Fig. 9). In contrast, forelimb vascular resistance was similar during head-up movements before and after the removal of labyrinthine inputs, indicating that the vestibular system has distinct influences on lower and upper body vasculature (307). Furthermore, removal of vestibular inputs resulted in an increase in baseline blood flow to the head measured when the animals were prone (306), but no changes in baseline blood flow to the forelimb or hindlimb (307, 331). These observations, in combination with data from experiments using electrical stimulation of vestibular afferents, solidly demonstrate that VSR are anatomically patterned.

Since bilateral inhibition of the RVLM abolishes VSR (328), it might be expected that different populations of RVLM neurons regulate upper and lower-body blood flow. However, studies incorporating the injection of excitatory amino acids into the RVLM of cats indicated that injections that affected muscle blood flow simultaneously increased forelimb and hindlimb perfusion (187). This previous study did not consider the possibility that separate populations of neurons located in the same region of the RVLM innervated sympathetic preganglionic neurons in different regions of the thoracic spinal cord. The organization of sympathetic preganglionic neurons in the spinal cord provides a convenient anatomical substrate for regionally-specific regulation of activity of sympathetic efferent fibers. By injecting fluorescent tracers into different sympathetic prevertebral ganglia, Strack et al. (279) demonstrated that sympathetic preganglionic neurons in the upper thoracic cord regulate sympathetic outflow to the upper body, whereas sympathetic preganglionic neurons in the lower thoracic and upper lumbar spinal cord regulate sympathetic outflow to the lower body. In addition, transneuronal tracing studies that injected retrogradely-transported viruses into sympathetically-innervated targets in the hindlimb $(180,290)$ and tail (264) showed that all the sympathetic preganglionic neurons that regulate lower body smooth muscle are confined to the lower thoracic and upper lumbar 
spinal segments. This topographic organization of sympathetic preganglionic neurons would complicate the global activation of sympathetic efferent fibers, in that the axon of an RVLM neuron would need to branch extensively in the spinal cord and activate sympathetic preganglionic neurons in many spinal segments in order to elicit changes in sympathetic efferent activity across the body.

To investigate whether RVLM neurons have branching connections to multiple spinal cord segments, a recent study incorporated large injections of two different fluorescent dyes into the T4 and T10 spinal cord segments (125). Only a small fraction of RVLM neurons was double-labeled by both dyes, supporting the notion that individual RVLM neurons regulate the activity of sympathetic efferent fibers innervating a limited number of body regions. Double-labeling was higher amongst the subpopulation of catecholaminergic RVLM neurons, although most of these cells did not apparently innervate both the T4 and T10 segments. These data support the hypothesis that individual RVLM neurons have the connectivity in the spinal cord to regulate either upper- or lower-body blood flow. Yet, another study cast doubt on whether RVLM neurons are solely responsible for the anatomical patterning of VSR. This study showed that RVLM neurons whose axons terminated rostral to the T10 spinal segment had similar responses to electrical stimulation of the vestibular nerve as RVLM neurons whose axons extended beyond T10 (281). In particular, the large majority of RVLM neurons were excited by electrical stimulation of vestibular afferents, in contradiction to the observation that hindlimb vasoconstrictor efferents were inhibited by the same stimuli $(168,169)$.

These findings raise the possibility that brainstem areas in addition to the RVLM are involved in shaping the properties of VSR. Although bilateral ablation of the RVLM abolishes sympathetic nerve responses elicited by vestibular stimulation (328), this could simply be due to the fact that without tonic excitatory drive from the RVLM, excitability of sympathetic preganglionic neurons becomes too low for sensory inputs to modulate the firing of sympathetic nerves. Studies in rodents involving the retrograde transneuronal transport of neurotropic viruses by sympathetic efferent fibers that innervate blood vessels in the hindlimb $(180)$ or kidney $(54,253)$ have shown that a number of brainstem areas in addition to the RVLM provide inputs to sympathetic preganglionic neurons: the medullary raphe nuclei, rostral ventromedial medulla, A5 adrenergic cell group region, locus coeruleus, nucleus subcoeruleus, and the paraventricular nucleus of the hypothalamus. Several of these regions receive vestibular inputs (for review, see (22)), and thus could mediate labyrinthine influences on sympathetic nervous system activity. Further studies will be required to determine the role of brain areas other than the RVLM in the patterning of blood flow to different body regions during vestibular stimulation.

\section{Summary}

The activity of only a subset of sympathetic efferent fibers is affected by stimulation of vestibular afferents. Sympathetic preganglionic neurons that regulate peripheral vascular resistance receive the strongest inputs from the vestibular system. In addition, sympathetic nerve fibers that control upper and lower-body blood flow have different responses to labyrinthine inputs. Most other inputs do not appear to elicit anatomical patterning of 
sympathetic responses, and thus vestibular signals may be somewhat unique in eliciting such response patterning. Although the RVLM appears to play an important role in relaying labyrinthine signals to sympathetic preganglionic neurons, other descending pathways from the brainstem also appear to be important in establishing the patterning of VSR. Curiously, studies in human subjects have not generally established that VSR are anatomically patterned, as discussed below in the section "Vestibulosympathetic Reflexes Evoked by Natural Stimulation in Humans." It is yet to be determined whether this difference in results between human and animal studies is due to species differences or distinctions in the methodology used in the experiments.

\section{Neural Pathways that Mediate Vestibulosympathetic Responses}

Lesions placed near the caudal aspect of the vestibular nucleus complex (the caudal medial and adjacent inferior vestibular nuclei) abolish sympathetic nerve responses elicited by electrical or natural stimulation of vestibular afferents $(170,224,288,323,327)$. Neurons in this portion of the vestibular nucleus complex make connections with a number of medullary regions that participate in regulating sympathetic nerve activity, including nucleus tractus solitarius $(17,51,232,246,321)$, the lateral medullary reticular formation (lateral tegmental field and caudal ventrolateral regions) $(232,278,316)$, and the $\operatorname{RVLM}(142,232,278)$. On the basis of their responses to rotations, it appears that many neurons in the caudal regions of the vestibular nucleus complex receive inputs from the vestibular otolith organs $(13,94$, 189, 195). As discussed above (see Fig. 8)(327), the response dynamics of VSR suggest that these responses are also mainly elicited by otolith organ inputs. In combination, these converging lines of evidence demonstrate that neurons localized in the caudal medial and adjacent inferior vestibular nuclei elicit VSR.

The average latencies of responses of RVLM neurons to electrical stimulation of vestibular afferents were greater than $10 \mathrm{msec}(280,330)$. The RVLM neurons with such long-latency responses to vestibular stimulation included those confirmed to receive baroreceptor inputs and/or to have slowly-conducting projections to the thoracic spinal cord $(280,330)$, indicating that they participated in regulating sympathetic nerve activity. These findings suggest that despite the existence of direct connections from the caudal aspect of the vestibular nucleus complex to the RVLM $(142,232,278)$, signals are relayed principally through multisynaptic connections from the vestibular nuclei to the RVLM. Neurons in the lateral and ventrolateral medullary reticular formation, including those whose axons could be antidromically activated from the RVLM, responded to electrical stimulation of vestibular afferents at shorter latency than did RVLM neurons $(277,316)$. In addition, chemical lesions of the lateral medullary reticular formation abolished VSR $(275,276)$. The responses to body rotations of neurons in the medullary lateral tegmental field were similar to those of VSR, supporting the notion that this region serves as a relay between the vestibular nuclei and RVLM (212). Similarly, nucleus tract solitarius neurons with baroreceptor inputs, which presumably participate in regulating sympathetic nervous system activity, responded to activation of vestibular afferents by whole body rotations with response dynamics mirroring those of VSR (280). These data suggest that multiple parallel pathways participate in producing VSR; the role of each pathway in producing the responses is unknown. 
The first recordings of RVLM neuronal activity in conscious animals were recently conducted $(27,84)$. Only $1 \%$ of RVLM neurons in conscious cats responded to $10-15^{\circ}$ rotations in vertical planes (84). This finding was not surprising, since $20^{\circ}$ head-up tilts had little effect on blood distribution in the body $(307,331)$ and elicited no appreciable vasoconstriction in conscious cats (307)(see Fig. 3). However, in decerebrate cats, the activity of $\sim 50 \%$ of RVLM neurons, including those with baroreceptor inputs, was modulated by $\leq 10^{\circ}$ rotations in vertical planes (84). Furthermore, activation of vestibular receptors by $10-15^{\circ}$ head-up tilts in decerebrate cats produced strong increases in sympathetic nerve activity (327), as shown in Fig. 7. These data suggest that the brainstem circuitry mediating VSR is highly sensitive to changes in body position in space, such that non-physiologic (exaggerated) increases in SNA occur during head-up tilts in decerebrate animals. Presumably, descending projections from higher brain centers modulate the responsiveness to labyrinthine inputs of neurons in the VSR circuit.

The fraction of RVLM neurons with cardiac-related activity, or rhythmic bursts of action potentials synchronized with the cardiac cycle, also varied considerably during and between recording sessions, even when neuronal sampling was confined to a limited area (27).

Cardiac-related activity is a characteristic feature of brainstem neurons and sympathetic nerve fibers that control blood pressure, and the incidence of cardiac-related activity increases when baroreceptor reflex gain is elevated $(64,112,114,122,123)$. No disturbances in homeostasis preceded changes in expression of cardiac-related activity by RVLM neurons, indicating that variations in incidence of cardiac-related activity were due to mechanisms other than feedback reflexes, presumably cognition. These findings thus suggest that baroreceptor reflexes can be regulated cognitively.

The notion that higher brain centers regulate the activity of brainstem neurons that control sympathetic nerve activity is supported by research on "central command" $(97,186,197$, 298, 305). Experiments monitoring cardiovascular responses in human and animal subjects showed that adjustments in these responses necessary during exercise are initiated before exercise begins $(97,298)$. As noted above in the section "Recovery of Posturally-Related Cardiovascular Responses Following Vestibular System Lesions," there is evidence that the cerebellar uvula elicits increases in the gain of baroreceptor reflexes following a removal of vestibular inputs. Furthermore, the cerebellar uvula may also participate in regulating the gains of VSR and baroreceptor reflexes in accordance with expected disturbances in cardiovascular homeostasis. Several lines of evidence support this hypothesis. First, Purkinje cells in the posterior cerebellar vermis project to the caudal vestibular nucleus complex, which participates in autonomic regulation $(9,226,233,258,297)$, providing a direct pathway that could be responsible for modulation of VSR. A disynaptic link has also been established between the uvula and NTS that may participate in adjusting the gain of baroreceptor reflexes $(226,227)$. Electrical or chemical stimulation of the uvula produces changes in RVLM unit activity (262) and blood pressure $(42,138,219,225)$. In addition, the pressor responses elicited by stimulation of the uvula are reversed by injection of bicuculline into nucleus tractus solitarius (227), suggesting that this region is a component of the autonomic pathways affected by the caudal cerebellar vermis. 
Inputs to the uvula are also consistent with the hypothesis that this cerebellar region modulates cardiovascular responses when disturbances in homeostasis are expected. Regions of the inferior olive that provide climbing fiber inputs to the uvula (dorsomedial cell column, subnucleus $\beta$, and the rostral aspect of the medial accessory olive $(46,69,130$, 164)) receive afferents from areas of the midbrain and posterior hypothalamus that regulate blood pressure $(265,266,293)$. Stimulation in and around these inferior olive regions elicits changes in blood pressure, suggesting that they influence cardiovascular regulation (266, 299). Furthermore, these regions contain the imidazoline receptor protein, a marker of brain areas that participate in autonomic control (247). Other pathways may also participate in regulating autonomic function when perturbations in blood pressure are expected. For example, the parabrachial nucleus receives descending signals from the limbic system and hypothalamus, and modulates neuronal activity in brainstem areas that control blood pressure, including the nucleus tractus solitarius $(100,131,174,176,193)$ and RVLM $(6$, $181,201)$. However, the notion that the cerebellar uvula plays a paramount role in regulating the gains of cardiovascular responses during movement and changes in posture is appealing for several reasons. As noted above, the connections of the uvula are appropriate to simultaneously affect the two reflex systems that alter blood distribution in the body during movement: VSR and baroreceptor reflexes. In addition, this notion is aligned with the general role of the cerebellum in both the feedback and feedforward control of movement, but extends this role to autonomic motor systems. Fig. 10 summarizes this model of the neural connections that regulate blood distribution in the body during both unexpected and planned movements and changes in body position in space.

Cerebellar regions in addition to the uvula may also participate in modulating VSR. There is an extensive literature on potential contributions of a portion of a deep cerebellar nucleus, the rostral fastigial nucleus, to the regulation of blood pressure $(44,45,82,83,88,89,199$, 200). The rostral fastigial nucleus receives labyrinthine inputs, including those from otolith organs $(50,99,111,115,172,256,260,261,272,273,333)$, and projects to regions of the vestibular nuclei that mediate $\operatorname{VSR}(8,55,58)$. There is also some evidence that rostral fastigial nucleus neurons project to nucleus tractus solitarius $(8,28,216)$. Studies in conscious nonhuman primates have suggested that the rostral fastigial nucleus integrates labyrinthine and nonlabyrinthine inputs, and transforms these signals such that the firing rate of fastigial nucleus neurons reflects the movement of an animal in body-centered coordinates $(47,257)$. The connections of the rostral fastigial nucleus within the brainstem are appropriate for this nucleus to modulate VSR, although the specific role that the structure plays in regulating blood pressure during movement are yet to be determined.

Although lesions of the RVLM abolish VSR (328), other descending pathways may modulate VSR. Anatomical studies have shown that several brainstem regions participate in regulating sympathetic nervous system activity $(54,180,253)$. In cats, neurons located in the raphe nuclei (particularly raphe pallidus) participate in cardiovascular regulation. These neurons exhibit cardiac-related activity (209), and raphespinal neurons that are excited by baroreceptor stimulation project to the intermediolateral cell column (210). Some raphespinal neurons have restricted axonal branching patterns, supporting the view that the medullary raphe complex is capable of regional control over SNA (208). Recent anatomical experiments involving the injection of fluorescent dyes into the vicinity of sympathetic 
preganglionic neurons in the $\mathrm{T} 4$ and $\mathrm{T} 10$ spinal cord also show that some neurons in raphe pallidus project selectively to either the rostral or caudal thoracic levels (57). Furthermore, raphe pallidus neurons receive inputs from the vestibular nuclei (232) and respond to vestibular stimulation $(318,320)$. These observations raise the possibility that whereas the RVLM is responsible for setting the general level of SNA, raphe neurons participate in finetuning that activity, and are responsible for the patterning of VSR.

Recent evidence suggests that the role of the vestibular system in autonomic regulation extends well beyond the reflexive control of blood pressure $(16,18,19,21,22)$. Patients who experience dizziness often exhibit symptoms of anxiety disorders, which include those generated by the autonomic nervous system (e.g., palpitations, increased blood pressure, sweating, etc.) (147-150). The link between vestibular disorders and anxiety may be mediated through connections between the superior vestibular nucleus and the parabrachial nucleus, which in turn provides afferents to the limbic system $(16,18,19,21,22)$. There is also considerable comorbidity between migraine, anxiety, and vestibular disorders, such that the three conditions are components of a proposed new disorder: migrane-anxiety related dizziness (MARD) (109). The neural pathways described above, including interconnections between the limbic system and brainstem trigeminal nuclei through the periaqueductal gray, are likely responsible for triggering the three conditions in parallel (19).

\section{Summary}

Relatively direct connections relay signals from the caudal medial and inferior vestibular nuclei to the RVLM. However, the gain of VSR is much higher than in decerebrate than in conscious animals, suggesting that higher brain centers adjust the gain of the responses. The circuitry that regulates VSR gain likely includes cerebellar neurons, particularly Purkinje cells in the uvula. In addition to this core circuitry, raphespinal pathways may be responsible for establishing the patterning of VSR. Complex autonomic responses associated with vestibular dysfunction, such as those related to anxiety disorders, are mediated through projections from the superior vestibular nucleus to the parabrachial nucleus.

\section{Vestibulosympathetic reflexes evoked by electrical stimulation in humans}

While many studies in human subjects (considered in detail in a subsequent section) have used physiological means of activating the vestibular system, recent studies supporting the existence of robust VSR in humans have utilized galvanic vestibular stimulation (GVS). Typically, a weak current (usually 1-2 mA) is applied across two surface electrodes over one or (usually) both mastoid processes (behind the ears). Unilateral GVS can be produced by applying a current between an anode on one mastoid process and a cathode on the back of the head or the forehead (105). GVS has been primarily used to investigate the role of the vestibular system in the control of posture and locomotion $(60,104,105)$. The advantage of GVS is that it provides an essentially selective means of changing the firing of vestibular nerve afferents $(105,119,196)$, although it cannot target specific components of the vestibular apparatus. Nevertheless, as a means of modulating vestibular input without changing the inputs from other sources, GVS offers distinct advantages over natural stimuli: there are no changes in baroreceptor inputs, no fluid shifts within the body, and no changes in heart rate, blood pressure or respiration. It is evident that GVS changes vestibular inputs 
because the stimulus induces robust vestibular illusions: a standing subject will sway towards the anode during application of a step pulse across the mastoid processes, while a seated subject will perceive a lateral shift in head (and body) position. Application of lowfrequency $(<2 \mathrm{~Hz}$ ) sinusoidal GVS (sGVS, -2 to $+2 \mathrm{~mA}$ ) in seated subjects induces strong postural illusions without activating muscles; typically, subjects report sensations of "rocking in a boat" or "swinging in a hammock." Interestingly, with the head vertical no subjects report illusions of head rotation, nor do they perceive displacements back and forth - the illusions are limited to side-to-side movements. Indeed, it has been argued that VSR evoked by GVS are mediated exclusively by the otolith organs (63).

\section{Modulation of muscle sympathetic nerve activity during GVS}

Most investigations of the influence of GVS on sympathetic nerve activity in humans entailed determining the effects of the stimulus on muscle sympathetic nerve activity (MSNA), the activity of sympathetic efferent fibers that regulate muscle blood flow. MSNA is recorded using microneurography. In brief, this technique involves the use of fine (200 $\mu \mathrm{m}$ diameter) tungsten needle electrodes inserted percutaneously into a peripheral nerve to extracellularly record activity of single nerve fibers or small groups of nerve fibers (291). Using similar methodology, skin sympathetic nerve activity (SSNA) can also be recorded.

Recordings of MSNA from the lower limbs of awake human subjects revealed that delivery of a 1-sec step of GVS at different times within the cardiac cycle, despite causing vestibular illusions, had no effect on MSNA (38). Conversely, Voustianiouk and colleagues showed that brief (30 ms) trains of 10 pulses caused a short-lasting increase in MSNA when delivered $500 \mathrm{~ms}$ after the R-wave of the electrocardiogram (ECG) (296). This suggests that dynamic rather than static galvanic vestibular stimulation is required to modulate sympathetic outflow. Furthermore, sinusoidal trains of bipolar GVS, delivered binaurally at 0.5-0.8 Hz, caused a clear modulation of MSNA (29). This is shown in Fig. 11, in which the normal cardiac-locked bursts of MSNA (indicated by ' $\mathbf{c}$ ') are occasionally joined by an additional burst - within the same cardiac cycle - generated by the vestibular input ('v'). In this way, two bursts of MSNA could occasionally be observed in a single cardiac cycle, but there appeared to be competition between the cardiac-locked bursts and the bursts evoked by vestibular stimulation. Indeed, close inspection of the traces encompassed by the rectangles in Fig. 11 reveals that the outcome of the evident competition between the two rhythms cardiac and vestibular - depends on the temporal separation between the most effective phase of the vestibular stimulus and the ECG: if the vestibular input coincides with the middle of the cardiac interval, then there will be no competition with the baroreceptormediated cardiac rhythm. This is illustrated in the second box in panel $\mathrm{C}$, in which a burst was generated out of phase with the cardiac cycle. This is considered to represent de novo synthesis of a sympathetic burst by the vestibular input. Conversely, the first box in panel D has a single peak that can be simply explained by the dominance of the cardiac rhythm.

In this (29) and subsequent studies, Bent and colleagues analyzed the negative-going action potentials in the nerve recordings, rather than the smoothed (RMS-processed) mean-voltage levels. It was shown that sinusoidal galvanic vestibular stimulation (sGVS) does not significantly alter the overall level of MSNA, as measured in terms of bursts per minute or 
bursts per 100 heart beats. Moreover, the lack of change in blood pressure fits with this lack of change in overall level of MSNA: sGVS produces a change in the pattern of sympathetic outflow, not a change in its intensity (129). Interestingly, despite the clear evidence for VSR uncovered by cross-correlation analysis, using this same approach the authors also showed that sGVS had no effect on the discharge of spontaneously active, or volitionally activated, muscle spindles in human subjects $(30,31)$, despite evidence for vestibular modulation of fusimotor neuronal activity in experimental animals $(56,231)$. This emphasizes that not all physiological phenomena observed in anesthetized experimental animals can be observed in human subjects, but also that certain physiological mechanisms are preserved through evolution. The fact that VSR have been preserved, and are expressed in humans, surely attests to their physiological importance.

Fig. 12A shows the cross-correlation analysis between MSNA and the ECG (white histogram), as well as the autocorrelogram of the ECG (black histogram), after shifting the ECG. Fig. 12B indicates that sGVS, delivered at $0.5 \mathrm{~Hz}$, had no effect on the timing of each heartbeat; GVS also had no effect on respiration (Fig. 12C). Strong coupling between MSNA and the vestibular input (MSNA vs GVS) is shown for the same subject in Fig. 12D (white histogram). A $0.5 \mathrm{~Hz}$ sine wave superimposed on the histogram represents the GVS, whereas the black histogram shows the result of synchronizing MSNA recorded during a rest period to a mathematically-generated sine wave (control) of the same frequency as the actual GVS. Similar data from another subject are shown in Fig. 12E, but with a higher frequency of stimulation $(0.8 \mathrm{~Hz})$. It is evident that MSNA becomes partially entrained to the sinusoidal vestibular stimulus.

When the period of continuous sinusoidal GVS illustrated in Fig. 12D was divided into four equal parts, it was possible to discern the variation in relative strength of the coupling between MSNA and the cardiac and vestibular rhythms. In Fig. 13A, the first quarter of the two min stimulation period had very little vestibular component, even though the subject reported a strong and continuous postural illusion, and is clearly dominated by the cardiac rhythm. In the next two segments the authors obtained an important observation: while the sympathetic bursts are still locked to the cardiac rhythm, sinusoidal GVS causes a temporal shift of the MSNA (Fig. 13B) and a tendency for the peaks to be larger during a particular phase of the vestibular input. This tendency was all but lost in the next segment (Fig. 13C), whereas the final sequence (Fig. 13D) is clearly dominated by the vestibular rhythm. This competition between vestibular and cardiac rhythms was explored further in a subsequent study by delivering sGVS at a range of frequencies ranging from 0.2 to $2.0 \mathrm{~Hz}$ (129). It turned out that the weakest vestibular modulation of MSNA was obtained during stimulation at $0.8 \mathrm{~Hz}$. Given that this is close to the average heart rate, James and Macefield performed another study in which they specifically tested the hypothesis that baroreceptors and vestibular inputs compete to modulate MSNA. By delivering sGVS at the resting heart rate of a given subject, and at frequencies above or below this central frequency, they confirmed that vestibular modulation of MSNA is lowest when it coincides with the cardiac rhythm and concluded that vestibular inputs do indeed compete with the baroreceptors in modulating MSNA (153). 
More recently, the effects of vestibular inputs on muscle sympathetic outflow were examined when sGVS was delivered at lower frequencies: 0.08-0.18 Hz. Interestingly, it was discovered that low-frequency sinusoidal GVS induced two bursts of modulation of MSNA for each cycle of stimulation (133), as illustrated in Fig. 14. In these studies, the stimulating anode was placed over the right mastoid process and the cathode over the left. Because the sympathetic recordings were always made from the left peroneal nerve, the authors surmised that the primary peak of modulation occurred when the left vestibular nerve was depolarized and the right vestibular nerve was hyperpolarized. The smaller secondary peak occurred when the current shifted to the right side and depolarized the right vestibular nerve while hyperpolarizing the left vestibular nerve. The incidence of double peaks of MSNA was highest at $0.08 \mathrm{~Hz}$ and lowest at $0.18 \mathrm{~Hz}$, and was never observed at the higher frequencies of stimulation used previously $(0.2-2.0 \mathrm{~Hz})$, presumably because at such frequencies there is insufficient time for a second peak to be expressed. The authors interpreted the existence of two peaks of modulation of MSNA as reflecting bilateral projections from the vestibular nuclei to the rostral ventrolateral medulla (RVLM) on each side. As noted above, the RVLM is the brainstem region that primarily controls MSNA (79), and receives both baroreceptor (79) and vestibular inputs $(84,319,330)$. Certainly, evidence obtained in experimental animals indicates that sympathetic outflow on one side of the body can be evoked by stimulation of either the ipsilateral or contralateral vestibular nerve (170). Anatomical evidence additionally indicates that the projections from the vestibular nuclei to the RVLM are bilateral, with a greater representation ipsilaterally (142).

If this interpretation is correct, one would expect to observe differential expression of vestibular modulation of MSNA on both sides of the body. To test this, bilateral recordings of MSNA were recently obtained (93). Experimental records from one subject, during application of sGVS at $0.08 \mathrm{~Hz}$, are shown in Fig. 15. The overall pattern of sympathetic outflow was similar for the left and right nerves, yet it is also apparent that there were subtle differences across the two sides. As noted above, double peaks of MSNA could occasionally be identified within a single cardiac interval, in which one peak was aligned to the cardiac cycle and the other to the vestibular stimulus. The expanded regions in Fig. 15 reveal that this second peak was of different amplitudes on each side of the body, with vestibularrelated peaks being occasionally present on one side but absent on the other. It is also apparent that there is a dynamic interaction between cardiac-related (i.e. baroreceptormediated) and vestibular inputs from the two sides during sGVS. The differential modulation of MSNA on the two sides supports the idea that sympathetic control of blood pressure and blood flow is lateralized, at least with respect to VSR. It is generally accepted that sympathetic outflow is symmetrical: resting burst rates and amplitude distributions of muscle sympathetic nerve activity have been shown to be similar on the two sides (282, 285). Only one other study in humans has specifically addressed lateralization of sympathetic control: Diedrich et al. (86) showed that loading of carotid sinus baroreceptors by sinusoidal neck suction caused a differential expression of MSNA on the left and right sides, abolishing the normally right-sided dominance of MSNA. These studies in combination indicate that the influence of vestibular, as well as baroreceptor, inputs is partially lateralized. However, this needs to be reconciled with the anatomical evidence obtained from experimental animals showing that preganglionic sympathetic neurons in the 
spinal cord receive bilateral projections from the RVLM, as well as the raphe and other brainstem regions and the hypothalamus. Approximately half of the spinally-projecting neurons in the RVLM are directed to the contralateral spinal cord, suggesting a limited capacity to regulate blood flow independently on either side of the body $(125,180)$. Indeed, the bilateral projections from the RVLM to the spinal cord may explain why bursts of MSNA are, on the whole, so similar between the two sides.

Summary-Studies using GVS have shown that sinusoidally modulating the activity of the vestibular nerves in awake human subjects has a pronounced effect on sympathetic outflow to muscle. There is evidence that vestibular inputs compete with the dominant baroreceptor inputs in modulating MSNA, with vestibular modulation being weakest when the vestibular input essentially coincides with the baroreceptor input. Bipolar, binaural GVS delivered at frequencies below $0.2 \mathrm{~Hz}$ evoked two peaks of modulation of MSNA, one peak associated with depolarization of one vestibular nerve and one with depolarizing of the opposite nerve. Bilateral recordings confirmed that there is a lateralized expression of VSR in humans.

\section{Modulation of skin sympathetic nerve activity during GVS}

Like sympathetic outflow to muscle, skin sympathetic nerve activity (SSNA) directed to the blood vessels and sweat glands (and hairs) also occurs as bursts, though these are not as strongly modulated by baroreceptor inputs as sympathetic outflow to muscle. Regulation of skin blood flow by the central system is distinct from regulation of blood flow to most other vascular beds, as it serves a different purpose: thermoregulation. Although the RVLM plays the predominant role in controlling the activity of sympathetic efferents that regulate blood flow, the raphe nuclei have been implicated in regulating SSNA $(211,214,222)$.

While a 1-s pulse of GVS failed to modulate MSNA, the same stimuli did evoke a brief burst of SSNA, together with cutaneous vasoconstriction and sweat release (38), suggesting a more potent effect of vestibular inputs on skin sympathetic outflow. Indeed, application of sGVS at frequencies of 0.08 (153)- $0.18 \mathrm{~Hz}$ (132) revealed an overt entrainment of SSNA the bursts becoming time-locked to the sinusoidal vestibular input. Unlike the vestibular modulation of MSNA, modulation of SSNA was high at all frequencies of stimulation, although it was lowest at $2 \mathrm{~Hz}$. While there was no fall in modulation at $0.8 \mathrm{~Hz}$, the normally weak cardiac rhythmicity of SSNA actually increased during sGVS (153). Like MSNA, low-frequency sGVS $(<0.2 \mathrm{~Hz})$ evoked two bursts of SSNA (132) - a primary peak and a smaller secondary peak, and bilateral recordings revealed that these peaks were reversed on each side of the body (132). The vestibular nuclei project to the medullary raphe nuclei $(20,318,320)$, and both the medullary and pontine raphe nuclei process baroreceptor signals $(25,26,214,222,248,280,321,332)$. Consequently, at least in animals, the neural pathways that regulate SSNA integrate vestibular and baroreceptor signals, such that one signal can affect the processing of the other.

An interesting effect of low-frequency sGVS is that some subjects experience nausea. While this was rare at higher frequencies of stimulation $(29,129,152,153)$, half of the subjects exposed to sGVS at frequencies $<0.2 \mathrm{~Hz}$ reported varying degrees of nausea. At 0.13 and $0.18 \mathrm{~Hz}$, one subject reported "strong dizziness", a sensation of seasickness and nausea; at 
$0.08 \mathrm{~Hz}$ the subject requested that the stimulation be terminated. Although this subject had a history of motion sickness, it can be seen in Fig. 16 that the vestibular modulation of SSNA was higher in all subjects reporting nausea than those who did not. One might expect more reports of nausea at low stimulus frequencies, given that the illusions of motion subjects report are at frequencies similar to those experienced by movements typically associated with nauseogenic stimuli, such as rocking in a boat. It is known that the signs of motion sickness include pallor (cutaneous vasoconstriction) and sweating, both of which are brought about by increases in skin sympathetic outflow. However, it is unclear why vestibular inputs cause such pronounced modulation of SSNA, which is even higher than that of MSNA. In particular, the marked modulation of SSNA induced by GVS, particularly in subjects who did not experience nausea, is difficult to explain. Vestibular-induced modulation of SSNA may have no physiological significance at all; it may very well be an epiphenomenon. However, given that vestibular modulation of MSNA plays a role in the control of blood pressure, and that cardiac output needs to be distributed to skeletal muscle and skin with the opposing demands of maintaining an adequate blood pressure and thermoregulation. It may be that when these two demands compete, such as in exercise with an additional environmental heat load, there needs to be common regulation of blood flow in muscle and skin (70).

Summary-Like MSNA, the vestibular system exerts a potent modulation of sympathetic outflow to skin. A difference between MSNA and SSNA is that the SSNA is not dominated by baroreceptor inputs (98), perhaps allowing a greater expression of VSR. As with MSNA, bilateral recordings confirmed that there is a lateralized expression of vestibular modulation of SSNA in humans.

\section{Vestibulosympathetic Reflexes Evoked by Natural Stimulation in Humans}

While there is clear and well established experimental evidence in animals that the vestibular system contributes to the regulation of cardiovascular function, its role in cardiovascular regulation in the human has been more difficult to ascertain. Although lesions of the vestibular nerves result in a profound impairment of blood pressure regulation during head up tilts in anesthetized and paralyzed cats (89) and complex changes in posturally-related blood pressure regulation in conscious cats (162), there are no reports of similar compromises in blood pressure regulation in humans following labyrinthectomy. This may reflect real differences between the bipedal human and quadruped species, but the challenges in performing studies in humans have made it difficult to directly test the role of the vestibular system in autonomic regulation. Consequently, it has been necessary to apply unique strategies and approaches to this line of investigation in human subjects. The focus of this section is to critically review the evidence of involvement of the vestibular system in the regulation of cardiovascular function derived directly from human studies, expanding on the evidence provided by studies employing galvanic vestibular stimulation.

The use of natural stimulation to determine the role of the vestibular system in cardiovascular regulation in humans can be divided into two types of studies. First, those that determine whether there is an association between a clinically defined or identified vestibular dysfunction and altered cardiovascular function and, second, those that perturb the 
vestibular system in healthy vestibular and cardiovascular-intact individuals to determine whether the vestibular perturbation modulates cardiovascular function. The physiological parameters used to measure cardiovascular function vary significantly between studies and include measures of blood pressure, heart rate and rhythm, limb and cerebral blood flow, limb vascular resistance and peripheral sympathetic nerve activity known to be associated with cardiovascular regulation. This makes it difficult to directly compare findings from these studies. Consequently, this consideration of effects of natural stimulation of vestibular receptors on cardiovascular responses in humans will initially examine studies involving clinically defined vestibular dysfunction and then examine the physiological studies that have perturbed the vestibular system in healthy individuals.

\section{Influence of Clinically-Defined Labyrinthine Dysfunction on Cardiovascular Function in Humans}

There are no general reports in the literature that vestibular dysfunction in the human results in alteration of cardiovascular function. Whereas it has been suggested that loss of vestibular function during aging (205) or exposure to microgravity $(322,325)$ increases susceptibility for orthostatic hypotension, it is very difficult to segregate the contributions of diminished VSR from the many other physiological changes that occur during these conditions. For example, the gain of baroreceptor reflexes also tends to decrease during aging (103); the decline in functioning of multiple responses that regulate blood pressure results in difficulty in assigning a specific etiology to many cases of aging-related orthostatic hypotension.

It might be expected that, if the vestibular system affects functioning of the autonomic nervous system, there would be a higher incidence of cardiovascular dysfunction identified in patients with compromised vestibular function. However, a study of 81 cases of vestibular neuritis noted that $15.2 \%$ of the prospective analyzed patient group and $14.6 \%$ of patients in the retrospective patient group were under clinical care for arterial hypertension. These findings were not outside the prevalence expected for age and sex correlated individuals in the community from whom the study groups were drawn (263) suggesting that altered vestibular afferent function is unlikely to be responsible for altered cardiovascular function.

In a study designed to determine the incidence of the coexistence of vestibular and cardiovascular autonomic dysfunction, Heidenreich et al. (137) undertook a retrospective study of patients $(\mathrm{n}=56)$ with a primary presenting complaint of dizziness exacerbated by changes in posture. These patients had also been tested for orthostatic intolerance using a tilt table and for vestibular dysfunction using caloric tests, ocular motor and positional testing, and assessment of the vestibulo-ocular reflex involving the rotating chair test. There was no significant difference in the rates of postural orthostatic hypotension in subjects with peripheral vestibular hypofunction compared to those with normal vestibular function with only 6 of the 56 patients exhibiting abnormal findings on both the tilt table and vestibular functional tests. However, the test for orthostatic hypotension in this study only reported if findings were positive or negative. That is, whether or not there were decreases in systolic blood pressure of $>20 \mathrm{mmHg}$ and/or a change in diastolic blood pressure of $>5 \mathrm{mmHg}$ with changes in heart rate that were $<10 / \mathrm{min}$ or $>20 / \mathrm{min}$. In spite of the limitations of this study which included its retrospective design, and the selection of subjects with predominate canal 
dysfunction but use of a test (tilt table) that evaluates changes in otolith generated signals, this study suggests that large alterations in blood pressure and heart rate are unlikely to result during changes in posture in vestibular compromised but otherwise healthy humans.

While these studies, together with the lack of reports of cardiovascular compromise following labyrinthectomy might suggest there is little involvement of the vestibular system in cardiovascular regulation in humans, these negative findings could also be explained by the presence of an effective compensatory mechanism as occurs in other animals (see "Recovery of Posturally-Related Cardiovascular Responses Following Vestibular System Lesions" above). Interestingly other studies that have looked more closely at cardiovascular function in cohorts of individuals with clinically defined vestibular dysfunction have shown altered cardiovascular function when compared to vestibular intact control subjects during various imposed head and or body displacements.

Yates et al. (315) examined the cardiovascular response of 3 patients with idiopathic profound bilateral reduction in vestibular function and 10 normal persons to linear acceleration and then deceleration imposed while seated upright in a chair mounted on a sled. This imposed a stimulus comparable to a $12^{\circ}$ head tilt but with minimal blood volume shifts in the rostro-caudal axis, thereby reducing the influence of extra-vestibular graviceptors (198). The forward, backward and lateral accelerations were performed while the subjects adopted different head positions. The head was fixed upright during some trials thereby activating hair cells in both the utriclus and sacculus while in other trials the head was held fully pitched (neck flexed) forward or backward (neck extended) to primarily activate the sacculus. Normal subjects exhibited an increase in systolic blood pressure of 7-9 $\mathrm{mmHg}$ and a rapid decrease (14-27 ms) in R-R interval (time between heart beats) for a few (2.1) sec. However, the changes were only significant for forward acceleration with head upright, head back, or head down and for backward acceleration with head down and for acceleration to the right. The $\mathrm{R}-\mathrm{R}$ interval then increased above pre-acceleration values by $37-56 \mathrm{~ms}$ for all fore-aft accelerations but only by $10-20 \mathrm{~ms}$ during lateral stimulations. The largest change in the decrease in R-R interval occurred at the second heartbeat following the start of acceleration, but given that the stimulus was not synchronized with the ECG it probably occurred within one heart beat. The vestibular compromised subjects had a reduced cardiovascular response. For example, forward linear acceleration induced a mean change of $8.9 \pm 0.6$ (SEM) $\mathrm{mmHg}$ in the systolic pressure of controls but $<4.0 \pm 0.9 \mathrm{mmHg}$ in the vestibular compromised group. The diminished systolic blood pressure response to body acceleration in the bilateral vestibular compromised individuals in this study suggests that a normally functioning vestibular system contributes to the systolic blood pressure response associated with acceleration of the human body.

Using a novel dynamic stimulus of the peripheral vestibular organs with the body stationary to avoid activation of somatic graviceptors, Bronstein, Gresty and colleagues (198, 234, 235 ) investigated the effects of vestibular stimulation (head falls producing an acceleration of $0.8 \mathrm{G}$ for $140 \mathrm{~ms}$ ) on heart rate, systolic blood pressure, diastolic blood pressure and digital blood flow in labyrinthine-defective and control subjects in the supine position. The head drop stimulus induces both linear and angular acceleration and thus stimulated both otolith and semicircular canal receptors. Importantly, the study included a control condition for 
startle responses, and respiratory and non-labyrinthine sensory stimuli were excluded as possible sources of any response. The labyrinthine defective status in both studies was evidenced clinically by the significant impairment or absence of vestibulo-ocular reflexes in all planes, oscillopsia with head shaking, presence of postural instability in the dark, and lack of nystagmus when caloric $\left(30^{\circ}\right.$ or $\left.44^{\circ} \mathrm{C}\right)$ stimulation or sinusoidal horizontal head rotations $(40 \%$ up to $0.2 \mathrm{~Hz})$ were performed in the dark. Interestingly, the labyrinthine defective individuals $(\mathrm{n}=15)$ did not exhibit a shortening of the ongoing cardiac cycle that was noted in individuals with intact labyrinths $(\mathrm{n}=26)$. By varying the stimulus relative to the cardiac cycle these investigators showed that the latency of the transient vestibulocardiac reflex (acceleration of heart rate) observed in the labyrinthine functioning controls ranged from 500-600 ms. They also showed that 3-4 heartbeats ( 3-4 sec) after the head drop the systolic blood pressure rose slightly (1-3\%) and digital blood flow decreased (7-24\%) in both labyrinthine intact and labyrinthine defective subjects. This provides further evidence that activation of vestibular system may have an excitatory influence on the heart rate.

A series of studies by Jauregui-Renaud and colleagues examined cardiovascular responses in cohorts of patients with acute vertigo (158), benign paroxysmal positional vertigo (BPPV) (157) or chronic bilateral idiopathic loss of vestibular function (159). In the first of these studies (158), the heart rate, systolic and diastolic blood pressures and the power spectrum of heart rate variability of seven patients were examined within 72 hours of developing vertigo involving unilateral peripheral vestibular failure due to acute vestibular neuritis. They were then examined again at two-weeks follow up. The vestibular dysfunction was evidenced by second or third degree spontaneous nystagmus in the light, tilt of visual vertical, and unilateral canal paresis on caloric testing. Age and sex-matched controls were also examined. As part of this study, cardiovascular parameters were recorded when subjects were supine, seated upright, and upon standing. In the acute phase ( $<72$ hours), and while in the supine position, there was no difference between the vestibular dysfunction group and controls in heart rate, systolic blood pressure, diastolic blood pressure or power spectrum analysis of heart rate variability during spontaneous breathing. There was also no difference in the cardiovascular parameters when subjects were sitting upright and breathing was paced. However, while there was no change in absolute heart rate and blood pressure on standing with paced breathing, the vestibular intact (control) subjects showed a significant decrease in high frequency (HF) component of heart rate variability with an increase in the low frequency (LF)/HF ratio. In contrast, the vestibular dysfunction group had no change in HF or LF/HF heart rate variability ratio (see Fig. 17). This difference resolved at two weeks following the initial consultation, and anti-vertiginous agents that were prescribed for the first week. Since the subjects had paced breathing, the modulation of heart rate variability can't be attributed to the respiratory influence on sympathetic activity. The lack of change in the frequency domain in the vestibular dysfunctional subjects during the orthostatic challenge suggests a vestibular interaction with cardiac function.

In the second study, Jauregui-Renauld et al. (157) examined patients with benign paroxysmal positional vertigo (BPPV), which involves dysfunction of the semicircular canal system due to the normal mechanical dynamics of the canal system being altered by displaced otoconia. The study compared cardiovascular parameters in patients with 
unilateral $(n=3)$ or bilateral $(n=1)$ BPPV and healthy $(n=9)$ subjects. Pulse and respiratory rate, blood oxygen saturation, and three-dimensional eye position were compared during posterior directed head-down tilts $\left(-45^{\circ}\right.$ from Earth-horizontal) in the plane of the left anterior/right posterior canals (LARP) or the right anterior/left posterior canals (RALP). Healthy subjects exhibited a decrease in pulse rate $(-11 \pm 6$ beats/min in LARP and $-10 \pm 8$ beats/min in RALP) within the first $10 \mathrm{sec}(6.0 \pm 2.2 \mathrm{sec})$ of the head-down tilt. This was accompanied by variable respiratory rates and no significant change in oxygen saturation. In contrast, while the baseline data of patients were similar to those of the controls, the patients with unilateral BPPV had significantly smaller drops in heart rate when tilted in the plane of the compromised canal compared to the non-compromised canal, with static head-down tilt in the plane of the non-compromised canal failing to inducing vertigo or nystagmus. Interesting, when the affected canal was activated and the patients experienced positional vertigo and nystagmus, there was very little change in pulse rate ( $-1 \pm 1$ beats per minute), while respiration was increased but blood oxygen saturation was not significantly affected. The bilateral BPPV subject did not demonstrate any reduction in pulse rate when tilted in the planes of the affected canals. That is, tilt in the plane of the affected canal did not induce a rapid reduction in heart rate observed in both normal subjects and unilaterally affected patients when tilted in the plane of the unaffected canal. Given that there was a lack of congruity between respiration and heart rate responses, these effects are unlikely to be driven by respiration.

In the third study, Jauregui-Renaud et al (159) examined six patients with chronic bilateral (idiopathic) vestibular dysfunction evidenced by unsteadiness or oscillopsia of $>$ three years duration and an absence of nystagmus in response to both caloric irrigation of the ear and horizontal rotation in the dark. Three of the patients had reduced otolith (utricular) function evidenced by testing vestibulo-ocular responses to lateral horizontal linear displacement. One patient had compromised ocular responses in the yaw and pitch planes during eccentric rotational testing with head thrust forward. Breathing movements were recorded and heart rate variability was determined. Linear accelerations were imposed on the blind-folded and head-fixed subjects seated in a chair on a sled that produced $0.26 \mathrm{G}$ over $100 \mathrm{msec}$, which was maintained for $160 \mathrm{msec}$, and then a variable deceleration occurred (with a peak deceleration of $0.14 \mathrm{G}$ ). Predictable and unpredictable acceleration profiles were used. In some trials acceleration commenced at the end of inspiration or the end of expiration. The imposed accelerations induced increased heart rate within the first to second heart beat of the initial acceleration. This increased heart rate continued to the $5^{\text {th }}$ heart beat in normal subjects. In contrast, the vestibular dysfunction patients did not exhibit the increased heart rate after the maximal jerk into the third, fourth and fifth beat. Notably, there was no difference in the response if initiated at the end of inspiration or end of expiration. Furthermore, the response pattern was the same whether the subject expected the stimulus or it was unexpected. These findings provide further evidence that transient increases in heart rate occurring with linear acceleration involve a contribution from the vestibular system, since the prolonged transient response observed in subjects with intact vestibular inputs was reduced in patients with the loss of vestibular function.

Most recently, Aoki et al. (10) investigated systolic blood pressure changes induced by an orthostatic challenge involving standing from a seated position in patients $(\mathrm{n}=11)$ with a 
putative compromised vestibular system, clinically defined by the presence of both acute dizziness and abnormal deviation of the subjective visual vertical (SVV) which, in the absence of brain stem lesions, indicates a peripheral vestibular lesion (294) involving the otolith organs (127). They compared these data with findings from patients with nonlabyrinthine acute dizziness $(n=11)$ who presented with normal SVV and a control group of 'non-dizzy' persons $(\mathrm{n}=11)$. Active standing induced a significant difference in the change (drop) in systolic blood pressure of the vestibular compromised patients $(6.8 \pm 3.0 \mathrm{mmHg})$ compared to both the dizzy patients with normal SVV $(2.6 \pm 2.2 \mathrm{mmHg})$ and the control subjects $(2.1 \pm 2.6 \mathrm{mmHg})$. All subjects had an increase in heart rate on standing but the change was not significant different between the three groups. In a more recent study involving a larger cohort of dizzy patients ( $n=127$ male, 121 female), Aoki et al. (11) used vestibular evoked myogenic potentials (VEMPs) in the sternocleidomastoid muscles to determine the integrity of the vestibular system. A loss of the p13-n23 VEMP response indicates a compromised vestibular input, particularly a loss of inputs from the sacculus (65, 66). In this study male patients with asymmetrical or normal VEMPs were found to have a significant increase in their systolic blood pressure at one minute and a significant increase in diastolic pressure at two minutes after standing compared to the pre-standing rest period. In contrast, those males in whom VEMPs could not be evoked had a significant drop in diastolic blood pressure at one minute, but not at two minutes after standing compared to the average diastolic pressure at rest prior to standing, and had no change in systolic blood pressure after standing up. Females with normal VEMPs had significant increases in systolic and diastolic blood pressure at one minute. Those females with absent or asymmetrical VEMPs had a decrease in systolic blood pressure at one minute after standing while diastolic pressure did not change on standing up. When classified on the basis of the SVV rather than VEMP status, males with small SVV $\left(\leq 2^{\circ}\right)$ were found to have a significant increase in systolic blood pressure at one minute whereas those with larger SVV $\left(>2^{\circ}\right)$ had a decrease (albeit a non-statistically significant) in systolic blood pressure at one minute after standing up. Both small and large SVV groups showed significant increases in heart rate but no change in diastolic blood pressure at one minute compared to the rest period prior to standing. While there were increases in heart rate among females on standing there were no differences in systolic blood pressure one minute after standing when females where classified on the basis of SVV. However, those with large SVV $\left(>2^{\circ}\right)$ had a significant increase in diastolic blood pressure. The difference in male and female responses in this study may reflect that the study did not control for menstrual cycle which is known to influence blood pressure regulation (91). Nevertheless, these data suggest that in those persons with an intact peripheral vestibular system there is an increase in systolic blood pressure at one minute after standing but that this is compromised in those persons with dysfunctional peripheral vestibular organs.

Summary-Studies of clinical populations indicate that dysfunction of the vestibular system may have varied effects on blood pressure regulation in the presence of a normally functioning baroreflex $(10,158,234,235,315)$. However, some studies reported that changes in heart rate $(157,158,234,235,315)$ and heart rate variability (158) normally exhibited in vestibular intact persons are compromised or lost in persons with vestibular dysfunction, suggesting the vestibular system plays a role in cardiovascular regulation in the 
human. While these studies suggest that the peripheral otolith organs $(8,10,11,159,234$, $235,315)$ and semicircular canals $(234,235)$ may be involved, it is difficult to draw conclusions regarding the mechanism(s) or role(s) of the vestibular system in cardiovascular regulation from these few heterogeneous clinical cohort studies.

\section{Influences of Vestibular Stimulation on Cardiovascular Regulation in Healthy Individuals: Activation of Otolith Organs}

One of the first laboratory studies in individuals with normal vestibular function suggesting that the vestibular system contributes to cardiovascular regulation involved the monitoring of limb blood flow during head movements about a stationary body. The blood flow in the limbs of prone adults was recorded using venous occlusion strain-gauge plethysmography and compared while the head and neck were aligned with the body axis or the head was tilted downwards, in a maneuver called head-down neck flexion (HDNF). This maneuver is illustrated in Fig. 18. In this study, Essandoh et al. (95) showed that, in the absence of changes in arterial blood pressure and heart rate, HDNF resulted in an initial (first 30s) average decrease in blood flow in the forearm and the calf of $39 \%$ and 35\%, respectively. With the head still held in the head-down flexed position the response then slowly recovered to pre-HDNF values by 12 minutes. Since there was no change in blood pressure, other circulatory changes presumably compensated for the changes in blood flow to the limbs. Essandoh et al. hypothesized that the vestibular system was responsible for this reflex response since they showed in a subset of the subjects $(n=3)$ that neck congestion or active neck contraction did not produce the same effect.

Concerned that the study by Essandoh et al. (95) did not exclude the contributions to responses of neck mechanoreceptors, Normand et al (220) repeated this study, but in addition to measuring blood pressure, heart rate and limb blood flow during HDNF and neck extension (HDNE) with the subjects lying prone, they also measured the parameters during head movements with subjects in the lateral decubitus position. They argued that when subjects were in the prone position, both otolith organ receptors and neck mechanoreceptors would be activated when the head was flexed down or extended up. However, they postulated that head flexion and extension while lying in the lateral decubitus position does not affect the inputs from otolith organs, since the orientation of the otolith organs does not change with respect to gravity. Consequently, the effects of otolith organ stimulation could be discriminated by subtracting data collected for a respective subject in the lateral decubitus position (neck only stimulation) and the prone position (neck plus otolith organ stimulation). By subtracting the findings collected from subjects in the prone and lateral decubitus position, Normand et al (220) determined that otolith organ stimulation during head flexion decreases mean arterial pressure and blood flow to both the calf and forearm. They also noted that the otolith organ activation during head extension did not significantly affect the cardiovascular parameters.

Ray and colleagues performed microneurography studies to assess the influence of the vestibular system on both MSNA and SSNA $(239,259)$. They determined whether the HDNF stimulus previously described by Essandoh et al. (95) affected MSNA or SSNA, arterial blood pressure, heart rate, calf blood flow, calf vascular resistance, or skin blood 
flow conductance. Baseline measures were recorded with the subjects lying prone and the head and neck extended to emulate the head upright (vertex to zenith) position. The frequency of MSNA bursts increased $63 \pm 23 \%$ during the 10-minute period that the head was subsequently flexed down (HDNF), as illustrated in Fig. 19. During the first minute of head flexion, heart rate increased from $71 \pm 2$ to $76 \pm 3$ beats $/ \mathrm{min}$, and the increased heart rate was sustained while the head flexion stimulus continued. Although systolic blood pressure did not change, diastolic blood pressure increased slightly from $80 \pm 3 \mathrm{mmHg}$ to $82 \pm 3 \mathrm{mmHg}$ after the first minute in the HDNF. The stimulus also elicited a decrease in calf blood flow and an $\sim 12 \%$ increase in calf vascular resistance, with the greatest change occurring in the first two minutes of HDNF. In a subsequent series of experiments Ray and colleagues demonstrated that partial (50\%) HDNF elicited smaller changes in MSNA than did larger head movements, indicating that the cardiovascular responses depended on the magnitude of the stimulus (143). However, HDNF did not cause a change in SSNA, demonstrating that the stimulus does not have the same effects on all sympathetic efferent fibers (239).

In a later study, Ray and colleagues (204) compared MSNA activity in both the arm and leg during HDNF, and showed that both increased similarly. These changes were accompanied by a decrease in blood flow in the calf and arm, although vasoconstriction was $61 \%$ greater in the calf than the arm. However, there was little change in mean arterial blood pressure, suggesting that vasoconstriction in the limbs was offset by vasodilation in other vascular beds. When monitored over longer periods (30 $\mathrm{min}$ ) of HDNF, MSNA remained the same for the duration of the stimulus (143). The parallel changes in arm and leg MSNA evoked by HDNF in humans differed from the patterned responses in animals, where reciprocal changes in forelimb and hindlimb blood flow were elicited by vestibular stimulation (see section "Patterning of Vestibulosympathetic Reflexes" above). It is unclear whether the differences in responses in humans and animals were related to use of different techniques to activate vestibular afferents, or to species differences. One study in female human subjects showed that vestibular stimulation can produce divergent changes in arm and leg vascular resistance during some phases of the menstrual cycle, indicating that humans have a similar capacity to generate patterned VSR that animals do (178).

The influence of HDNF on MSNA has also been examined in upright subjects. Watenpaugh et al. (301) showed that while $60^{\circ}$ head-up body tilt caused MSNA to increase, in accordance with previous studies (49), small $\left(<30^{\circ}\right)$ changes (flexion or extension) in head orientation during the head-up body tilt did not alter the MSNA responses. The authors interpreted the findings as suggesting that head orientation (and otolith organ stimulation) in the upright posture evokes minimal changes in sympathetic nerve activity. However, Ray's group (252) found that even though resting MSNA was greater in subjects that were seated upright or positioned $60^{\circ}$ head-up on a tilt table than subjects who were prone, head-down flexion still elicited changes in MSNA. The studies by Watenpaugh et al. (301) and Ray's group (252) differed, in that the latter experiments made use of larger head rotations. These findings suggest that whereas otolith organ activation during head movements alters sympathetic nerve activity in humans, the head movements required to produce the responses are relatively large. Thus, vestibulo-sympathetic responses are different than other vestibular-elicited responses in humans, such as vestibulo-ocular reflexes, which are evoked by head movements of magnitudes $<1^{\circ}(23,118,120)$. 
Ray et al. (239, 259), like Essandoh and colleagues (95), postulated that the cardiovascular system effects of HDNF were due to activation of the vestibular endorgans, particularly the otolith organs. They argued that the increase in MSNA during HDNF was not due to engagement of the baroreflex, since arterial blood pressure remained unchanged during the initial period of the stimulus, although it subsequently slowly increased. They noted that such an increase in blood pressure would be expected to be associated with a decrease in sympathetic nerve activity, whereas in their studies increases in MSNA were observed. Furthermore, their subjects had no change in central blood volume, as measured with impedance cardiography, during the head down position and thus no modulation (loading or unloading) of cardiopulmonary baroreceptors (259).

However, these arguments are not explicit evidence that demonstrates that the vestibular system is responsible for increased MSNA during HDNF. To rule out other possible effects of HDNF on the regulation of sympathetic nerve activity during HDNF, Ray and colleagues introduced a variety of controls in their experiments. For example, they blindfolded subjects so no visual inputs were present that could affect blood pressure. Gender was excluded as a factor, as men and women exhibited similar changes in MSNA, calf blood flow, and calf vascular during HDNF (236). A potentially significant confounder of the HDNF stimulus is activation of neck muscle mechanoreceptors, which is known to produce changes in sympathetic nerve activity in quadruped animals (37). In order to test whether activation of neck receptors during HDNF elicited changes in MSNA, Ray and colleagues compared the effects of HDNF on MSNA in subjects that were prone or lying on the left or right side (238). They also considered the effects of horizontal rotation of the head (yaw) on MSNA. Consistent with their previous studies, HDNF in the prone position produced a significant increase in MSNA. In contrast, neither yaw head rotation nor head flexion in subjects lying on their side affected MSNA. These findings show that activation of neck mechanoreceptors during HDNF in prone subjects was not responsible for the observed changes in MSNA. Based on the results of another series of experiments, Ray et al. concluded that changes in MSNA during HDNF were not due to activation of extra-vestibular receptors or increases in cerebral pressure, since head extension in prone subjects did not alter MSNA (238).

Using an alternate approach to examine the influence of head displacement on autonomic regulation of cardiovascular function, Lee et al. (179) demonstrated that HDNF of prone subjects significantly changed heart rate variability. In particular, there was an increase in the low-frequency and decrease in the high-frequency components of heart rate variability during HDNF, suggesting an increase in sympathetic nervous system activity. Furthermore, there was a lowering of the standard deviation of intervals between heart beats during HDNF, suggesting a withdrawal of parasympathetic influences on heart rate. The alterations in heart rate variability during HDNF were not apparent when subjects were in the lateral decubitus (side lying) position.

Cui et al. (72) considered changes in MSNA elicited by quite a different stimulus paradigm that activates otolith organ receptors: sinusoidal linear accelerations along the $\mathrm{x}$-axis (forwards and backwards). MSNA burst rate decreased during the sinusoidal linear accelerations but heart rate, thoracic impedance, and mean arterial pressure did not change. In a subsequent study, the same group (71) showed that y-axis (side-to-side) linear 
acceleration also produced changes in MSNA. There was no change in mean arterial pressure, indicating the changes in sympathetic nerve activity were not due to activation of baroreceptors. Respiration was controlled at $0.25 \mathrm{~Hz}$, and thus the MSNA decrease was not due to respiratory changes.

More recently, linear acceleration was used by other investigators to ascertain the effects of selective stimulation of otolith organs on sympathetic nerve activity. For example, Grewal et al. (128) recorded SSNA in subjects with eyes closed during sinusoidal antero-posterior ( $\mathrm{x}$ axis) and medio-lateral (y-axis) sinusoidal displacements of low frequency and amplitude. Subjects either could only barely distinguish the presence of movements, but not their direction, or did not perceive any movement. There was no change in blood pressure, heart rate, respiration rate, sweating or skin blood flow during the movements. However, SSNA was significantly modulated by the sinusoidal displacements with two response peaks noted. Both $\mathrm{x}$-axis and $\mathrm{y}$-axis accelerations elicited the responses. The group also demonstrated that the linear acceleration paradigm similarly increased lower limb MSNA (134). These findings deviated from those of Cui et al., who demonstrated that horizontal plane linear acceleration diminished MSNA. It is noteworthy that the stimuli used in the studies were quite different, in that Cui et al. delivered accelerations that were much higher in frequency and magnitude than those used in the recent experiments. These observations suggest that sympathetic nerve responses to vestibular stimulation can vary tremendously on the basis of the properties of the stimulus that is delivered.

These results differed from those of Ray $(239,259)$ and Essandoh $(95)$, which showed that only one direction of head movement (HDNF) elicited changes in MSNA. However, there are important differences in the stimuli used in these studies. HDNF affects both the utriculus and sacculus, whereas linear acceleration in the horizontal plane, with the head vertical, mainly activates the utriculus. In addition, the large head movements during HDNF provided a much larger stimulus to otolith organs than the linear accelerations used by Cui et al. These observations provide further support for the argument that very large stimuli must be applied to the otolith organs in order to produce substantial cardiovascular system responses.

Yet another approach that has been employed to determine whether inputs from the vestibular otolith organs contribute to regulation of sympathetic nerve activity is the monitoring of MSNA during off-vertical axis rotation (OVAR) (167). This work entailed continuous rotation of the body at constant velocity about its longitudinal axis with the axis of rotation tilted by 15 degrees from Earth vertical. After a brief period (10-12s), the signals from the semicircular canals are lost as they adapt to constant velocity rotations $(23,118$, 120). However, the otolith organs are activated during this stimulus, as the body is tilted relative to gravity during the rotations. Since the direction of tilt rotates about the body, OVAR can be used to determine the best tilt direction for producing a response. An additional advantage of this stimulus is that the neck is not moved relative to the body. OVAR was performed in the dark, and the intervals between heart beats, lower limb MSNA, respiratory rate, and eye movements were recorded. The OVAR stimulus elicited maximal MSNA activity when the nose was tilted upwards (see Figs. 20 and 21). The responses were unaffected when subjects held their breath during rotations, indicating that they were not due 
to respiratory entrainment to stimuli. It was also shown that the latency of changes in MSNA was too short for the responses to be due to baroreceptor activation. This study suggests nose-up displacement modulates MSNA in the lower limbs, and argued that similar stimulation of the otolith organs would occur during standing, such that the responses would be helpful in offsetting postural hypotension. Notably, however, changes in MSNA elicited by OVAR differ from those produced by HDNF, where the nose is tilted downwards. There were significant differences in the experimental paradigms between these studies, such as subject posture relative to gravity, use of dynamic versus static stimuli, and neck displacement in one study but not the other. All of these stimulus components may have influenced the way the central nervous system processed the respective stimuli.

Summary-Direct recordings from sympathetic nerves have shown that MSNA increases when the head is flexed downwards in prone or upright healthy individuals $(204,252,259)$. Although pitching the head activates both vestibular and extra-vestibular receptors, the physiological effects of the stimulus appear to be due to activation of the otolith organs. A single study examining heart rate variability suggests that HDNF may also modulate parasympathetic regulation of heart rate (179), although this observation needs to be confirmed. Use of OVAR stimuli (167) also indicated that inputs from otolith organs affect sympathetic nerve activity in humans, although the direction of head tilt producing an increase in sympathetic nerve activity was opposite during OVAR and HDNF stimuli. Use of linear acceleration to activate the otolith organs showed that both side-to-side and fore-aft movements can alter MSNA $(71,72,128,134)$, although the responses could either be excitatory or inhibitory depending on the properties of the stimulus. These observations demonstrate that inputs from the vestibular otolith organs affect sympathetic nervous system activity in humans. However, the direction of head movement eliciting the responses varies in accordance with stimulation technique, and presumably the extra-vestibular receptors activated by the technique. Thus, these findings suggest that sympathetic nervous system responses to vestibular stimulation in humans may be highly integrative, in that they are modulated by a variety of different signals.

Whereas head-up rotations produce changes in sympathetic nerve activity and blood pressure in animals $(312,327)$, a variety of different directions of movement altered sympathetic nerve activity in humans. Although there is no experimental evidence to demonstrate why such species differences exit, one possible explanation relates to the variety of initial postures from which humans can execute postural changes (e.g., standing from a prone, supine, or lateral decubitus position). It is feasible that the nervous system adapts to the vestibular stimuli that accompany postural changes in each individual, such that the direction of vestibular stimulation that triggers a change in sympathetic nervous system activity in one person might not have the same effect in another. Further experiments will be needed to test this hypothesis.

\section{Influences of Vestibular Stimulation on Cardiovascular Regulation in Healthy Individuals: Activation of Semicircular Canals}

Although most studies of vestibulo-sympathetic responses in humans utilized stimuli that activate otolith organ receptors, a few also considered the effects of stimulation of 
semicircular canal receptors. Invariably, these studies utilized stimuli that activated the horizontal semicircular canals, and there is little evidence in humans to determine whether inputs from the vertical semicircular canals (i.e., the anterior and posterior canals) affect sympathetic nerve activity.

Ray et al. $(240,309)$ examined the effects of passive $(0.1 \mathrm{~Hz})$ or active $(0.6 \mathrm{and} 1 \mathrm{~Hz})$ active horizontal (yaw) rotations of the head on MSNA, SSNA, mean arterial blood pressure, heart rate and skin blood flow. None of these parameters were affected substantially by the stimulus. However, there are a number of caveats that must be considered when interpreting these data. First, the passive rotations were delivered at a slow frequency that would have not substantially altered the firing rate of semicircular canal afferents (102). Although $1 \mathrm{~Hz}$ sinusoidal rotations of the head would provide an appreciable stimulus for horizontal semicircular canal afferents, the central nervous system can respond differently to active and passive rotations of the head (74).

To determine whether activation of the horizontal semicircular canal participates in the withdrawal of sympathetic activity during motion sickness, Costa et al. (68) recorded integrated MSNA in subjects during caloric vestibular stimulation of one ear. This unilateral caloric stimulation was sufficient to induce nystagmus in all subjects, which indicated unilateral activation of a horizontal semicircular canal. Unilateral caloric vestibular stimulation did not affect blood pressure, heart rate or MSNA, suggesting that unilateral stimulation of a horizontal semicircular canal does not alter muscle blood flow. In contrast, Cui et al. (73) reported that caloric vestibular stimulation modulates MSNA recorded from the tibial nerve. There were several differences between the two studies. First, Cui et al. (73) measured MSNA burst area from rectified and integrated neurograms, while Costa et al. (68) considered peak amplitudes of the sympathetic bursts. It is thus likely that the methodology used by Cui et al. was more sensitive in discerning changes in sympathetic nerve activity. In addition, Cui el al. alternately provided hot and cold water irrigations to the two ears, whereas Costa et al. provided warm water irrigation to only one ear canal. All cold water irrigations induced nystagmus, whereas only some (27/56) of the warm irrigations evoked nystagmus, suggesting that cold stimuli were more effective in activating the horizontal semicircular canal. Although blood pressure did not change, cold water irrigation induced an increase in heart rate. Importantly it was noted that heart rate increased before caloric irrigation was initiated, suggesting a cognitive component to the cardiovascular response. Warm water irrigation of the ear canal induced a smaller increase in heart rate. Although two peaks of MSNA occurred in response to cold water caloric stimuli, the initial peak could also be produced by immersing the hand in cold water, suggesting that the response was nonspecific. Furthermore, the warm stimulus only produced a single increase in MSNA activity with a similar temporal onset as the delayed response following cold stimuli. Those subjects exhibiting nystagmus had larger responses than those without nystagmus, and there was a significant linear correlation between MSNA response magnitudes and the maximum slow phase velocity of the nystagmus that was evoked. However, it is impossible to determine whether the differences in findings between the two studies were related to higher sensitivity of methodology used in the Cui et al. study (73), or the fact that the responses in this study were nonspecific and due to noxious properties of the stimulus. 
Summary-The contributions of inputs from semicircular canals on the regulation of sympathetic nervous system activity have not been adequately examined in human subjects. There has been no conclusive study of the effects of stimulation of the anterior and posterior semicircular canals on sympathetic nerve activity, and studies that activated the horizontal semicircular canal have technical problems. Although studies in animals have provided little evidence to suggest that semicircular canal inputs substantially contribute to the regulation of peripheral blood flow and blood pressure (327), this issue deserves more consideration in experiments conducted on humans.

\section{Combined Effects of Stimulation of Cardiovascular and Vestibular Receptors on Regulation of Blood Pressure}

Experiments in animals led to the hypothesis that vestibulo-sympathetic responses supplement baroreceptor responses in maintaining stable blood pressure during postural alterations. Ray (237) tested this hypothesis in human subjects by combining the unloading of baroreceptors through lower body negative pressure with stimulation of the otolith organs through HDNF. This study demonstrated that increases in MSNA resulting from diminished activation of cardiopulmonary receptors are augmented by otolith organ stimulation. The increases in MSNA were equivalent to the summation of the individual sympathetic nerve responses to baroreceptor unloading and vestibular stimulation. The author concluded that although vestibulosympathetic and baroreceptor reflexes are independent, the two complement each other. This conclusion is consistent to that of Bent et al. (29), (see "Vestibulosympathetic Reflexes Evoked by Electrical Stimulation in Humans" above).

In a subsequent study (92), HDNF was combined with the infusion of drugs that raised (phenylephrine) or lowered (nitroprusside) blood pressure. Nitroprusside infusion induced a decrease in mean arterial pressure and increases in heart rate and MSNA. Consistent with the previous study using lower body negative pressure (237), HDNF augmented the increases in MSN resulting from the unloading of baroreceptors following nitroprusside administration. However, HDNF did not affect MSNA when blood pressure was raised using phenylephrine. These findings provide further evidence to suggest that VSR protect against hypotension.

Wilson et al. (308) examined the effects of HDNF and HDNE on middle cerebral artery blood flow velocity measured using Doppler ultrasound in prone and supine subjects.

Although changes in head position did not affect head blood flow in the absence of other physiological perturbations, both HDNF and HDNE produced changes in blood flow during the application of lower body negative pressure. However, cerebro-vascular resistance was greater during HDNE compared to HNDF during lower body negative pressure. Serrador et al. (255) examined the effects of sinusoidal head movements and centrifugal stimuli on cerebral blood flow. Both stimuli modulated cerebral blood flow velocity, depending on the frequency of stimulation. Since the centrifugal stimuli selectively activated otolith organs, it was concluded that otolith inputs triggered the changes is cerebral blood flow. The changes in cerebral blood flow were in opposition to changes in blood pressure and not fully dependent on changes in end-tidal $\mathrm{CO}_{2}$. On the basis of these findings, the authors concluded that activation of the vestibular apparatus, specifically the otolith organs, directly 
affects cerebral blood flow regulation, independent of blood pressure and end tidal $\mathrm{CO}_{2}$ changes.

Summary-Several studies have provided evidence that VSR complement baroreceptor responses in regulating blood pressure during postural changes that result in an unloading of baroreceptors $(92,237)$. Vestibular stimulation also elicits changes in cerebral blood flow $(255,308)$ that appear to be mediated by different neural mechanisms than regulate systemic blood flow. Consequently, vestibular-elicited reflexes may contribute to maintenance of stable blood pressure during postural changes through two separate mechanisms.

\section{Conclusion}

Evidence accumulated during a period of over 30 years, from experiments on both animals and human subjects, has conclusively demonstrated that the vestibular system contributes to the regulation of blood distribution in the body and blood pressure during movement and changes in posture. These findings have come from experiments that included stimulation of vestibular receptors in normal individuals, as well as observations of altered physiological function following the loss of labyrinthine inputs. Furthermore, neuroanatomical and neurophysiological experiments in animals have demonstrated that brainstem areas that regulate cardiovascular functions, including nucleus tractus solitarius and the rostral ventrolateral medulla (RVLM), receive both direct and multisynaptic inputs from the vestibular nuclei. In addition, vestibulosympathetic responses are modulated by signals from the cerebellum and higher brain centers.

Experiments in both human subjects and animals have shown that inputs from vestibular otolith organs, and not the semicircular canals, play the primary role in regulating sympathetic nervous system activity. In contrast, most other vestibular-elicited responses, such as vestibulo-spinal and vestibulo-ocular reflexes, are elicited following an integration of inputs from both the otolith organs and semicircular canals. Another major difference between vestibulosympathetic responses and other vestibular-elicited responses is the magnitude of head movements required to produce the responses. Whereas vestibulo-ocular and vestibulo-spinal reflexes are elicited during head rotations of only a few degrees, vestibulosympathetic responses only occur during large head movements. The neural mechanisms responsible for the calibration of vestibulosympathetic responses are not currently known, but experiments in animals have shown that the responses are exaggerated in anesthetized or decerebrate preparations. Thus, the calibration of the responses likely requires inputs from higher brain centers, raising the possibility that the gain of vestibulosympathetic responses can be altered based on the perception of whether posturally-related perturbations in blood pressure are likely to occur.

Studies in both animals and humans have also shown that vestibulosympathetic responses interact with baroreceptor responses, such that vestibulosympathetic responses are enhanced when blood pressure is low and diminished when blood pressure increases. This evidence supports the notion that the two responses are complementary, and act together to maintain cardiovascular homeostasis during postural changes. There is some evidence that the latency of vestibulosympathetic reflexes is shorter than that of baroreceptor responses. In addition, 
unlike baroreceptor responses, vestibulosympathetic responses can be activated at the onset of movements that affect blood distribution in the body, even before blood pressure changes appreciably.

The sympathetic nervous system responses to vestibular stimulation differ based on the properties of the vestibular stimulus. For example, abrupt linear accelerations of the head can elicit either an increase or decrease in the activity of muscle vasoconstrictor efferents based on the frequency, amplitude, and time course of the accelerations. Some vestibular stimuli such as head down neck flexion selectively activate muscle sympathetic efferent fibers, whereas others such as low-frequency sinusoidal linear acceleration in the horizontal plane or low-frequency sinusoidal galvanic vestibular stimulation can partially entrain the activity of both skin and muscle sympathetic efferent fibers. It is unclear how vestibular stimuli are parsed by the central nervous system to elicit such a variety of physiological responses, but it is clear that the nature of the vestibular stimulus may determine the pattern of the vestibulosympathetic response.

Although many of the characteristics of vestibulosympathetic responses are similar in human subjects and animal models, there are some species-specific differences. For example, vestibular-elicited changes in sympathetic nervous system activity are anatomically patterned in at least some animals such as felines, as they differ between the upper and lower body. In contrast, there is little evidence of such anatomical response patterning from experiments on human subjects. Additional studies will be required to discern the particular characteristics of vestibulosympathetic responses that deviate between species, and the physiological significance of these differences.

While the existence of vestibular influences on the regulation of blood flow has now been unequivocally established, the clinical implications of the responses are less certain. There is no evidence that loss of labyrinthine inputs in either human subjects or animals has a deleterious effect on the maintenance of cardiovascular homeostasis. Undoubtedly, part of the reason why loss of labyrinthine inputs does not adversely affect the control of blood pressure is the presence of redundant mechanisms such as the responses to high-pressure and low-pressure baroreceptors. Visual signals play an important role in stabilizing posture in patients with labyrinthine dysfunction, and similar "sensory substitution" related to vestibulosympathetic responses may also occur. An important caveat is that all prior studies have considered vestibulosympathetic responses under laboratory conditions where the subjects were likely highly vigilant. It may only be possible to discern the physiological significance of vestibulosympathetic responses during experiments conducted in "real world" conditions, where postural perturbations can be truly unexpected.

\section{Acknowledgments}

The authors' research related to this article is supported by the following grants: National Institutes of Health (United States) grants R01 DC00693 and R01 DC03732 (to BJY) and Australian Research Council grant ARC DP 1096179 (to VGM). 


\section{References}

1. Abboud, FM.; Thames, MD. Interaction of cardiovascular reflexes in circulatory control. In: Shepherd, JT.; Abboud, FM., editors. Handbook of Physiology Section 2: Circulation Volume III: Peripheral Circulation and Organ Blood Flow, Part 2. American Physiological Society; Bethesa, MD: 1983. p. 497-555.

2. Abe C, Kawada T, Sugimachi M, Morita H. Interaction between vestibulo-cardiovascular reflex and arterial baroreflex during postural change in rats. J Appl Physiol. 2011; 111:1614-1621. [PubMed: 21921247]

3. Abe C, Tanaka K, Awazu C, Chen H, Morita H. Plastic alteration of vestibulo-cardiovascular reflex induced by 2 weeks of 3-G load in conscious rats. Exp Brain Res. 2007; 181:639-646. [PubMed: 17492278]

4. Abe C, Tanaka K, Awazu C, Morita H. Strong galvanic vestibular stimulation obscures arterial pressure response to gravitational change in conscious rats. J Appl Physiol. 2008; 104:34-40. [PubMed: 17916676]

5. Abe $\mathrm{C}$, Tanaka $\mathrm{K}$, Awazu C, Morita $\mathrm{H}$. The vestibular system is integral in regulating plastic alterations in the pressor response to free drop mediated by the nonvestibular system. Neurosci Lett. 2008; 445:149-152. [PubMed: 18804148]

6. Agarwal SK, Calaresu FR. Supramedullary inputs to cardiovascular neurons of rostral ventrolateral medulla in rats. Am J Physiol. 1993; 265:R111-R116. [PubMed: 8342674]

7. Anderson JH, Blanks RHI, Precht W. Response characteristics of semicircular canal and otolith systems in the cat. I. Dynamic responses of primary vestibular fibers. Exp Brain Res. 1978; 32:491507. [PubMed: 28960]

8. Andrezik JA, Dormer KJ, Foreman RD, Person RJ. Fastigial nucleus projections to the brain stem in beagles: pathways for autonomic regulation. Neurosci. 1984; 11:497-507.

9. Angaut P, Brodal A. The projection of the "vestibulocerebellum" onto the vestibular nuclei in the cat. Arch Ital Biol. 1967; 105:441-479. [PubMed: 5585723]

10. Aoki M, Sakaida Y, Hayashi H, Yamada N, Mizuta K, Ito Y. The orthostatic dysregulation of blood pressure in dizzy patients. J Vestib Res. 2008; 18:223-229. [PubMed: 19208966]

11. Aoki M, Sakaida Y, Tanaka K, Mizuta K, Ito Y. Evidence for vestibular dysfunction in orthostatic hypotension. Exp Brain Res. 2012; 217:251-259. [PubMed: 22205233]

12. Arndt JO, Brambring P, Hindorf K, Rohnelt M. The afferent discharge pattern of atrial mechanoreceptors in the cat during sinusoidal stretch of atrial strips in situ. J Physiol. 1974; 240:33-52. [PubMed: 4854642]

13. Arshian MS, Puterbaugh SR, Miller DJ, Catanzaro MF, Hobson CE, McCall AA, Yates BJ. Effects of visceral inputs on the processing of labyrinthine signals by the inferior and caudal medial vestibular nuclei: ramifications for the production of motion sickness. Exp Brain Res. 2013; 228:353-363. [PubMed: 23712685]

14. Bahr R, Bartel B, Blumberg H, Janig W. Functional characterization of preganglionic neurons projecting in the lumbar splanchnic nerves: vasoconstrictor neurons. J Autonom Nerv Syst. 1986; 15:131-140.

15. Bahr R, Blumberg H, Janig W. Do dichotomizing afferent fibers exist which supply visceral organs as well as somatic structures? A contribution to the problem or referred pain. Neurosci Lett. 1981; 24:25-28. [PubMed: 7266936]

16. Balaban CD. Neural substrates linking balance control and anxiety. Physiol Behav. 2002; 77:469_ 475. [PubMed: 12526985]

17. Balaban CD, Beryozkin G. Vestibular nucleus projections to nucleus tractus solitarius and the dorsal motor nucleus of the vagus nerve: potential substrates for vestibulo-autonomic interactions. Exp Brain Res. 1994; 98:200-212. [PubMed: 8050507]

18. Balaban CD, Jacob RG. Background and history of the interface between anxiety and vertigo. J Anxiety Disord. 2001; 15:27-51. [PubMed: 11388357]

19. Balaban CD, Jacob RG, Furman JM. Neurologic bases for comorbidity of balance disorders, anxiety disorders and migraine: neurotherapeutic implications. Expert Rev Neurotherapeutics. $2011 ; 11: 379-394$. 
20. Balaban CD, Porter JD. Neuroanatomic substrates for vestibulo-autonomic interactions. J Vestib Res. 1998; 8:7-16. [PubMed: 9416584]

21. Balaban CD, Thayer JF. Neurological bases for balance-anxiety links. J Anxiety Disord. 2001; 15:53-79. [PubMed: 11388358]

22. Balaban, CD.; Yates, BJ. Vestibulo-autonomic interactions: a teleologic perspective. In: Highstein, SM.; Fay, RR.; Popper, AN., editors. Anatomy and Physiology of the Central and Peripheral Vestibular System. Springer; Heidelberg: 2004. p. 286-342.

23. Barmack NH. Central vestibular system: vestibular nuclei and posterior cerebellum. Brain Res Bull. 2003; 60:511-541. [PubMed: 12787870]

24. Barman SM, Gebber GL. The posterior vermis of the cerebellum selectively inhibits $10-\mathrm{Hz}$ sympathetic nerve discharge in anesthetized cats. Am J Physiol Reg Integr Comp Physiol. 2009; 297:R210-217.

25. Barman SM, Gebber GL. Rostral ventrolateral medullary and caudal medullary raphe neurons with activity correlated to the $10-\mathrm{Hz}$ rhythm in sympathetic nerve discharge. J Neurophysiol. 1992; 68:1535-1547. [PubMed: 1479429]

26. Barman SM, Gebber GL, Calaresu FR. Differential control of sympathetic nerve discharge by the brain stem. Am J Physiol. 1984; 247:R513-519. [PubMed: 6476150]

27. Barman SM, Sugiyama Y, Suzuki T, Cotter LA, DeStefino VJ, Reighard DA, Cass SP, Yates BJ. Rhythmic activity of neurons in the rostral ventrolateral medulla of conscious cats: effect of removal of vestibular inputs. Am J Physiol Regul Integr Comp Physiol. 2011; 301:R937-946. [PubMed: 21734018]

28. Beart PM, Summers RJ, Stephenson JA, Christie MJ. Excitatory amino acid projections to the nucleus of the solitary tract in the rat: a retrograde transport study utilizing D-[3H]aspartate and [3H]GABA. J Auton Nerv Syst. 1994; 50:109-122. [PubMed: 7844309]

29. Bent LR, Bolton PS. Macefield VG. Modulation of muscle sympathetic bursts by sinusoidal galvanic vestibular stimulation in human subjects. Exp Brain Res. 2006; 174:701-711. [PubMed: 16721608]

30. Bent LR, Bolton PS, Macefield VG. Vestibular inputs do not influence the fusimotor system in relaxed muscles of the human leg. Exp Brain Res. 2007; 180:97-103. [PubMed: 17221220]

31. Bent LR, Sander M, Bolton PS, Macefield VG. The vestibular system does not modulate fusimotor drive to muscle spindles in contracting leg muscles of seated subjects. Exp Brain Res. 2013; 227:175-183. [PubMed: 23552997]

32. Berdeaux A, Duranteau J, Pussard E, Edouard A, Giudicelli JF. Baroreflex control of regional vascular resistances during simulated orthostatism. Kidney Int Suppl. 1992; 37:S29-33. [PubMed: 1630072]

33. Bishop, VS.; Malliani, A.; Thoren, P. Cardiac mechanoreceptors. In: Shepherd, JT.; Abboud, FM., editors. Handbook of Physiology Section 2: Circulation Volume III: Peripheral Circulation and Organ Blood Flow, Part 2. American Physiological Society; Bethesa, MD: 1983. p. 497-555.

34. Bles W, Bos JE, Kruit H. Motion sickness. Curr Opin Neurol. 2000; 13:19-25. [PubMed: 10719645]

35. Blomqvist, C.; Stone, H. Cardiovascular adjustments to gravitational stress. In: Shepherd, JT.; Abboud, FM., editors. Handbook of Physiology The Cardiovascular System Sect 2. Vol. III. American Physiological Society; Bethesda: 1983. p. 1025-1063.

36. Boczek-Funcke A, Dembowsky K, Häbler H-J, Jänig W, McAllen RM, Michaelis M. Classification of preganglionic neurones projecting into the cat cervical sympathetic trunk. $\mathrm{J}$ Physiol. 1992; 453:319-339. [PubMed: 1464832]

37. Bolton PS, Kerman IA, Woodring SF, Yates BJ. Influences of neck afferents on sympathetic and respiratory nerve activity. Brain Res Bull. 1998; 47:413-419. [PubMed: 10052569]

38. Bolton PS, Wardman DL, Macefield VG. Absence of short-term vestibular modulation of muscle sympathetic outflow, assessed by brief galvanic vestibular stimulation in awake human subjects. Exp Brain Res. 2004; 154:39-43. [PubMed: 14504857]

39. Bourassa EA, Sved AF, Speth RC. Angiotensin modulation of rostral ventrolateral medulla (RVLM) in cardiovascular regulation. Molec Cell Endocrinol. 2009; 302:167-175. [PubMed: 19027823] 
40. Boyle R, Pompeiano O. Convergence and interaction of neck and macular vestibular inputs on vestibulospinal neurons. J Neurophysiol. 1981; 45:852-868. [PubMed: 7241173]

41. Bradley DJ, Ghelarducci B, La Noce A, Paton JF, Spyer KM, Withington-Wray DJ. An electrophysiological and anatomical study of afferents reaching the cerebellar uvula in the rabbit. Exp Physiol. 1990; 75:163-177. [PubMed: 2340158]

42. Bradley DJ, Ghelarducci B, Paton JF, Spyer KM. The cardiovascular responses elicited from the posterior cerebellar cortex in the anaesthetized and decerebrate rabbit. J Physiol. 1987; 383:537550. [PubMed: 3656134]

43. Bradley DJ, Ghelarducci B, Spyer KM. The role of the posterior cerebellar vermis in cardiovascular control. Neurosci Res. 1991; 12:45-56. [PubMed: 1660994]

44. Bradley DJ, Pascoe JP, Paton JF, Spyer KM. Cardiovascular and respiratory responses evoked from the posterior cerebellar cortex and fastigial nucleus in the cat. J Physiol. 1987; 393:107-121. [PubMed: 3446792]

45. Bradley DJ, Paton JF, Spyer KM. Cardiovascular responses evoked from the fastigial region of the cerebellum in anaesthetized and decerebrate rabbits. J Physiol. 1987; 392:475-491. [PubMed: 3446788]

46. Brodal A. The olivocerebellar projection in the cat as studied with the method of retrograde axonal transport of horseradish peroxidase. II. The projection to the uvula. J Comp Neurol. 1976; 166:417-426. [PubMed: 1270615]

47. Brooks JX, Cullen KE. Multimodal integration in rostral fastigial nucleus provides an estimate of body movement. J Neurosci. 2009; 29:10499-10511. [PubMed: 19710303]

48. Broussard DM, Titley HK, Antflick J, Hampson DR. Motor learning in the VOR: the cerebellar component. Exp Brain Res. 2011; 210:451-463. [PubMed: 21336828]

49. Burke DS, Sundölf G, Wallin BG. Postural effects on muscle nerve sympathetic activity in man. J Physiol. 1977; 272:399-414. [PubMed: 592197]

50. Buttner U, Glasauer S, Glonti L, Kleine JF, Siebold C. Otolith processing in the deep cerebellar nuclei. Ann N Y Acad Sci. 1999; 871:81-93. [PubMed: 10372064]

51. Cai YL, Ma WL, Li M, Guo JS, Li YQ, Wang LG, Wang WZ. Glutamatergic vestibular neurons express Fos after vestibular stimulation and project to the NTS and the PBN in rats. Neurosci Lett. 2007; 417:132-137. [PubMed: 17412503]

52. Cannon, WB. Bodily Changes in Pain, Hunger, Fear and Rage: An Account of Recent Researches into the Function of Emotional Excitement. Harper \& Row; New York: 1963.

53. Cannon, WB. The Wisdom of the Body. W. W. Norton; New York: 1963.

54. Cano G, Card JP, Sved AF. Dual viral transneuronal tracing of central autonomic circuits involved in the innervation of the two kidneys in rat. J Comp Neurol. 2004; 471:462-481. [PubMed: 15022264]

55. Carleton SC, Carpenter MB. Afferent and efferent connections of the medial, inferior and lateral vestibular nuclei in the cat and monkey. Brain Res. 1983; 278:29-51. [PubMed: 6315158]

56. Carli G, Diete-Spiff K, Pompeiano O. Responses of the muscle spindles and of the extrafusal fibres in an externsor muscle to stimulation of the lateral vestibular nucleus in the cat. Arch Ital Biol. 1967; 105:209-242. [PubMed: 4228469]

57. Carlino L, Weber SA, Gowen MF, Yates BJ. Selective innervation of upper and loer thoracic spinal segments by medullary raphe neurons. FASEB J. 2012; 26:1091.2.

58. Carpenter MB, Bard DS, Alling FA. Anatomical connections between the fastigial nuclei, the labyrinth and the vestibular nuclei in the cat. J Comp Neurol. 1959; 111:1-26.

59. Carter JR, Kupiers NT, Ray CA. Neurovascular responses to mental stress. J Physiol. 2005; 564:321-327. [PubMed: 15705649]

60. Cathers I, Day BL, Fitzpatrick RC. Otolith and canal reflexes in human standing. J Physiol. 2005; 563:229-234. [PubMed: 15618274]

61. Chalmers J, Arnolda L, Llewellynsmith I, Minson J, Pilowsky P, Suzuki S. Central neurons and neurotransmitters in the control of blood pressure. Clin Exp Pharmacol Physiol. 1994; 21:819 829. [PubMed: 7867233] 
62. Cobbold AF, Megirian D, Sherrey JH. Vestibular evoked activity in autonomic motor outflows. Arch Ital Biol. 1968; 106:113-123. [PubMed: 5681889]

63. Cohen B, Martinelli GP, Raphan T, Schaffner A, Xiang Y, Holstein GR, Yakushin SB. The vasovagal response of the rat: its relation to the vestibulosympathetic reflex and to Mayer waves. FASEB J. 2013; 27:2564-2572. [PubMed: 23504712]

64. Cohen MI, Gootman PM. Periodicities in efferent discharge of splanchnic nerve of the cat. Am J Physiol. 1970; 218:1092-1101. [PubMed: 5435407]

65. Colebatch J, Halmagyi G. Vestibular evoked potentials in human neck muscles before and after unilateral vestibular deafferentation. Neurology. 1992; 42:1635-1636. [PubMed: 1641165]

66. Colebatch J, Halmagyi G, Skuse N. Myogenic potentials generated by a click-evoked vestibulocollic reflex. J Neurol Neurosurg Psychiatry. 1994; 57:190-197. [PubMed: 8126503]

67. Convertino VA, Ryan KL, Rickards CA, Glorsky SL, Idris AH, Yannopoulos D, Metzger A, Lurie KG. Optimizing the respiratory pump: harnessing inspiratory resistance to treat systemic hypotension. Respir Care. 2011; 56:846-857. [PubMed: 21333089]

68. Costa F, Lavin P, Robertson D, Biaggioni I. Effect of neurovestibular stimulation on autonomic regulation. Clin Autonom Res. 1995; 5:289-293.

69. Courville, J.; Faraco-Cantin, F. Topography of the olivo-cerebellar projection. An experimental study in the cat with an autoradiographic tracing method. In: Courville, J.; Montigny, Cd; Lamarre, Y., editors. The Inferior Olivary Nucleus-Anatomy and Physiology. Raven; New York: 1980.

70. Crandall CG, Gonzalez-Alonso J. Cardiovascular function in the heat-stressed human. Acta Physiol (Oxf). 2010; 199:407-423. [PubMed: 20345414]

71. Cui J, Iwase S, Mano T, Katayama N, Mori S. Muscle sympathetic outflow during horizontal linear acceleration in humans. Am J Physiol Regul Integr Comp Physiol. 2001; 281:R625-634. [PubMed: 11448868]

72. Cui J, Iwase S, Mano T, Katayama N, Mori S. Sympathetic nerve response to muscle during anteroposterior acceleration in humans. Environ Med. 1998; 42:71-75. [PubMed: 12212619]

73. Cui J, Mukai C, Iwase S, Sawasaki N, Kitazawa H, Mano T, Sugiyama Y, Wada Y. Response to vestibular stimulation of sympathetic outflow to muscle in humans. J Autonom Nerv Syst. 1997; 66:154-162.

74. Cullen KE, Brooks JX, Jamali M, Carriot J, Massot C. Internal models of self-motion: computations that suppress vestibular reafference in early vestibular processing. Exp Brain Res. 2011; 210:377-388. [PubMed: 21286693]

75. Dampney RA. Brain stem mechanisms in the control of arterial pressure. Clin Exp Hypertens. 1981; 3:379-391. [PubMed: 6265165]

76. Dampney RA. The subretrofacial nucleus: its pivotal role in cardiovascular regulation. News in Physiological Sciences. 1990; 5:63-67.

77. Dampney RA. The subretrofacial vasomotor nucleus - anatomical, chemical and pharmacological properties and role in cardiovascular regulation. Prog Neurobiol. 1994; 42:197-227. [PubMed: 8008825]

78. Dampney RA, Goodchild AK, McAllen RM. Vasomotor control by subretrofacial neurones in the rostral ventrolateral medulla. Can J Physiol Pharmacol. 1987; 65:1572-1579. [PubMed: 3319108]

79. Dampney RA, Horiuchi J, Tagawa T, Fontes MA, Potts PD, Polson JW. Medullary and supramedullary mechanisms regulating sympathetic vasomotor tone. Acta Physiol Scand. 2003; 177:209-218. [PubMed: 12608991]

80. Dampney RAL, McAllen RM. Differential control of sympathetic fibres supplying hindlimb skin and muscle by subretrofacial neurones in the cat. J Physiol. 1988; 395:41-56. [PubMed: 2900889]

81. Dean C, Seagard JL, Hopp FA, Kampine JP. Differential control of sympathetic activity to kidney and skeletal muscle by ventral medullary neurons. J Autonom Nerv Syst. 1992; 37:1-10.

82. Del Bo A, Sved AF, Reis DJ. Fastigial nucleus stimulation and concurrent activation of cardiovascular receptors; differentiate effects on arterial pressure, heart rate and vasopressin release. J Hypertension - Supplement. 1984; 2:S49-51.

83. Del Bo A, Sved AF, Reis DJ. Inhibitory influences from arterial baroreceptors on vasopressin release elicited by fastigial stimulation in rats. Circ Res. 1984; 54:248-253. [PubMed: 6697448] 
84. Destefino VJ, Reighard DA, Sugiyama Y, Suzuki T, Cotter LA, Larson MG, Gandhi NJ, Barman SM, Yates BJ. Responses of neurons in the rostral ventrolateral medulla to whole body rotations: comparisons in decerebrate and conscious cats. J Appl Physiol. 2011; 110:1699-1707. [PubMed: 21493724]

85. Dickman JD, Angelaki DE. Vestibular convergence patterns in vestibular nuclei neurons of alert primates. J Neurophysiol. 2002; 88:3518-3533. [PubMed: 12466465]

86. Diedrich A, Porta A, Barbic F, Brychta RJ, Bonizzi P, Diedrich L, Cerutti S, Robertson D, Furlan R. Lateralization of expression of neural sympathetic activity to the vessels and effects of carotid baroreceptor stimulation. Am J Physiol Heart Circ Physiol. 2009; 296:H1758-1765. [PubMed: 19363133]

87. Dieterich M. Central vestibular disorders. J Neurol. 2007; 254:559-568. [PubMed: 17417688]

88. Doba N, Reis DJ. Changes in regional blood flow and cardiodynamics evoked by electrical stimulation of the fastigial nucleus in the cat and their similarity to orthostatic reflexes. J Physiol. 1972; 227:729-747. [PubMed: 4650936]

89. Doba N, Reis DJ. Role of the cerebellum and vestibular apparatus in regulation of orthostatic reflexes in the cat. Circ Res. 1974; 34:9-18. [PubMed: 4543723]

90. Dulac S, Raymond JL, Sejnowski TJ, Lisberger SG. Learning and memory in the vestibulo-ocular reflex. Annu Rev Neurosci. 1995; 18:409-441. [PubMed: 7605068]

91. Dunne F, Barry D, Ferriss J, Grealy G, Murphy D. Changes in blood pressure during the normal menstrual cycle. Clin Sci (Lond). 1991; 81:515-518. [PubMed: 1657498]

92. Dyckman DJ, Monahan KD, Ray CA. Effect of baroreflex loading on the responsiveness of the vestibulosympathetic reflex in humans. J Appl Physiol. 2007; 103:1001-1006. [PubMed: 17615277]

93. El Sayed K, Dawood T, Hammam E, Macefield VG. Evidence from bilateral recordings of sympathetic nerve activity for lateralisation of vestibular contributions to cardiovascular control. Exp Brain Res. 2012; 221:427-436. [PubMed: 22811217]

94. Endo K, Thomson DB, Wilson VJ, Yamaguchi T, Yates BJ. Vertical vestibular input to and projections from the caudal parts of the vestibular nuclei of the decerebrate cat. J Neurophysiol. 1995; 74:428-436. [PubMed: 7472343]

95. Essandoh LK, Duprez DA, Shepherd JT. Reflex constriction of human resistance vessels to headdown neck flexion. Am J Physiol. 1988; 64:767-770.

96. Ezure K, Wilson VJ. Interaction of tonic neck and vestibular reflexes in the forelimb of the decerebrate cat. Exp Brain Res. 1984; 54:289-292. [PubMed: 6609834]

97. Fadel PJ, Raven PB. Human investigations into the arterial and cardiopulmonary baroreflexes during exercise. Exp Physiol. 2012; 97:39-50. [PubMed: 22002871]

98. Fatouleh R, Macefield VG. Cardiorespiratory coupling of sympathetic outflow in humans: a comparison of respiratory and cardiac modulation of sympathetic nerve activity to skin and muscle. Exp Physiol. 2013; 98:1327-1336. [PubMed: 23625953]

99. Favilla M, Ghelarducci B, Hill CD, Spyer KM. Vestibular inputs to the fastigial nucleus; evidence of convergence of macular and ampullar inputs. Pflugers Arch. 1980; 384:193-201. [PubMed: 6106184]

100. Felder RB, Mifflin SW. Modulation of carotid sinus afferent input to nucleus tractus solitarius by parabrachial nucleus stimulation. Circ Res. 1988; 63:35-49. [PubMed: 3383382]

101. Fernandez C, Goldberg JM. Physiology of peripheral neurons innervating otolith organs of the squirrel monkey. III. Response dynamics. J Neurophysiol. 1976; 39:996-1008. [PubMed: 824414]

102. Fernandez C, Goldberg JM. Physiology of peripheral neurons innervating semicircular canals of the squirrel monkey. II. Response to sinusoidal stimulation and dynamics of peripheral vestibular system. J Neurophysiol. 1971; 34:661-675. [PubMed: 5000363]

103. Ferrari AU. Modifications of the cardiovascular system with aging. Am J Geriatr Cardiol. 2002; 11:30-33. [PubMed: 11773713]

104. Fitzpatrick RC, Butler JE, Day BL. Resolving head rotation for human bipedalism. Curr Biol. 2006; 16:1509-1514. [PubMed: 16890526] 
105. Fitzpatrick RC, Day BL. Probing the human vestibular system with galvanic stimulation. J Appl Physiol. 2004; 96:2301-2316. [PubMed: 15133017]

106. Fu Q, Iwase S, Niimi Y, Kamiya A, Michikami D, Mano T. Effects of aging on leg vein filling and venous compliance during low levels of lower body negative pressure in humans. Environ Med. 1999; 43:142-145. [PubMed: 12296367]

107. Fu Q, Witkowski S, Levine BD. Vasoconstrictor reserve and sympathetic neural control of orthostasis. Circulation. 2004; 110:2931-2937. [PubMed: 15505093]

108. Furlan R, Barbic F, Casella F, Severgnini G, Zenoni L, Mercieri A, Mangili R, Costantino G, Porta A. Neural autonomic control in orthostatic intolerance. Respir Physiol Neurobiol. 2009; 169(Suppl 1):S17-20. [PubMed: 19379844]

109. Furman JM, Balaban CD, Jacob RG, Marcus DA. Migraine-anxiety related dizziness (MARD): a new disorder? J Neurol, Neurosurg, Psych. 2005; 76:1-8.

110. Gandevia SC, Killian K, McKenzie DK, Crawford M, Allen GM, Gorman RB, Hales JP. Respiratory sensations, cardiovascular control, kinaesthesia and transcranial stimulation during paralysis in humans. J Physiol (Lond). 1993; 470:85-107. [PubMed: 8308755]

111. Gardner EP, Fuchs AF. Single-unit responses to natural vestibular stimuli and eye movements in deep cerebellar nuclei of the alert rhesus monkey. J Neurophysiol. 1975; 38:627-649. [PubMed: 1079240]

112. Gebber GL. Basis for phase relations between baroreceptor and sympathetic nervous discharge. Am J Physiol. 1976; 230:263-270. [PubMed: 1259002]

113. Gebber GL, Barman SM. Rhythmogenesis in the sympathetic nervous system. Federation Proc. 1980; 39:2526-2530. [PubMed: 7380025]

114. Gebber GL, Barman SM, Kocsis B. Coherence of medullary unit activity and sympathetic nerve discharge. Am J Physiol. 1990; 259:R561-571. [PubMed: 2396714]

115. Ghelarducci B. Responses of the cerebellar fastigial neurones to tilt. Pflugers Arch. 1973; 344:195-206. [PubMed: 4543976]

116. Gilbey MP, Spyer KM. Essential organization of the sympathetic nervous system. Bailliere Clin Endocrinol Met. 1993; 7:259-278.

117. Goldberg JM, Fernandez C. Vestibular mechanisms. Annu Rev Physiol. 1975; 37:129-162. [PubMed: 164818]

118. Goldberg, JM.; Fernández, C. The vestibular system. In: Darian-Smith, I., editor. Handbook of Physiology Section I: The Nervous System Volume III, Sensory Processes, Part 2. American Physiological Society; Bethesda, MD: 1984. p. 977-1022.

119. Goldberg JM, Smith CE, Fernandez C. Relation between discharge regularity and responses to externally applied galvanic currents in vestibular nerve afferents of the squirrel monkey. $\mathrm{J}$ Neurophysiol. 1984; 51:1236-1256. [PubMed: 6737029]

120. Goldberg, JM.; Wilson, VJ.; Cullen, KE.; Angelaki, DE.; Broussard, DM.; Buttner-Ennever, J.; Fukushima, K.; Minor, LB. The Vestibular System: A Sixth Sense. Oxford University Press; 2012. p. 560

121. Golding JF, Gresty MA. Motion sickness. Curr Opin Neurol. 2005; 18:29-34. [PubMed: 15655399]

122. Gootman PM, Cohen MI. Efferent splanchnic activity and systemic arterial pressure. Am J Physiol. 1970; 219:897-903. [PubMed: 5459490]

123. Gootman PM, Cohen MI. Periodic modulation (cardiac and respiratory) of spontaneous and evoked sympathetic discharge. Acta Physiologica Polonica. 1973; 24:97-109. [PubMed: 4716352]

124. Gotoh TM, Fujiki N, Matsuda T, Gao S, Morita H. Roles of baroreflex and vestibulosympathetic reflex in controlling arterial blood pressure during gravitational stress in conscious rats. Am J Physiol Regul Integr Comp Physiol. 2004; 286:R25-30. [PubMed: 14500268]

125. Gowen MF, Ogburn SW, Suzuki T, Sugiyama Y, Cotter LA, Yates BJ. Collateralization of projections from the rostral ventrolateral medulla to the rostral and caudal thoracic spinal cord in felines. Exp Brain Res. 2012; 220:121-133. [PubMed: 22623097] 
126. Granata AR, Ruggiero DA, Park DH, Joh TH, Reis DJ. Brain stem area with C1 epinephrine neurons mediates baroreflex vasodepressor responses. Am J Physiol. 1985; 248:H547-H567. [PubMed: 3985177]

127. Gresty M, Bronstein A, Brandt T, Dieterich M. Neurology of otolith function. Peripheral and central disorders. Brain. 1992; 115:647-673. [PubMed: 1628197]

128. Grewal T, Dawood T, Hammam E, Kwok K, Macefield VG. Low-frequency physiological activation of the vestibular utricle causes biphasic modulation of skin sympathetic nerve activity in humans. Exp Brain Res. 2012; 220:101-108. [PubMed: 22623094]

129. Grewal T, James C, Macefield VG. Frequency-dependent modulation of muscle sympathetic nerve activity by sinusoidal galvanic vestibular stimulation in human subjects. Exp Brain Res. 2009; 197:379-386. [PubMed: 19582437]

130. Groenewegen HJ, Voogd J. The parasagittal zonation within the olivocerebellar projection. I. Climbing fiber distribution in the vermis of cat cerebellum. J Comp Neurol. 1977; 174:417-488. [PubMed: 903414]

131. Hamilton RB, Ellenberger H, Liskowsky D, Schneiderman N. Parabrachial area as mediator of bradycardia in rabbits. J Auton Nerv Syst. 1981; 4:261-281. [PubMed: 7299042]

132. Hammam E, Dawood T, Macefield VG. Low-frequency galvanic vestibular stimulation evokes two peaks of modulation in skin sympathetic nerve activity. Exp Brain Res. 2012; 219:441-446. [PubMed: 22526950]

133. Hammam E, James C, Dawood T, Macefield VG. Low-frequency sinusoidal galvanic stimulation of the left and right vestibular nerves reveals two peaks of modulation in muscle sympathetic nerve activity. Exp Brain Res. 2011; 213:507-514. [PubMed: 21800255]

134. Hammam E, Kwok K, Macefield VG. Modulation of muscle sympathetic nerve activity by lowfrequency physiological activation of the vestibular utricle in awake humans. Exp Brain Res. 2013; 230:137-142. [PubMed: 23852323]

135. Hargens AR, Richardson S. Cardiovascular adaptations, fluid shifts, and countermeasures related to space flight. Respir Physiol Neurobiol. 2009; 169(Suppl 1):S30-33. [PubMed: 19615471]

136. Harms MP, Colier WN, Wieling W, Lenders JW, Secher NH, van Lieshout JJ. Orthostatic tolerance, cerebral oxygenation, and blood velocity in humans with sympathetic failure. Stroke. 2000; 31:1608-1614. [PubMed: 10884461]

137. Heidenreich K, Weisend S, Fouad-Tarazi F, White J. The incidence of coexistent autonomic and vestibular dysfunction in patients with postural dizziness. Am J Otolaryngol. 2009; 30:225-229. [PubMed: 19563931]

138. Henry RT, Connor JD, Balaban CD. Nodulus-uvula depressor response: central GABA-mediated inhibition of alpha-adrenergic outflow. Am J Physiol. 1989; 256:H1601-H1608. [PubMed: 2472076]

139. Hilton SM, Spyer KM. Central nervous regulation of vascular resistance. Ann Rev Physiol. 1980; 42:399-411. [PubMed: 6996588]

140. Hinghofer-Szalkay H. Gravity, the hydrostatic indifference concept and the cardiovascular system. Eur J Appl Physiol. 2011; 111:163-174. [PubMed: 20857139]

141. Holmes MJ, Cotter LA, Arendt HE, Cass SP, Yates BJ. Effects of lesions of the caudal cerebellar vermis on cardiovascular regulation in awake cats. Brain Res. 2002; 938:62-72. [PubMed: 12031536]

142. Holstein GR, Friedrich VL Jr. Kang T, Kukielka E, Martinelli GP. Direct projections from the caudal vestibular nuclei to the ventrolateral medulla in the rat. Neurosci. 2011; 175:104-117.

143. Hume KM, Ray CA. Sympathetic responses to head-down rotations in humans. J Appl Physiol. 1999; 86:1971-1976. [PubMed: 10368363]

144. Ichinose M, Nishiyasu T. Arterial baroreflex control of muscle sympathetic nerve activity under orthostatic stress in humans. Front Physiol. 2012; 3:314. [PubMed: 22934064]

145. Ishikawa T, Miyazawa T. Sympathetic responses evoked by vestibular stimulation and their interactions with somato-sympathetic reflexes. J Autonom Nerv Syst. 1980; 1:243-254.

146. Ishikawa T, Miyazawa T, Shimizu I, Tomita H. Similarity between vestibulo-sympathetic response and supraspinal sympathetic reflex. Nihon Univ J Med. 1979; 21:201-210. 
147. Jacob RG, Furman JM. Psychiatric consequences of vestibular dysfunction. Curr Opin Neurol. 2001; 14:41-46. [PubMed: 11176216]

148. Jacob RG, Furman JM, Durrant JD, Turner SM. Panic, agoraphobia, and vestibular dysfunction. Am J Psychiatry. 1996; 153:503-512. [PubMed: 8599398]

149. Jacob, RG.; Furman, JM.; Perel, JM. Panic, phobia and vestibular dysfunction. In: Yates, BJ.; Miller, AD., editors. Vestibular Autonomic Regulation. CRC Press; Boca Raton, FL: 1996.

150. Jacob RG, Furman JMR, Clark DB, Durrant JD. Vestibular symptoms, panic and phobia: overlap and possible relationships. Annals of Clinical Psychiatry. 1992; 4:163-174.

151. Jacobsen TN, Morgan BJ, Scherrer U, Vissing SF, Lange RA, Johnson N, Ring WS, Rahko PS, Hanson P, Victor RG. Relative contributions of cardiopulmonary and sinoaortic baroreflexes in causing sympathetic activation in the human skeletal muscle circulation during orthostatic stress. Circ Res. 1993; 73:367-378. [PubMed: 8330379]

152. James C, Macefield VG. Competitive interactions between vestibular and cardiac rhythms in the modulation of muscle sympathetic nerve activity. Auton Neurosci. 2010; 158:127-131. [PubMed: 20675201]

153. James C, Stathis A, Macefield VG. Vestibular and pulse-related modulation of skin sympathetic nerve activity during sinusoidal galvanic vestibular stimulation in human subjects. Exp Brain Res. 2010; 202:291-298. [PubMed: 20041236]

154. Janig W, Habler HJ. Neurophysiological analysis of target-related sympathetic pathways--from animal to human: similarities and differences. Acta Physiol Scand. 2003; 177:255-274. [PubMed: 12608996]

155. Jänig, W.; McLachlan, EM. Neurobiology of the autonomic nervous system. In: Mathias, CJ.; Bannister, SR., editors. Autonomic Failure: A Textbook of Clinical Disorders of the Autonomic Nervous System. Oxford: 2013. p. 21-34.

156. Jänig W, McLachlan EM. Specialized functional pathways are the building blocks of the autonomic nervous system. J Autonom Nerv Syst. 1992; 41:3-14.

157. Jauregui-Renaud K, Aw ST, Todd MJ, McGarvie LA, Halmagyi GM. Benign paroxysmal positional vertigo can interfere with the cardiac response to head-down tilt. Otol Neurotol. 2005; 26:484-488. [PubMed: 15891654]

158. Jauregui-Renaud K, Hermosillo AG, Gomez A, Marquez MF, Cardenas M, Bronstein AM. Vestibular function interferes in cardiovascular reflexes. Arch Med Res. 2003; 34:200-204. [PubMed: 14567399]

159. Jauregui-Renaud K, Reynolds R, Bronstein AM, Gresty MA. Cardio-respiratory responses evoked by transient linear acceleration. Aviation Space Environ Med. 2006; 77:114-120.

160. Jeske I, Morrison SF, Cravo SL, Reis DJ. Identification of baroreceptor reflex interneurons in the caudal ventrolateral medulla. Am J Physiol. 1993; 264:R169-R178. [PubMed: 8381615]

161. Jian BJ, Acernese AW, Lorenzo J, Card JP, Yates BJ. Afferent pathways to the region of the vestibular nuclei that participates in cardiovascular and respiratory control. Brain Res. 2005; 1044:241-250. [PubMed: 15885222]

162. Jian BJ, Cotter LA, Emanuel BA, Cass SP, Yates BJ. Effects of bilateral vestibular lesions on orthostatic tolerance in awake cats. J Appl Physiol. 1999; 86:1552-1560. [PubMed: 10233117]

163. Jian BJ, Shintani T, Emanuel BA, Yates BJ. Convergence of limb, visceral, and vertical semicircular canal or otolith inputs onto vestibular nucleus neurons. Exp Brain Res. 2002; 144:247-257. [PubMed: 12012162]

164. Kanda K, Sato Y, Ikarashi K, Kawasaki T. Zonal organization of climbing fiber projections to the uvula in the cat. J Comp Neurol. 1989; 279:138-148. [PubMed: 2913058]

165. Kasper J, Schor RH, Wilson VJ. Response of vestibular neurons to head rotations in vertical planes. I. Response to vestibular stimulation. J Neurophysiol. 1988; 60:1753-1764. [PubMed: 3199179]

166. Kasper J, Schor RH, Wilson VJ. Response to vestibular neurons to head rotations in vertical planes. II. Response to neck stimulation and vestibular-neck interaction. J Neurophysiol. 1988; 60:1765-1778. [PubMed: 3199180] 
167. Kaufmann H, Biaggioni I, Voustianiouk A, Diedrich A, Costa F, Clarke R, Gizzi M, Raphan T, Cohen B. Vestibular control of sympathetic activity. An otolith-sympathetic reflex in humans. Exp Brain Res. 2002; 143:463-469. [PubMed: 11914792]

168. Kerman IA, Emanuel BA, Yates BJ. Vestibular stimulation leads to distinct hemodynamic patterning. Am J Physiol Reg Integr Comp Physiol. 2000; 279:R118-125.

169. Kerman IA, McAllen RM, Yates BJ. Patterning of sympathetic nerve activity in response to vestibular stimulation. Brain Res Bull. 2000; 53:11-16. [PubMed: 11033203]

170. Kerman IA, Yates BJ. Regional and functional differences in the distribution of vestibulosympathetic reflexes. Am J Physiol. 1998; 275:R824-835. [PubMed: 9728081]

171. Kerman IA, Yates BJ, McAllen RM. Anatomic patterning in the expression of vestibulosympathetic reflexes. Am J Physiol Reg Integr Comp Physiol. 2000; 279:R109-117.

172. Kleine JF, Wilden A, Siebold C, Glasauer S, Buttner U. Linear spatio-temporal convergence in vestibular neurons of the primate nucleus fastigii. Neuroreport. 1999; 10:3915-3921. [PubMed: 10716233]

173. Kondo M, Sears TA, Sadakane K, Nisimaru N. Vagal afferent projections to lobule VIIa of the rabbit cerebellar vermis related to cardiovascular control. Neurosci Res. 1998; 30:111-117. [PubMed: 9579644]

174. Korte SM, Jaarsma D, Luiten PG, Bohus B. Mesencephalic cuneiform nucleus and its ascending and descending projections serve stress-related cardiovascular responses in the rat. J Auton Nerv Syst. 1992; 41:157-176. [PubMed: 1491112]

175. Krabbendam I, Jacobs LC, Lotgering FK, Spaanderman ME. Venous response to orthostatic stress. Am J Physiol Heart Circ Physiol. 2008; 295:H1587-1593. [PubMed: 18708445]

176. Krukoff TL, Harris KH, Jhamandas JH. Efferent projections from the parabrachial nucleus demonstrated with the anterograde tracer Phaseolus vulgaris leucoagglutinin. Brain Res Bull. 1993; 30:163-172. [PubMed: 7678381]

177. Lackner JR, Dizio P. Space motion sickness. Exp Brain Res. 2006; 175:377-399. [PubMed: 17021896]

178. Lawrence JE, Klein JC, Carter JR. Menstrual cycle elicits divergent forearm vascular responses to vestibular activation in humans. Auton Neurosci. 2010; 154:89-93. [PubMed: 19939746]

179. Lee CM, Wood RH, Welsch MA. Influence of head-down and lateral decubitus neck flexion on heart rate variability. J Appl Physiol. 2001; 90:127-132. [PubMed: 11133902]

180. Lee TK, Lois JH, Troupe JH, Wilson TD, Yates BJ. Transneuronal tracing of neural pathways that regulate hindlimb muscle blood flow. Am J Physiol Reg Integr Comp Physiol. 2007; 292:R1532-1541.

181. Len WB, Chan JYH. Glutamatergic projection to RVLM mediates suppression of reflex bradycardia by parabrachial nucleus. Am J Physiol Heart Circ Physiol. 1999; 45:H1482-H1492.

182. Lisberger SG. The neural basis for learning of simple motor skills. Science. 1988; 242:728-735. [PubMed: 3055293]

183. MacNeilage PR, Banks MS, DeAngelis GC, Angelaki DE. Vestibular heading discrimination and sensitivity to linear acceleration in head and world coordinates. J Neurosci. 2010; 30:9084-9094. [PubMed: 20610742]

184. Mano T, Iwase S. Sympathetic nerve activity in hypotension and orthostatic intolerance. Acta Physiol Scand. 2003; 177:359-365. [PubMed: 12609007]

185. Matsuda T, Gotoh TM, Tanaka K, Gao S, Morita H. Vestibulosympathetic reflex mediates the pressor response to hypergravity in conscious rats: contribution of the diencephalon. Brain Res. 2004; 1028:140-147. [PubMed: 15527739]

186. Matsukawa K. Central command: control of cardiac sympathetic and vagal efferent nerve activity and the arterial baroreflex during spontaneous motor behaviour in animals. Exp Physiol. 2012; 97:20-28. [PubMed: 21984731]

187. McAllen RM, Dampney RAL. Vasomotor neurons in the rostral ventrolateral medulla are organized topographically with respect to type of vascular bed but not body region. Neurosci Lett. 1990; 110:91-96. [PubMed: 1970144] 
188. McAllen RM, May CN. Differential drives from rostral ventrolateral medullary neurons to three identified sympathetic outflows. Am J Physiol Regul Integr Comp Physiol. 1994; 267:R935R944.

189. McCall AA, Moy JD, Puterbaugh SR, DeMayo WM, Yates BJ. Responses of vestibular nucleus neurons to inputs from the hindlimb are enhanced following a bilateral labyrinthectomy. J Appl Physiol. 2013; 114:742-751. [PubMed: 23305979]

190. McCall AA, Yates BJ. Compensation following bilateral vestibular damage. Frontiers in Neurology. 2011; 88:1-14.

191. McKenna, KE. The autonomic neuroscience of sexual function. In: Mathias, CJ.; Bannister, SR., editors. Autonomic Failure: A Textbook of Clinical Disorders of the Autonomic Nervous System. Oxford: 2013. p. 119-131.

192. Megirian D, Manning JW. Input-output relations in the vestibular system. Arch Ital Biol. 1967; 105:15-30. [PubMed: 6049346]

193. Mifflin SW, Felder RB. Synaptic mechanisms regulating cardiovascular afferent inputs to solitary tract nucleus. Am J Physiol. 1990; 259:H653-661. [PubMed: 2204275]

194. Miles FA, Lisberger SG. Plasticity in the vestibulo-ocular reflex: a new hypothesis. Ann Rev Neurosci. 1981; 4:273-299. [PubMed: 6784658]

195. Miller DM, Cotter LA, Gandhi NJ, Schor RH, Cass SP, Huff NO, Raj SG, Shulman JA, Yates BJ. Responses of caudal vestibular nucleus neurons of conscious cats to rotations in vertical planes, before and after a bilateral vestibular neurectomy. Exp Brain Res. 2008; 188:175-186. [PubMed: 18368395]

196. Minor LB, Goldberg JM. Vestibular-nerve inputs to the vestibulo-ocular reflex: a functionalablation study in the squirrel monkey. J Neurosci. 1991; 11:1636-1648. [PubMed: 2045879]

197. Mitchell JH. Neural control of the circulation during exercise: insights from the 1970-1971 Oxford studies. Exp Physiol. 2012; 97:14-19. [PubMed: 21890521]

198. Mittelstaedt H. Somatic versus vestibular gravity reception in man. Ann NY Acad Sci. 1992; 656:124-139. [PubMed: 1599138]

199. Miura M, Reis DJ. A blood pressure response from fastigial nucleus and its relay pathway in the brainstem. Am J Physiol. 1970; 219:1330-1336. [PubMed: 5473117]

200. Miura M, Reis DJ. The paramedian reticular nucleus: a site of inhibitory interaction between projections from fastigial nucleus and carotid sinus nerve acting on blood pressure. J Physiol:. 1971; 216:441-460. [PubMed: 5559628]

201. Miura M, Takayama K. Circulatory and respiratory responses to glutamate stimulation of the lateral parabrachial nucleus of the cat. J Auton Nerv Syst. 1991; 32:121-133. [PubMed: 1709415]

202. Miyazawa T, Ishikawa T. Cerebellar inhibitory action on vestibulo-sympathetic responses. J Autonom Nerv Syst. 1983; 7:185-189.

203. Monahan KD, Ray CA. Gender affects calf venous compliance at rest and during baroreceptor unloading in humans. Am J Physiol Heart Circ Physiol. 2004; 286:H895-901. [PubMed: 14604855]

204. Monahan KD, Ray CA. Limb neurovascular control during altered otolithic input in humans. J Physiol. 2002; 538:303-308. [PubMed: 11773337]

205. Monahan KD, Ray CA. Vestibulosympathetic reflex during orthostatic challenge in aging humans. Am J Physiol Regul Integr Comp Physiol. 2002; 283:R1027-1032. [PubMed: 12376394]

206. Money KE. Motion sickness. Physiol Rev. 1970; 50:1-39. [PubMed: 4904269]

207. Mori RL, Cotter LA, Arendt HE, Olsheski CJ, Yates BJ. Effects of bilateral vestibular nucleus lesions on cardiovascular regulation in conscious cats. J Appl Physiol. 2005; 98:526-533. [PubMed: 15475594]

208. Morrison SF, Gebber GL. Axonal branching patterns and funicular trajectories of raphespinal sympathoinhibitory neurons. J Neurophysiol. 1985; 53:759-772. [PubMed: 3981237]

209. Morrison SF, Gebber GL. Classification of raphe neurons with cardiac-related activity. Am J Physiol. 1982; 243:R49-59. [PubMed: 7091395] 
210. Morrison SF, Gebber GL. Raphe neurons with sympathetic-related activity: baroreceptor responses and spinal connections. Am J Physiol. 1984; 246:R338-348. [PubMed: 6703087]

211. Morrison SF, Nakamura K. Central neural pathways for thermoregulation. Front Biosci (Landmark Ed). 2011; 16:74-104. [PubMed: 21196160]

212. Moy JD, Miller DJ, Catanzaro MF, Boyle BM, Ogburn SW, Cotter LA, Yates BJ, McCall AA. Responses of Neurons in the Caudal Medullary Lateral Tegmental Field to Visceral Inputs and Vestibular Stimulation in Vertical Planes. Am J Physiol Regul Integr Comp Physiol. 2012; 303:R929-R940. [PubMed: 22955058]

213. Nakamoto T, Matsukawa K, Liang N, Wakasugi R, Wilson LB, Horiuchi J. Coactivation of renal sympathetic neurons and somatic motor neurons by chemical stimulation of the midbrain ventral tegmental area. J Appl Physiol. 2011; 110:1342-1353. [PubMed: 21393462]

214. Nalivaiko E, Blessing WW. Potential role of medullary raphe-spinal neurons in cutaneous vasoconstriction: an in vivo electrophysiological study. J Neurophysiol. 2002; 87:901-911. [PubMed: 11826055]

215. Ng AV, Johnson DG, Callister R, Seals DR. Muscle sympathetic nerve activity during postural change in healthy young and older adults. Clin Auton Res. 1995; 5:57-60. [PubMed: 7780292]

216. Nisimaru N. Cardiovascular modules in the cerebellum. Jpn J Physiol. 2004; 54:431-448. [PubMed: 15667667]

217. Nisimaru N, Katayama S. Projection of cardiovascular afferents to the lateral nodulus-uvula of the cerebellum in rabbits. Neurosci Res. 1995; 21:343-350. [PubMed: 7777225]

218. Nisimaru N, Watanabe Y. A depressant area in the lateral nodulus-uvula of the cerebellum for renal sympathetic nerve activity and systemic blood pressure in the rabbit. Neurosci Res. 1985; 3:177-181. [PubMed: 3837866]

219. Nisimaru N, Yamamoto M. Depressant action of the posterior lobe of the cerebellum upon renal sympathetic nerve activity. Brain Res. 1977; 133:371-375. [PubMed: 902102]

220. Normand H, Etard O, Denise P. Otolithic and tonic neck receptors control of limb blood flow in humans. J Appl Physiol. 1997; 82:1734-1738. [PubMed: 9173934]

221. Okahara K, Nisimaru N. Climbing fiber responses evoked in lobule VII of the posterior cerebellum from a vagal nerve in rabbits. Neurosci Res. 1991; 12:232-239. [PubMed: 1660985]

222. Ootsuka Y, Blessing WW, McAllen RM. Inhibition of rostral medullary raphe neurons prevents cold-induced activity in sympathetic nerves to rat tail and rabbit ear arteries. Neurosci Lett. 2004; 357:58-62. [PubMed: 15036613]

223. Paintal AS. Vagal sensory receptors and their reflex effects. Physiol Rev. 1973; 53:159-227. [PubMed: 4568412]

224. Pan PS, Zhang YS, Chen YZ. Role of nucleus vestibularis medialis in vestibulo-sympathetic response in rats. Acta Physiologica Sinica. 1991; 43:184-188. [PubMed: 2068589]

225. Paton JF, Gilbey MP. Effect of anesthetic on sympathetic responses evoked from cerebellar uvula in decerebrate cats. Am J Physiol. 1992; 263:H1285-1291. [PubMed: 1415776]

226. Paton JF, La Noce A, Sykes RM, Sebastiani L, Bagnoli P, Ghelarducci B, Bradley DJ. Efferent connections of lobule IX of the posterior cerebellar cortex in the rabbit--some functional considerations. J Auton Nerv Syst. 1991; 36:209-224. [PubMed: 1724006]

227. Paton JFR, Silva-Carvalho L, Thompson CS, Spyer KM. Nucleus tractus solitarius as mediator of evoked parabrachial cariovascular responses in the decerebrate rabbit. J Physiol. 1990; 428:693705. [PubMed: 2231429]

228. Patterson SW, Starling EH. On the mechanical factors which determine the output of the ventricles. J Physiol. 1914; 48:357-379. [PubMed: 16993262]

229. Pilowsky PM, Goodchild AK. Baroreceptor reflex pathways and neurotransmitters: 10 years on. J Hypertens. 2002; 20:1675-1688. [PubMed: 12195099]

230. Pitman JR, Yolton RL. Etiology and treatment of motion sickness: a review. J Am Optometric Assoc. 1983; 54:31-38.

231. Pompeiano O. Vestibulospinal relations: vestibular influences on gamma motoneurons and primary afferents. Prog Brain Res. 1972; 37:197-232. [PubMed: 4264584] 
232. Porter JD, Balaban CD. Connections between the vestibular nuclei and brain stem regions that mediate autonomic function in the rat. J Vestib Res. 1997; 7:63-76. [PubMed: 9057160]

233. Precht W, Volkind R, Maeda M, Giretti ML. The effects of stimulating the cerebellar nodulus in the cat on the responses of vestibular neurons. Neurosci. 1976; 1:301-312.

234. Radtke A, Popov K, Bronstein AM, Gresty MA. Evidence for a vestibulo-cardiac reflex in man. Lancet. 2000; 356:736-737. [PubMed: 11085696]

235. Radtke A, Popov K, Bronstein AM, Gresty MA. Vestibulo-autonomic control in man: Short- and long-latency vestibular effects on cardiovascular function. J Vestib Res. 2003; 13:25-37. [PubMed: 14646022]

236. Ray CA. Effect of gender on vestibular sympathoexcitation. Am J Physiol Regul Integr Comp Physiol. 2000; 279:R1330-R1333. [PubMed: 11004001]

237. Ray CA. Interaction of the vestibular system and baroreflexes on sympathetic nerve activity in humans. Am J Physiol Heart Circ Physiol. 2000; 279:H2399-2404. [PubMed: 11045977]

238. Ray CA, Hume KM. Neck afferents and muscle sympathetic activity in humans: implications for the vestibulosympathetic reflex. J Appl Physiol. 1998; 84:450-453. [PubMed: 9475851]

239. Ray CA, Hume KM, Shortt TL. Skin sympathetic outflow during head-down neck flexion in humans. Am J Physiol. 1997; 273:R1142-1146. [PubMed: 9321897]

240. Ray CA, Hume KM, Steele SL. Sympathetic nerve activity during natural stimulation of horizontal semicircular canals in humans. Am J Physiol. 1998; 275:R1274-1278. [PubMed: 9756560]

241. Rea RF, Wallin BG. Sympathetic nerve activity in arm and leg muscles during lower body negative pressure in humans. J Appl Physiol. 1989; 66:2778-2781. [PubMed: 2745341]

242. Reason, JT.; Brandt, JJ. Motion Sickness. Academic Press; London: 1975.

243. Reis DJ, Ledoux JE. Some central neural mechanisms governing resting and behaviorally coupled control of blood pressure. Circulation. 1987; 76:I2-9. [PubMed: 3297404]

244. Reis DJ, Ross CA, Ruggiero DA, Granata AR, Joh TH. Role of adrenaline neurons of ventrolateral medulla (the $\mathrm{C} 1$ group) in the tonic and phasic control of arterial pressure. Clin Exp Hypertens A. 1984; 6:221-241. [PubMed: 6365368]

245. Rowland TW. The circulatory response to exercise: role of the peripheral pump. Int J Sports Med. 2001; 22:558-565. [PubMed: 11719890]

246. Ruggiero DA, Mtui EP, Otake K, Anwar M. Vestibular afferents to the dorsal vagal complex: Substrate for vestibular-autonomic interactions in the rat. Brain Res. 1996; 743:294-302. [PubMed: 9017258]

247. Ruggiero DA, Regunathan S, Wang H, Milner TA, Reis DJ. Immunocytochemical localization of an imidazoline receptor protein in the central nervous system. Brain Res. 1998; 780:270-293. [PubMed: 9507161]

248. Ruggiero DA, Underwood MD, Mann JJ, Anwar M, Arango V. The human nucleus of the solitary tract: visceral pathways revealed with an "in vitro" postmortem tracing method. J Autonom Nerv Syst. 2000; 79:181-190.

249. Rushmer, RF. Cardiovascular Dynamics. Saunders; Philadelphia: 1976.

250. Sadakane K, Kondo M, Nisimaru N. Direct projection from the cardiovascular control region of the cerebellar cortex, the lateral nodulus-uvula, to the brainstem in rabbits. Neurosci Res. 2000; 36:15-26. [PubMed: 10678528]

251. Sagawa, K. Baroreflex control of systemic arterial pressure and vascular bed. In: Shepherd, JT.; Abboud, FM., editors. Handbook of Physiology Section 2: Circulation Volume III: Peripheral Circulation and Organ Blood Flow, Part 2. American Physiological Society; Bethesa, MD: 1983. p. 453-496.

252. Sauder CL, Leonard TO, Ray CA. Greater sensitivity of the vestibulosympathetic reflex in the upright posture in humans. J Appl Physiol. 2012; 105:65-69. [PubMed: 18450977]

253. Schramm LP, Strack AM, Platt KB, Loewy AD. Peripheral and central pathways regulating the kidney - a study using pseudorabies virus. Brain Res. 1993; 616:251-262. [PubMed: 7689411] 
254. Seagard JL, Hopp FA, Drummond HA, Van Wynsberghe DM. Selective contribution of two types of carotid sinus baroreceptors to the control of blood pressure. Circ Res. 1993; 72:10111022. [PubMed: 8477517]

255. Serrador JM, Schlegel TT, Black FO, Wood SJ. Vestibular effects on cerebral blood flow. BMC Neurosci. 2009; 10:119. [PubMed: 19775430]

256. Shaikh AG, Ghasia FF, Dickman JD, Angelaki DE. Properties of cerebellar fastigial neurons during translation, rotation, and eye movements. J Neurophysiol. 2005; 93:853-863. [PubMed: 15371498]

257. Shaikh AG, Meng H, Angelaki DE. Multiple reference frames for motion in the primate cerebellum. J Neurosci. 2004; 24:4491-4497. [PubMed: 15140919]

258. Shojaku H, Sato Y, Ikarashi K, Kawasaki T. Topographical distribution of Purkinje cells in the uvula and the nodulus projecting to the vestibular nuclei in cats. Brain Res. 1987; 416:100-112. [PubMed: 3620947]

259. Shortt TL, Ray CA. Sympathetic and vascular responses to head-down neck flexion in humans. Am J Physiol. 1997; 272:H1780-1784. [PubMed: 9139962]

260. Siebold C, Glonti L, Glasauer S, Buttner U. Rostral fastigial nucleus activity in the alert monkey during three-dimensional passive head movements. J Neurophysiol. 1997; 77:1432-1446. [PubMed: 9084609]

261. Siebold C, Kleine JF, Glonti L, Tchelidze T, Buttner U. Fastigial nucleus activity during different frequencies and orientations of vertical vestibular stimulation in the monkey. J Neurophysiol. 1999; 82:34-41. [PubMed: 10400932]

262. Silva-Carvalho L, Paton JF, Goldsmith GE, Spyer KM. The effects of electrical stimulation of lobule IXb of the posterior cerebellar vermis on neurones within the rostral ventrolateral medulla in the anaesthetised cat. J Autonom Nerv Syst. 1991; 36:97-106.

263. Silvoniemi P. Vestibular neuronitis. An otoneurological evaluation. Acta Otolaryngol Suppl. 1988; 453:1-72. [PubMed: 3068952]

264. Smith JE, Jansen AS, Gilbey MP, Loewy AD. CNS cell groups projecting to sympathetic outflow of tail artery: neural circuits involved in heat loss in the rat. Brain Res. 1998; 786:153-164. [PubMed: 9554992]

265. Smith OA Jr. Clarke NP. Central Autonomic Pathways. A Study in Functional Neuroanatomy. J Comp Neurol. 1964; 122:399-406. [PubMed: 14184862]

266. Smith OA Jr. Nathan MA. Inhibition of the carotid sinus reflex by stimulation of the inferior olive. Science. 1966; 154:674-675. [PubMed: 5923785]

267. Somana R, Walberg F. Cerebellar afferents from the nucleus of the solitary tract. Neurosci Lett. 1979; 11:41-47. [PubMed: 431884]

268. Spiegel EA. Effect of labyrinthine reflexes on the vegetative nervous system. Arch Otolaryngol. 1946; 44:61-72. [PubMed: 20994672]

269. Spiegel EA, Démétriades TD. Der Einfluss des Vestibular-apparates auf das Gefässsystem. Pflügers Arch ges Physiol. 1922; 196:185-188.

270. Spyer KM. Annual review prize lecture - central nervous mechanisms contributing to cardiovascular control. J Physiol. 1994; 474:1-19. [PubMed: 8014887]

271. Spyer KM. Neural organisation and control of the baroreceptor reflex. Rev Physiol Biochem Pharmacol. 1981; 88:23-124.

272. Stanojevic M. Responses of cerebellar fastigial neurons to neck and macular vestibular inputs. Pflugers Arch. 1981; 391:267-272. [PubMed: 6118850]

273. Stanojevic M, Erway L, Ghelarducci B, Pompeiano O, Willis WD Jr. A comparison of the response characteristics of cerebellar fastigial and vermal cortex neurons to sinusoidal stimulation of macular vestibular receptors. Pflugers Archiv. 1980; 385:95-104. [PubMed: 6104803]

274. Starling, EH. The Linacre Lectue on the Law of the Heart. Longmans, Green; London: 1918.

275. Steinbacher BC Jr. Yates BJ. Brain-stem integrative sites for vestibulo-sympathetic reflexes. Ann N Y Acad Sci. 1996; 781:700-702. [PubMed: 8694481] 
276. Steinbacher BC, Yates BJ. Brainstem interneurons necessary for vestibular influences on sympathetic outflow. Brain Res. 1996; 720:204-210. [PubMed: 8782913]

277. Steinbacher BC, Yates BJ. Processing of vestibular and other inputs by the caudal ventrolateral medullary reticular formation. Am J Physiol Regul Integr Comp Physiol. 1996; 271:R1070_ R1077.

278. Stocker SD, Steinbacher BC, Balaban CD, Yates BJ. Connections of the caudal ventrolateral medullary reticular formation in the cat brainstem. Exp Brain Res. 1997; 116:270-282. [PubMed: 9348126]

279. Strack AM, Sawyer WB, Marubio LM, Loewy AD. Spinal origin of sympathetic preganglionic neurons in the rat. Brain Res. 1988; 455:187-191. [PubMed: 3416186]

280. Sugiyama Y, Suzuki T, DeStefino VJ, Yates BJ. Integrative responses of neurons in nucleus tractus solitarius to visceral afferent stimulation and vestibular stimulation in vertical planes. Am J Physiol Regul Integr Comp Physiol. 2011; 301:R1380-1390. [PubMed: 21832211]

281. Sugiyama Y, Suzuki T, Yates BJ. Role of the rostral ventrolateral medulla (RVLM) in the patterning of vestibular system influences on sympathetic nervous system outflow to the upper and lower body. Exp Brain Res. 2011; 210:515-527. [PubMed: 21267550]

282. Sundlof G, Wallin BG. The variability of muscle nerve sympathetic activity in resting recumbent man. J Physiol. 1977; 272:383-397. [PubMed: 592196]

283. Sved AF, Ito S, Madden CJ, Stocker SD, Yajima Y. Excitatory inputs to the RVLM in the context of the baroreceptor reflex. Ann NY Acad Sci. 2001; 940:247-258. [PubMed: 11458682]

284. Sved AF, Ito S, Sved JC. Brainstem mechanisms of hypertension: role of the rostral ventrolateral medulla. Current Hypertension Rep. 2003; 5:262-268.

285. Sverrisdottir YB, Rundqvist B, Elam M. Relative burst amplitude in human muscle sympathetic nerve activity: a sensitive indicator of altered sympathetic traffic. Clin Auton Res. 1998; 8:95100. [PubMed: 9613799]

286. Tang PC, Gernandt BE. Autonomic responses to vestibular stimulation. Exp Neurol. 1969; 24:558-578. [PubMed: 5799203]

287. Thoren PN. Atrial receptors with nonmedullated vagal afferents in the cat. Discharge frequency and pattern in relation to atrial pressure. Circ Res. 1976; 38:357-362. [PubMed: 1269072]

288. Uchino Y. Effects of electric stimulation of the vestibular nerve on sympathetic nervous activities. Shinkei Kenkyu No Shimpo. 1970; 14:129-133. [PubMed: 5465606]

289. Uchino Y, Kudo N, Tsuda K, Iwamura Y. Vestibular inhibition of sympathetic nerve activities. Brain Res. 1970; 22:195-206. [PubMed: 5458666]

290. Ugolini G. Transneuronal transfer of herpes simplex virus type 1 (HSV 1) from mixed limb nerves to the CNS. I. Sequence of transfer from sensory, motor, and sympathetic nerve fibres to the spinal cord. J Comp Neurol. 1992; 326:527-548. [PubMed: 1336502]

291. Valbo AH, Hagbath K-E, Wallin BG. Microneurography: how the techniques developed and its role in the investigation of the sympathetic nervosu system. J Appl Physiol. 2004; 96:1262-1269. [PubMed: 15016790]

292. van Lieshout JJ, Wieling W, Wesseling KH, Endert E, Karemaker JM. Orthostatic hypotension caused by sympathectomies performed for hyperhidrosis. Neth J Med. 1990; 36:53-57. [PubMed: 2314521]

293. Vertes RP, Crane AM. Descending projections of the posterior nucleus of the hypothalamus: Phaseolus vulgaris leucoagglutinin analysis in the rat. J Comp Neurol. 1996; 374:607-631. [PubMed: 8910738]

294. Vibert D, Safran A. Subjective visual vertical in peripheral unilateral vestibular diseases. J Vestib Res. 1999; 9:145-152. [PubMed: 10378186]

295. Vissing SF, Scherrer U, Victor RG. Increase of sympathetic discharge to skeletal muscle but not to skin during mild lower body negative pressure in humans. J Physiol. 1994; 481(Pt 1):233-241. [PubMed: 7853246]

296. Voustianiouk A, Kaufmann H, Diedrich A, Raphan T, Biaggioni I, Macdougall H, Ogorodnikov D, Cohen B. Electrical activation of the human vestibulo-sympathetic reflex. Exp Brain Res. 2006; 171:251-261. [PubMed: 16308690] 
297. Walberg F, Dietrichs E. The interconnection between the vestibular nuclei and the nodulus: a study of reciprocity. Brain Res. 1988; 449:47-53. [PubMed: 2456133]

298. Waldrop, TG.; Eldridge, FL.; Iwamoto, GA.; Mitchell, JH. Central neural control of respiration and circulation during exercise. In: Rowell, LB.; Shepherd, JT., editors. Handbook of Physiology, Section 12, Exercise: Regulation and Integration of Multiple Systems. Oxford University Press; New York: 1996.

299. Waldrop TG, Iwamoto GA. Cardiovascular responses to chemical stimulation of the inferior olive in the cat. Brain Res Bull. 1991; 26:667-670. [PubMed: 1682014]

300. Wang W, Han HY, Zucker IH. Depressed baroreflex in heart failure is not due to structural change in carotid sinus nerve fibers. J Auton Nerv Syst. 1996; 57:101-108. [PubMed: 8867092]

301. Watenpaugh DE, Cothron AV, Wasmund SL, Wasmund WL, Carter R 3rd, Muenter NK, Smith ML. Do vestibular otolith organs participate in human orthostatic blood pressure control? Auton Neurosci. 2002; 100:77-83. [PubMed: 12422963]

302. Watenpaugh, DE.; Hargens, AR. The cardiovascular system in microgravity. In: Fregley, MJ.; Blatteis, CM., editors. Handbook of Physiology Section 4: Environmental Physiology. Oxford University Press; New York: 1996. p. 631-674.

303. Wearne, S.; Raphan, T.; Waespe, W.; Cohen, B. Control of the three-dimensional dynamic characteristics of the angular vestibulo-ocular reflex by the nodulus and uvula. In: Dezeeuw, CI.; Strata, P.; Voogd, J., editors. Cerebellum: from Structure to Control. Elsevier; Amsterdam: 1997. p. 321-334.

304. Wieling W, Krediet CT, van Dijk N, Linzer M, Tschakovsky ME. Initial orthostatic hypotension: review of a forgotten condition. Clin Sci (Lond). 2007; 112:157-165. [PubMed: 17199559]

305. Williamson JW. The relevance of central command for the neural cardiovascular control of exercise. Exp Physiol. 2010; 95:1043-1048. [PubMed: 20696787]

306. Wilson TD, Cotter LA, Draper JA, Misra SP, Rice CD, Cass SP, Yates BJ. Effects of postural changes and removal of vestibular inputs on blood flow to the head of conscious felines. J Appl Physiol. 2006; 100:1475-1482. [PubMed: 16439511]

307. Wilson TD, Cotter LA, Draper JA, Misra SP, Rice CD, Cass SP, Yates BJ. Vestibular inputs elicit patterned changes in limb blood flow in conscious cats. J Physiol. 2006; 575:671-684. [PubMed: 16809368]

308. Wilson TD, Serrador JM, Shoemaker JK. Head position modifies cerebrovascular response to orthostatic stress. Brain Res. 2003; 961:261-268. [PubMed: 12531493]

309. Wilson TE, Kuipers NT, McHugh EA, Ray CA. Vestibular activation does not influence skin sympathetic nerve responses during whole body heating. J Appl Physiol. 2004; 97:540-544. [PubMed: 15075298]

310. Wilson VJ. Vestibulospinal and neck reflexes interaction in the vestibular nuclei. Arch Ital Biol. 1991; 129:43-52. [PubMed: 2012475]

311. Wilson VJ, Schor RH, Suzuki I, Park BR. Spatial organization of neck and vestibular reflexes acting on the forelimbs of the decerebrate cat. J Neurophysiol. 1986; 55:514-526. [PubMed: 3485706]

312. Woodring SF, Rossiter CD, Yates BJ. Pressor response elicited by nose-up vestibular stimulation in cats. Exp Brain Res. 1997; 113:165-168. [PubMed: 9028786]

313. Yates, BJ. Motion sickness. In: Binder, MD.; Hirokawa, N.; Windhorst, U., editors. Encyclopedia of Neuroscience. Springer-Verlag; Heidelberg: 2009. p. 2410-2413.

314. Yates BJ. Vestibular influences on the autonomic nervous system. Ann NY Acad Sci. 1996; 781:458-473. [PubMed: 8694435]

315. Yates BJ, Aoki M, Burchill P, Bronstein AM, Gresty MA. Cardiovascular responses elicited by linear acceleration in humans. Exp Brain Res. 1999; 125:476-484. [PubMed: 10323294]

316. Yates BJ, Balaban CD, Miller AD, Endo K, Yamaguchi Y. Vestibular inputs to the lateral tegmental field of the cat: potential role in autonomic control. Brain Res. 1995; 689:197-206. [PubMed: 7583323]

317. Yates, BJ.; Bronstein, AM. Vestibular system influences on respiratory muscle activity and cardiovascular functions. In: Mathias, CJ.; Bannister, SR., editors. Autonomic Failure: A Textbook of Clinical Disorders of the Autonomic Nervous System. Oxford: 2013. p. 97-107. 
318. Yates BJ, Goto T, Bolton PS. Responses of neurons in the caudal medullary raphe nuclei of the cat to stimulation of the vestibular nerve. Exp Brain Res. 1992; 89:323-332. [PubMed: 1623976]

319. Yates BJ, Goto T, Bolton PS. Responses of neurons in the rostral ventrolateral medulla of the cat to natural vestibular stimulation. Brain Res. 1993; 601:255-264. [PubMed: 8431771]

320. Yates BJ, Goto T, Kerman I, Bolton PS. Responses of caudal medullary raphe neurons to natural vestibular stimulation. J Neurophysiol. 1993; 70:938-946. [PubMed: 8229180]

321. Yates BJ, Grélot L, Kerman IA, Balaban CD, Jakus J, Miller AD. Organization of vestibular inputs to nucleus tractus solitarius and adjacent structures in cat brain stem. Am J Physiol. 1994; 267:R974-983. [PubMed: 7524372]

322. Yates BJ, Holmes MJ, Jian BJ. Plastic changes in processing of graviceptive signals during spaceflight potentially contribute to postflight orthostatic intolerance. J Vestib Res. 2003; 13:395-404. [PubMed: 15096680]

323. Yates BJ, Jakus J, Miller AD. Vestibular effects on respiratory outflow in the decerebrate cat. Brain Res. 1993; 629:209-217. [PubMed: 8111625]

324. Yates BJ, Jian BJ, Cotter LA, Cass SP. Responses of vestibular nucleus neurons to tilt following chronic bilateral removal of vestibular inputs. Exp Brain Res. 2000; 130:151-158. [PubMed: 10672468]

325. Yates BJ, Kerman IA. Post-spaceflight orthostatic intolerance: possible relationship to microgravity-induced plasticity in the vestibular system. Brain Res Rev. 1998; 28:73-82. [PubMed: 9795146]

326. Yates BJ, Miller AD. Physiological evidence that the vestibular system participates in autonomic and respiratory control. J Vestib Res. 1998; 8:17-25. [PubMed: 9416585]

327. Yates BJ, Miller AD. Properties of sympathetic reflexes elicited by natural vestibular stimulation: implications for cardiovascular control. J Neurophysiol. 1994; 71:2087-2092. [PubMed: 7931504]

328. Yates BJ, Siniaia MS, Miller AD. Descending pathways necessary for vestibular influences on sympathetic and inspiratory outflow. Am J Physiol Regul Integr Comp Physiol. 1995; 268:R1381-R1385.

329. Yates, BJ.; Wilson, TD. Vestibulo-autonomic responses. In: Squire, LR., editor. Encyclopedia of Neuroscience. Academic Press; Oxford: 2009. p. 133-138.

330. Yates BJ, Yamagata Y, Bolton PS. The ventrolateral medulla of the cat mediates vestibulosympathetic reflexes. Brain Res. 1991; 552:265-272. [PubMed: 1913189]

331. Yavorcik KJ, Reighard DA, Misra SP, Cotter LA, Cass SP, Wilson TD, Yates BJ. Effects of postural changes and removal of vestibular inputs on blood flow to and from the hindlimb of conscious felines. Am J Physiol Regul Integr Comp Physiol. 2009; 297:R1777-1784. [PubMed: 19793952]

332. Zhong S, Huang ZS, Gebber GL, Barman SM. Role of the brain stem in generating the 2- to 6-Hz oscillation in sympathetic nerve discharge. Am J Physiol. 1993; 265:R1026-1035. [PubMed: 8238603]

333. Zhou W, Tang BF, King WM. Responses of rostral fastigial neurons to linear acceleration in an alert monkey. Exp Brain Res. 2001; 139:111-115. [PubMed: 11482837] 


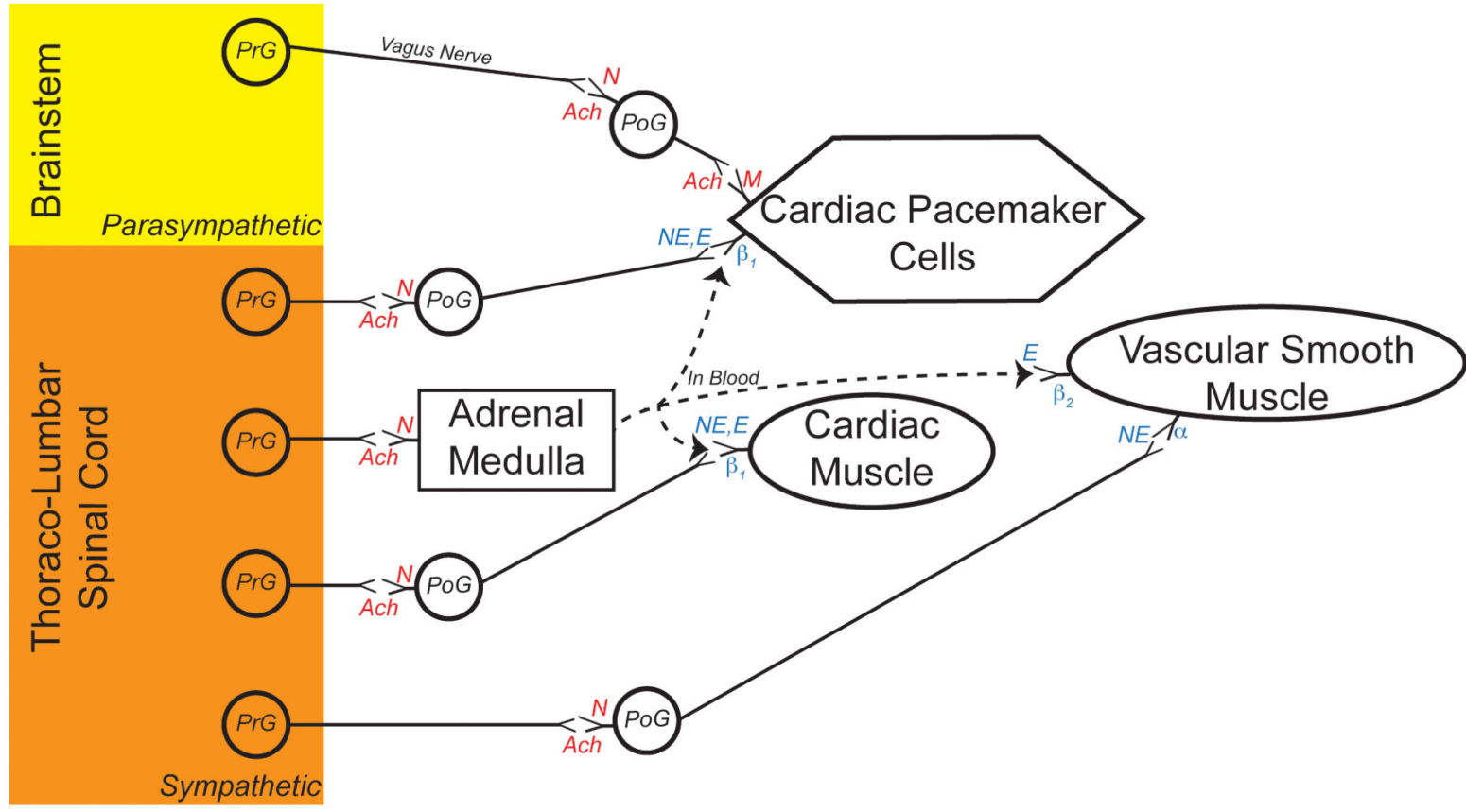

Fig. 1.

Primary connections of the sympathetic and parasympathetic nervous system that control blood flow and blood pressure. Parasympathetic preganglionic neurons $(\operatorname{Pr} G)$ whose cell bodies are located in the brainstem send axons principally through the vagus nerve to postganglionic neurons $(P o G)$ whose cell bodies are located in ganglia near the heart. Parasympathetic $\operatorname{PrG}$ release the neurotransmitter acetylcholine (Ach) onto nicotinic $(N)$ receptors on the cell body and dendrites of parasympathetic PoG. Parasympathetic PoG release acetylcholine onto muscarinic receptors on the surface of autorhythmic (pacemaker) cells in the heart, particularly those in the sinoatrial node. The binding of acetylcholine to these muscarinic receptors induces a decrease in heart rate.

Sympathetic PrG whose cell bodies are located in the thoracic and lumbar spinal cord send axons to PoG whose cell bodies are located in prevertebral or paravertebral ganglia. Like parasympathetic PrG, sympathetic PrG release Ach onto nicotinic receptors located on the cell body and dendrites of sympathetic PoG. Sympathetic PoG project to the heart, and release the neurotransmitter norepinephrine ( $N E$ ) onto $\beta_{1}$ receptors located on the surface of pacemaker cells. The binding of norepinephrine to these receptors induces an increase in heart rate.

Sympathetic PoG additionally release norepinephrine onto $\beta_{1}$ receptors located on myocytes in the ventricles of the heart. Binding of neurotransmitter to these receptors induces an increase in contractility of the muscle cells. Furthermore, sympathetic PoG innervate smooth muscle in the walls of blood vessels, primarily arterioles. Norepinephrine released from PoG binds primarily to a receptors on the surface of vascular smooth muscle. Binding of norepinephrine to these receptors causes vasoconstriction, and results in decreased blood flow through the affected vessels.

In addition, sympathetic PrG release acetylcholine onto nicotinic receptors on adrenal chromaffin cells. Binding of acetylcholine to these receptors induces the release of epinephrine (E) and some norepinephrine from the chromaffin cells. Epinephrine preferentially binds to $\beta$ receptors, and elicits an increase in heart rate and ventricular contractility by binding to $\beta_{1}$ receptors in the heart. Epinephrine also binds to $\beta_{2}$ receptors associated with vascular smooth muscle in particular vascular beds, including arterioles in skeletal muscle. Binding of epinephrine to $\beta_{2}$ receptors results in vasodilation. However, when epinephrine levels are high, the hormone binds to a receptors and causes vasoconstriction. Thus, epinephrine can result in an increase or decrease in blood flow to a particular tissue, depending on the amount of the hormone released into the bloodstream. 


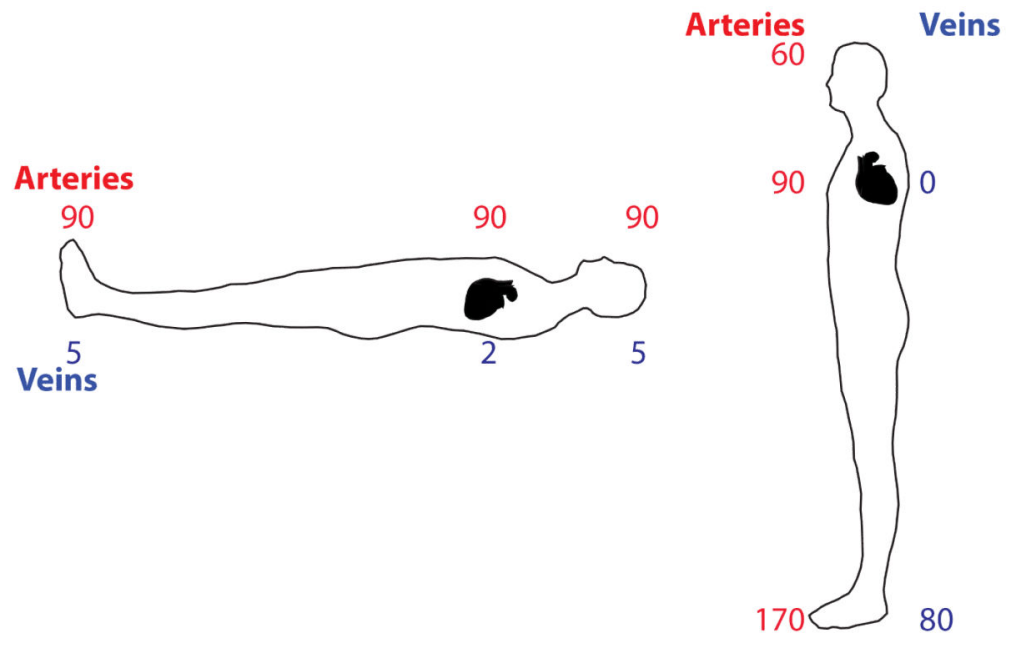

Fig. 2.

Pressures $(\mathrm{mm} \mathrm{Hg})$ in the large arteries (red) and veins (blue) when lying supine or standing. 


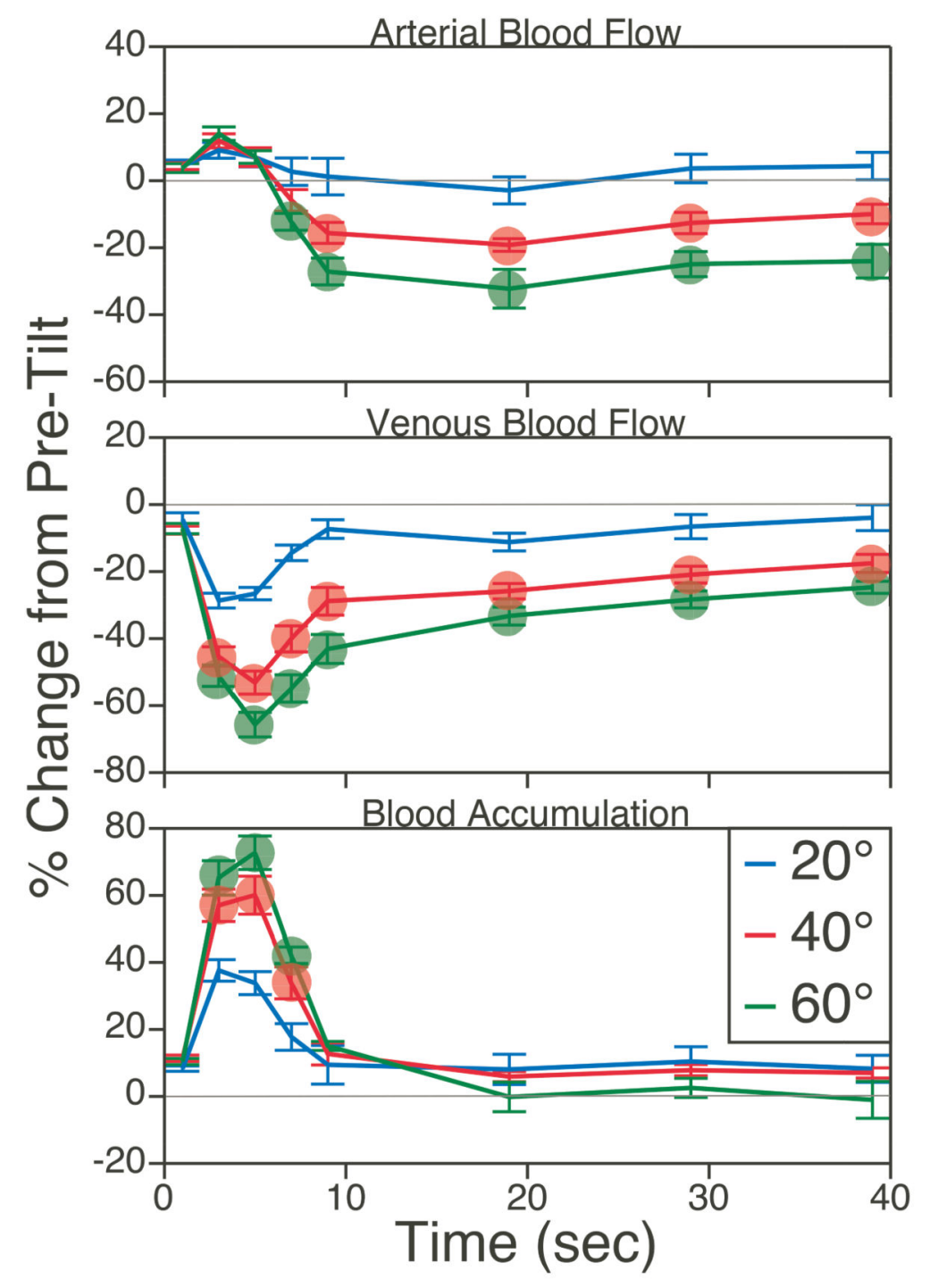

Fig. 3.

Average changes in femoral artery (top panel) and vein (middle panel) blood flow during $20^{\circ}$, $40^{\circ}$, and $60^{\circ}$ head-up tilts. Bottom trace: instantaneous blood accumulation at each time period, determined by subtraction of percent difference from baseline in venous blood flow from percent difference from baseline in arterial blood flow. Symbols designate changes in blood flow and blood accumulation elicited by $40^{\circ}$ and $60^{\circ}$ tilt that were significantly different from those resulting from $20^{\circ}$ tilt (ANOVA test). Adapted from (331), with permission. 


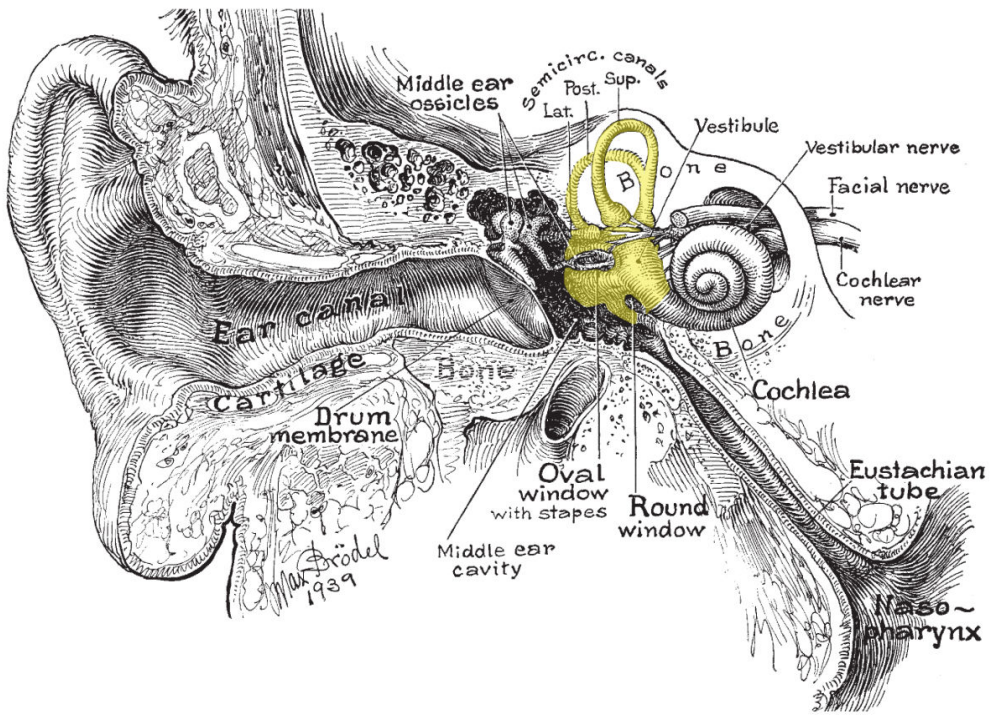

Fig. 4.

Section through the head showing the middle and inner ear. The portion of the inner ear containing the vestibular system endorgans is shaded in yellow. 

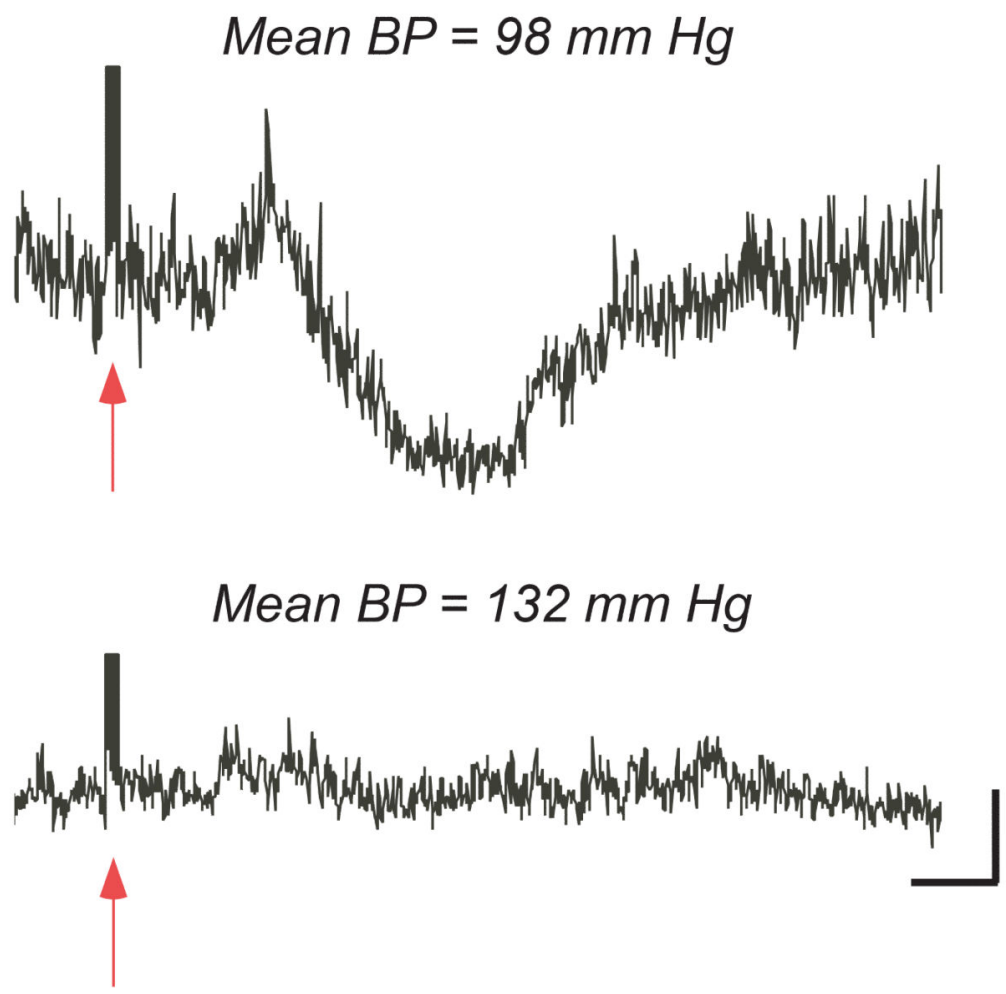

Fig. 5.

Effect of increasing mean blood pressure $(B P)$ by injecting an alpha adrenergic agonist on averaged superior mesenteric nerve responses elicited by a train of electrical stimuli delivered to vestibular afferents. Arrows indicate the latency of the stimulus. When blood pressure was normal ( $98 \mathrm{mmHg}$, top), stimulation of the vestibular nerve elicited large changes in sympathetic nerve activity. However, when blood pressure was raised modestly (132 mm Hg, bottom), the responses were attenuated.

Vertical calibration, $1 \mu \mathrm{V}$; time scale, $100 \mathrm{msec}$. Adapted from (170), with permission. 

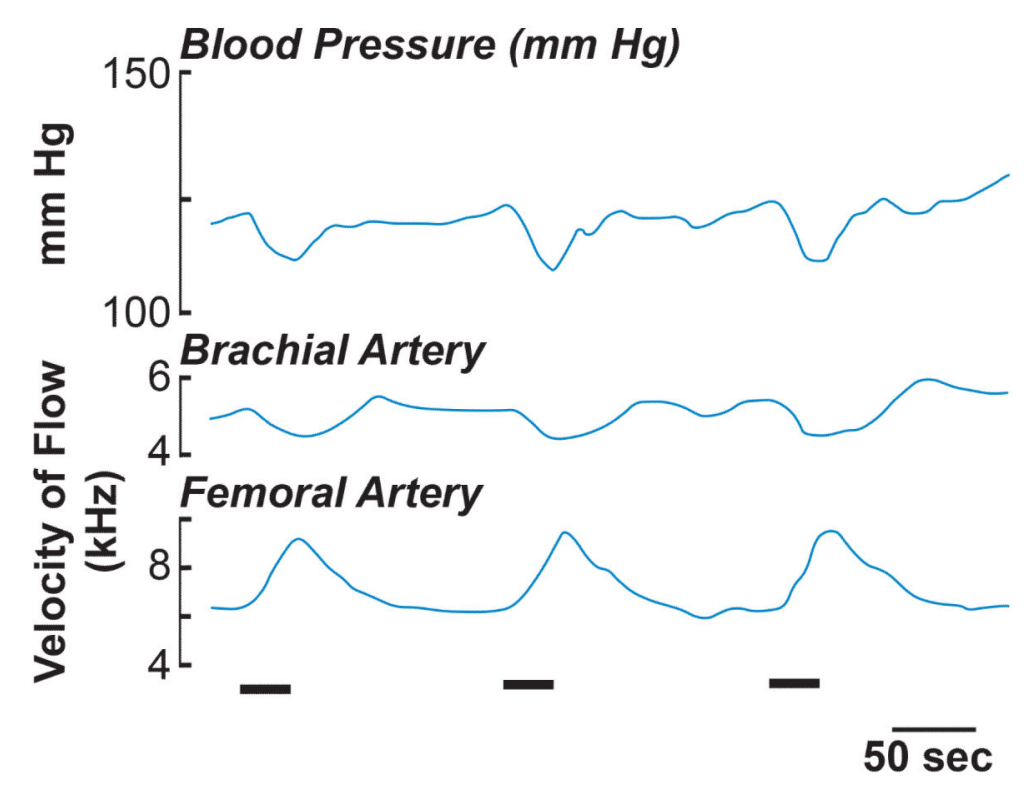

Fig. 6.

Effects of electrical vestibular stimulation (indicated by a bar at the bottom of traces) on arterial blood pressure (top trace) and brachial artery (middle trace) and femoral artery (bottom trace) blood flow. Adapted from (168), with permission. 


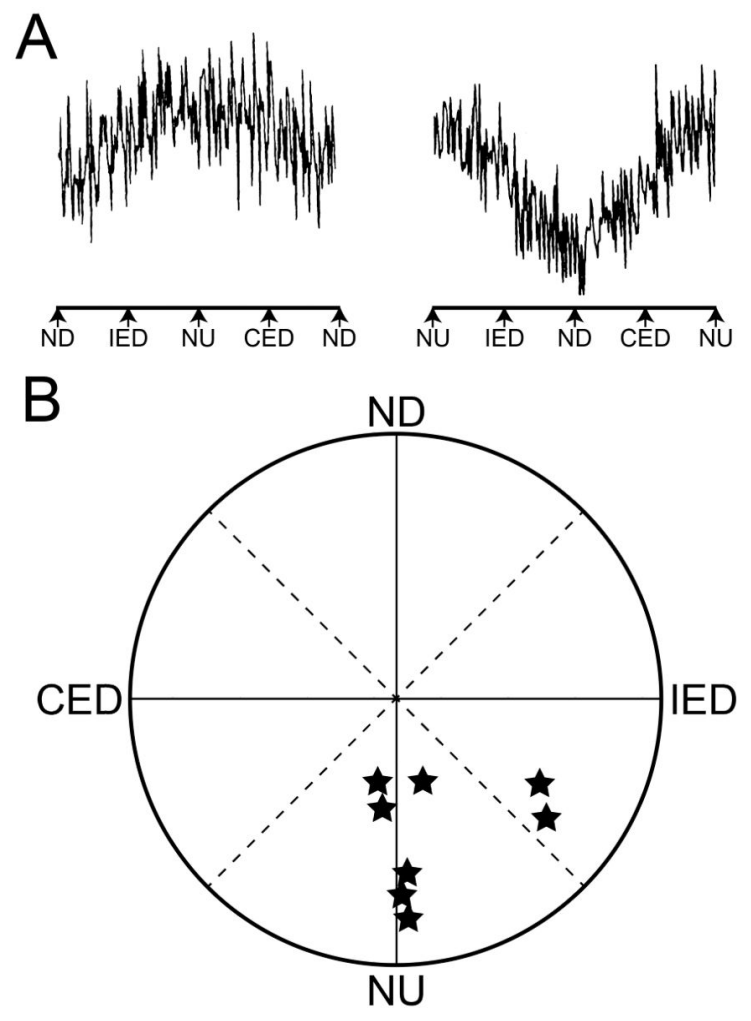

Fig. 7.

A: Averaged splanchnic nerve responses to $15^{\circ}$ head rotations in vertical planes. The rotations were delivered at $0.2 \mathrm{~Hz}$; in the left diagram the head was rotated in the clockwise direction, and in the right diagram the head rotations were in the counterclockwise direction. During both stimuli, maximal nerve activity occurred during nose-up head rotations. B: Polar diagram of vestibular vector orientations for splanchnic nerve responses to vestibular stimulation. The position of a symbol indicates the direction of tilt that produced maximal sympathetic nerve activity. Abbreviations: CED, contralateral ear down tilt; $I E D$, ipsilateral ear down tilt; $N D$, nose down tilt; $N U$, nose up tilt. Adapted from (327), with permission. 

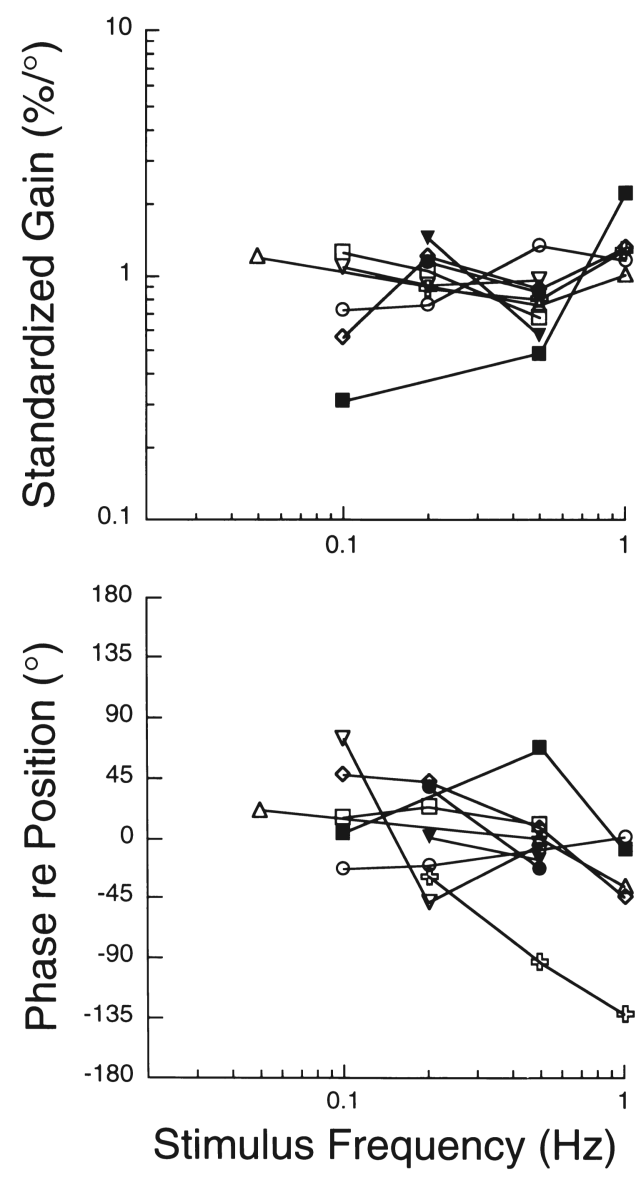

Fig. 8.

Bode diagrams of responses of the splanchnic nerve to head rotations. The responses whose characteristics are depicted were elicited by performing sinusoidal head rotations in the best plane for producing a response. Different symbols are used to designate responses from each animal. Responses gains were standardized by dividing the gain at each frequency by the average gain across frequencies. Data are plotted with respect to stimulus position. Adapted from (327), with permission. 


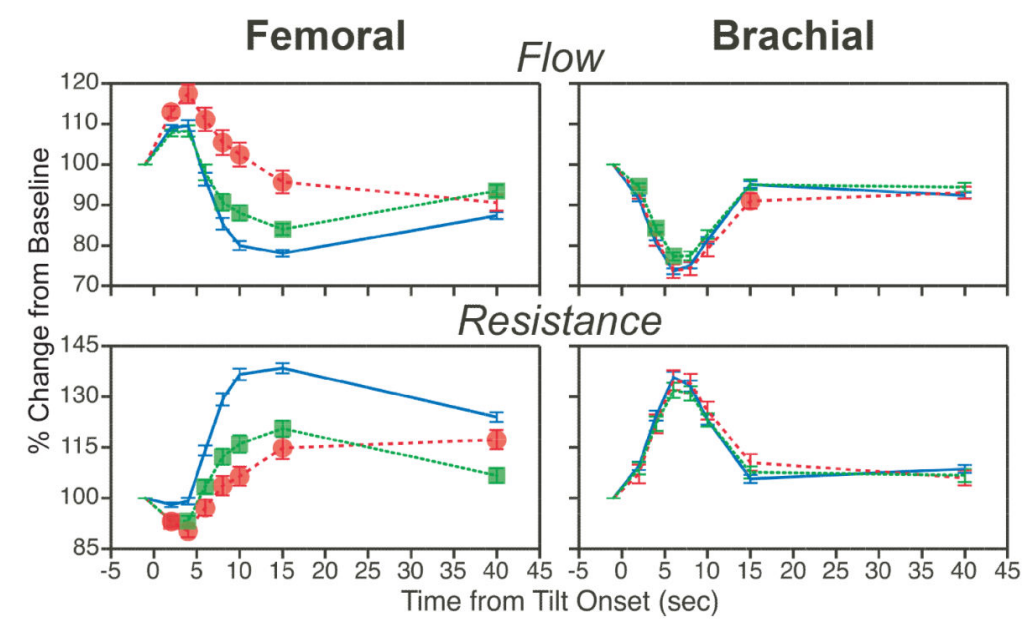

Fig. 9.

The average effects of removal of vestibular inputs on femoral artery (hindlimb; left column) and brachial artery (forelimb; right column) blood flow and vascular resistance during $60^{\circ}$ head-up tilts. Blue lines depict average changes in blood flow and vascular resistance prior to vestibular lesions; red lines and green lines respectively show tilt-related changes in blood flow and vascular resistance during the first week and subsequent three weeks after removal of vestibular inputs. Symbols designate postlesion changes in blood flow and vascular resistance during tilts that were significantly different from those recorded when vestibular inputs were present. Error bars indicate S.E.M. Adapted from (307), with permission. 


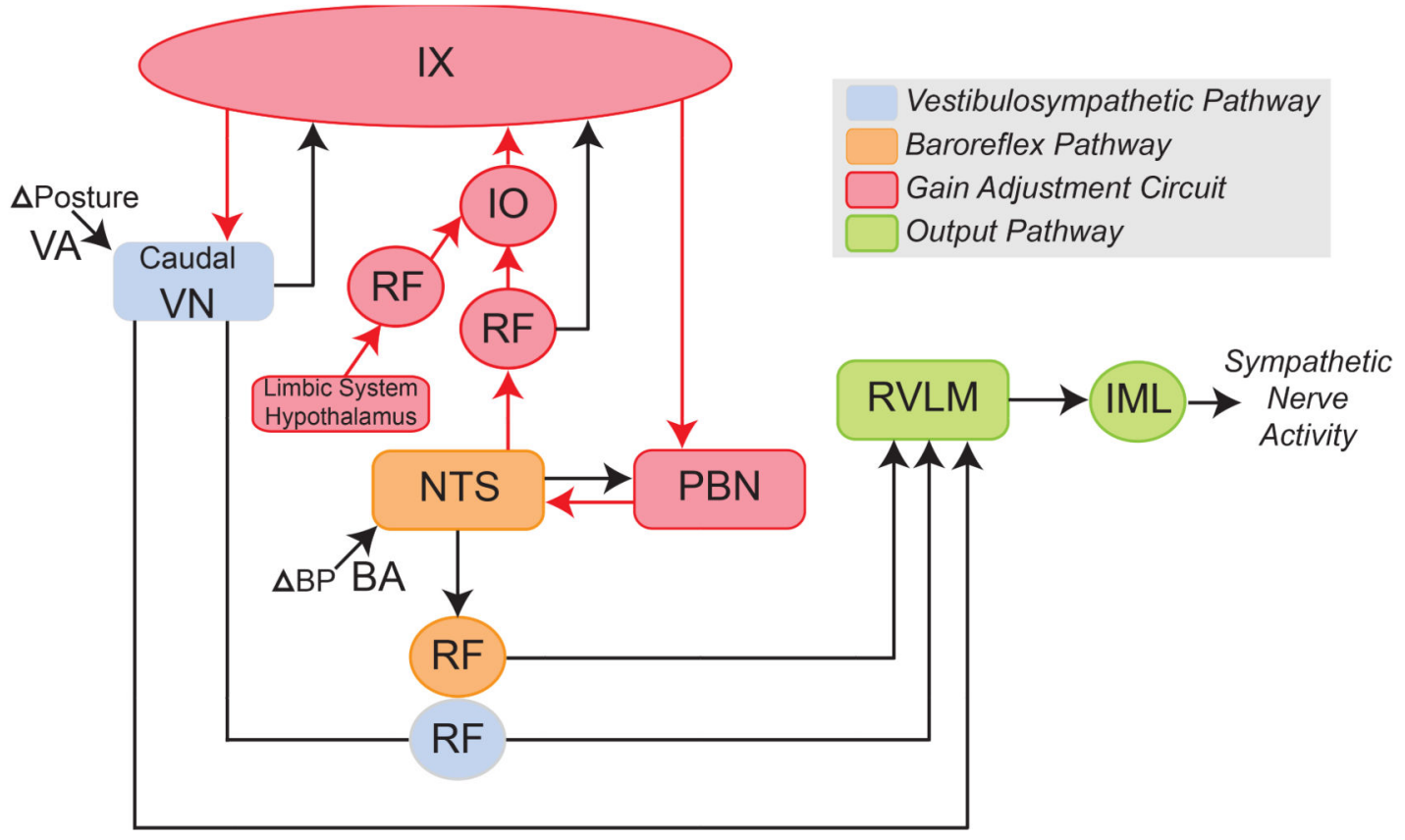

Fig. 10.

Neural regions that generate and modify the gains of vestibulosympathetic reflexes (VSR) and baroreceptor reflexes. Abbreviations: $B A$, baroreceptor afferent; $B P$, blood pressure; $I M L$, intermediolateral cell column; $I O$, inferior olivary nucleus; $I X$, cerebellar lobule IX, uvula; NTS, nucleus tractus solitaries; $P B N$, parabrachial nucleus; $R F$, reticular formation; $R V L M$ : rostral ventrolateral medulla; $V A$, vestibular afferent; $V N$, vestibular nucleus complex. 
A
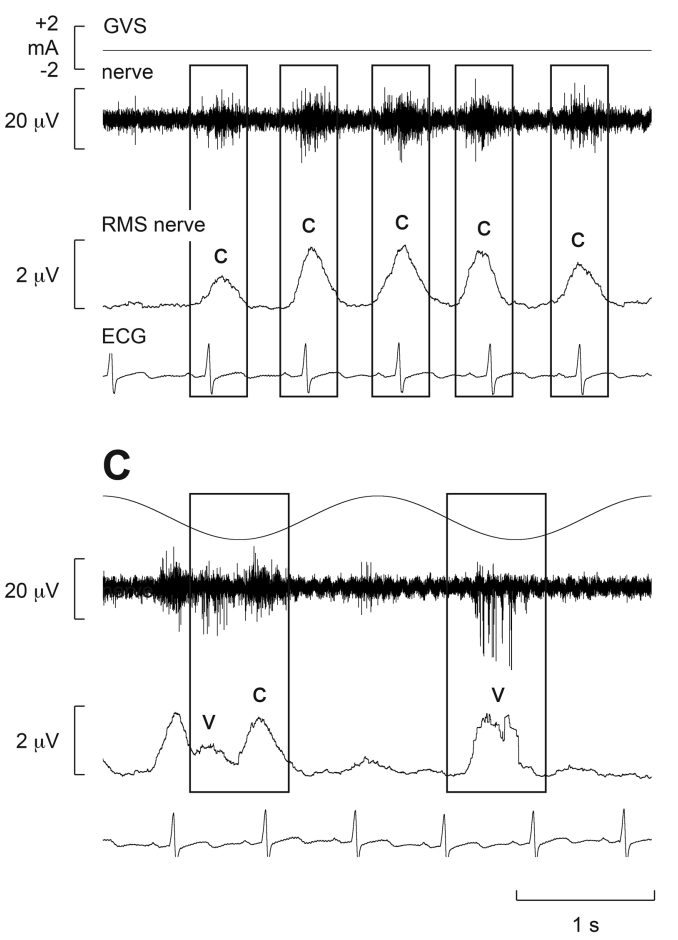

B
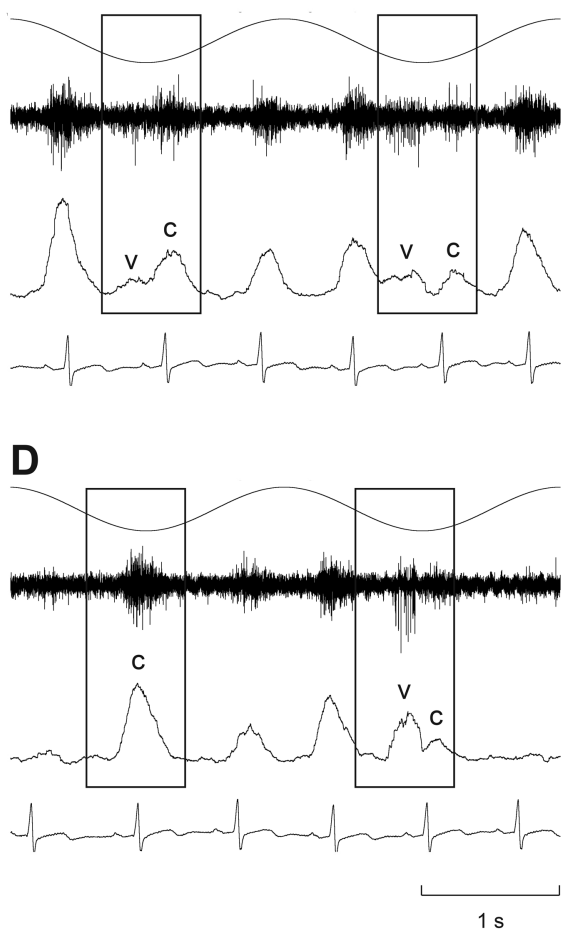

Fig. 11.

Cardiac-locked muscle sympathetic bursts are modulated by dynamic vestibular inputs. Experimental records from one subject. Spontaneous muscle sympathetic nerve activity was recorded from the peronei motor fascicle of the common peroneal nerve, and is presented as the filtered neurogram (nerve) and as an RMS-processed signal (RMS nerve). In each panel, the top trace indicates the onset and phase of the sinusoidal modulation when applied (B-D) and the bottom trace records the ECG. Each panel spans a $4 \mathrm{~s}$ data period. A, baseline activity; B-D, consecutive sequences obtained during sinusoidal galvanic vestibular stimulation (GVS) at $0.5 \mathrm{~Hz}$. The rectangles illustrate the relationship between the sympathetic burst and the cardiac rhythm (c) and the vestibular rhythm (v). Reproduced from (29), with permission. 

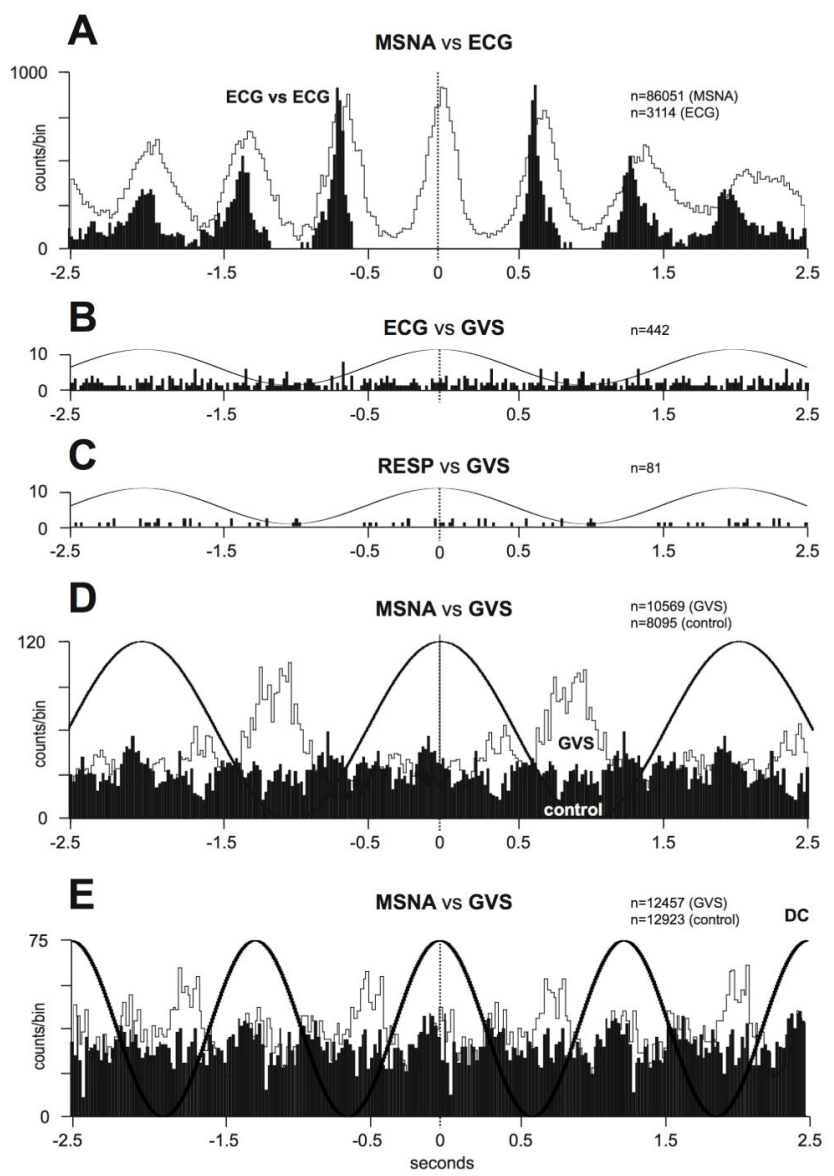

Fig. 12.

Correlations between muscle sympathetic bursts and cardiac and vestibular rhythms. A, cross-correlation histograms of the relationship between muscle sympathetic nerve activity (MSNA) and the electrocardiogram (ECG; white histogram) and autocorrelogram of the ECG (black histogram). B-C, cross-correlation histograms between ECG and galvanic vestibular stimulation (GVS) and respiration (inspiratory peaks) and GVS. A $0.5 \mathrm{~Hz}$ sine wave has been superimposed on the histogram to illustrate the timing of the GVS; it has been inverted for clarity. D-E, cross-correlation histograms of MSNA with respect to the vestibular input (GVS), in white, or to a control sine wave (control), in black. Data in panels A-D are from the same subject represented in Fig. 11; data in panel $\mathbf{E}$ were obtained from another subject. $20 \mathrm{~ms}$ bins in all panels. $\mathrm{n}=$ the numbers of counts comprising the histograms. Reproduced from (29), with permission. 


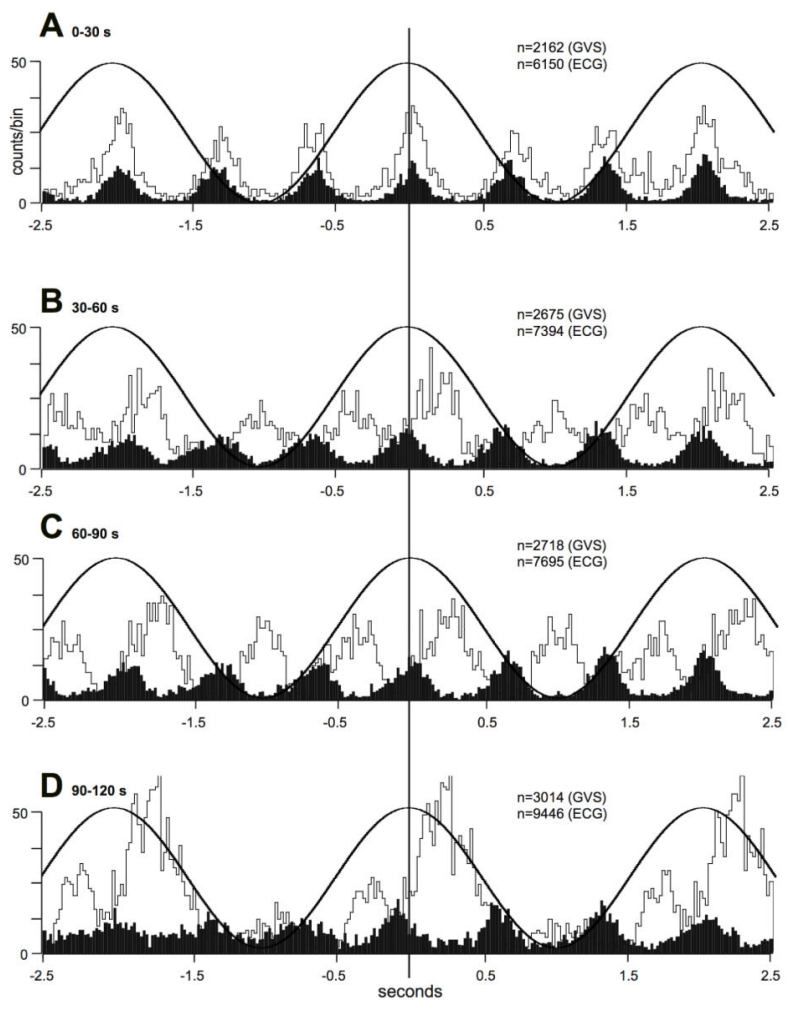

Fig. 13.

Variation in relative contributions of cardiac and vestibular rhythms over time. Cross-correlation histograms of the relationship between muscle sympathetic nerve activity (MSNA) and galvanic vestibular stimulation (GVS; white histogram) and the electrocardiogram (ECG, black histogram) after dividing the data into four consecutive $30 \mathrm{~s}$ segments, each composed of 15 cycles of GVS $(0.5 \mathrm{~Hz})$. The relative influences of the cardiac and vestibular rhythms changed during the course of stimulation. The muscle sympathetic nerve activity (MSNA)_ECG cross-correlograms have been compressed vertically to better illustrate these temporal relationships: 100 spikes is represented by one division on the vertical scale for these data. $20 \mathrm{~ms}$ bins in all panels. $\mathrm{n}=$ the numbers of counts comprising the histograms. Same subject as in Fig. 11 and Fig 12A-C. Reproduced from (29), with permission. 

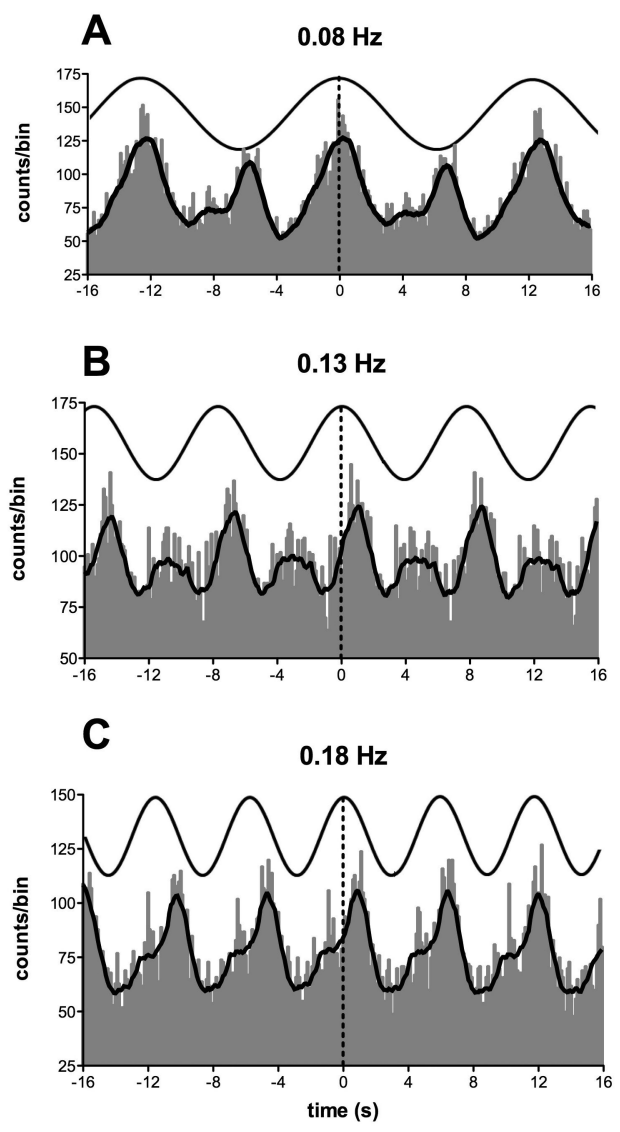

Fig. 14.

Cross-correlation histograms between muscle sympathetic nerve activity (MSNA) and sinusoidal galvanic vestibular stimulation (sGVS) in one subject. The thick curve superimposed on the histograms is the smoothed polynomial that was fitted to the data. The sinusoid above represents the galvanic stimulus, delivered at $0.08,0.13$ and $0.18 \mathrm{~Hz}$. Each cross-correlation histogram shows a large peak of modulation (primary peak), associated with the positive peak of the sinusoid, and a smaller peak (secondary peak). The secondary peak was largest at $0.08 \mathrm{~Hz}$ and smallest at $0.18 \mathrm{~Hz}$. Reproduced from (133), with permission. 


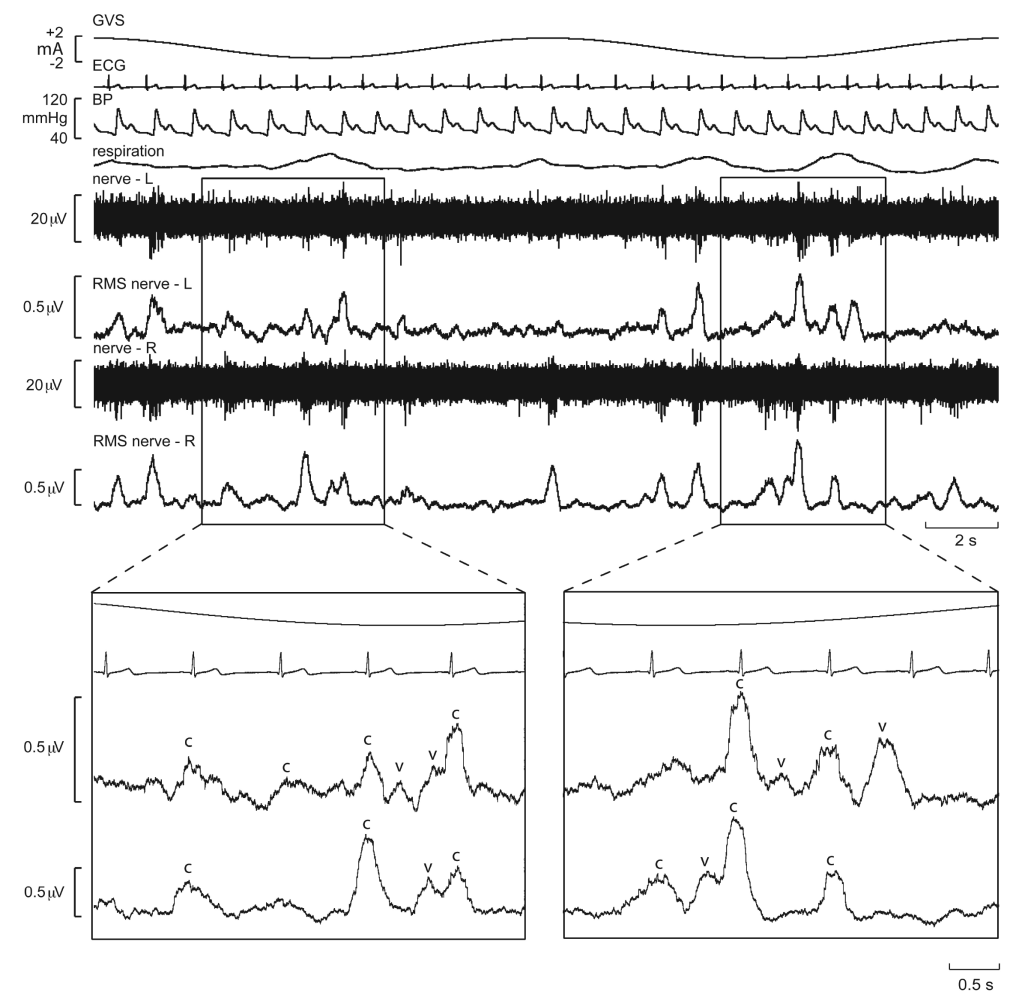

Fig. 15.

Bilateral recordings of muscle sympathetic nerve activity, together with ECG, blood pressure and respiration, during sinusoidal galvanic vestibular stimulation (GVS) at $0.08 \mathrm{~Hz}$ in one subject. Overall, sympathetic outflow was similar between the two sides, but close inspection revealed subtle differences. In the expanded sections, the sympathetic bursts have been shifted back $1.25 \mathrm{~s}$ in time to account for peripheral conduction delays, allowing those bursts aligned with the cardiac cycle ('c') or vestibular stimulus ('v') to be identified. Reproduced from (93), with permission. 


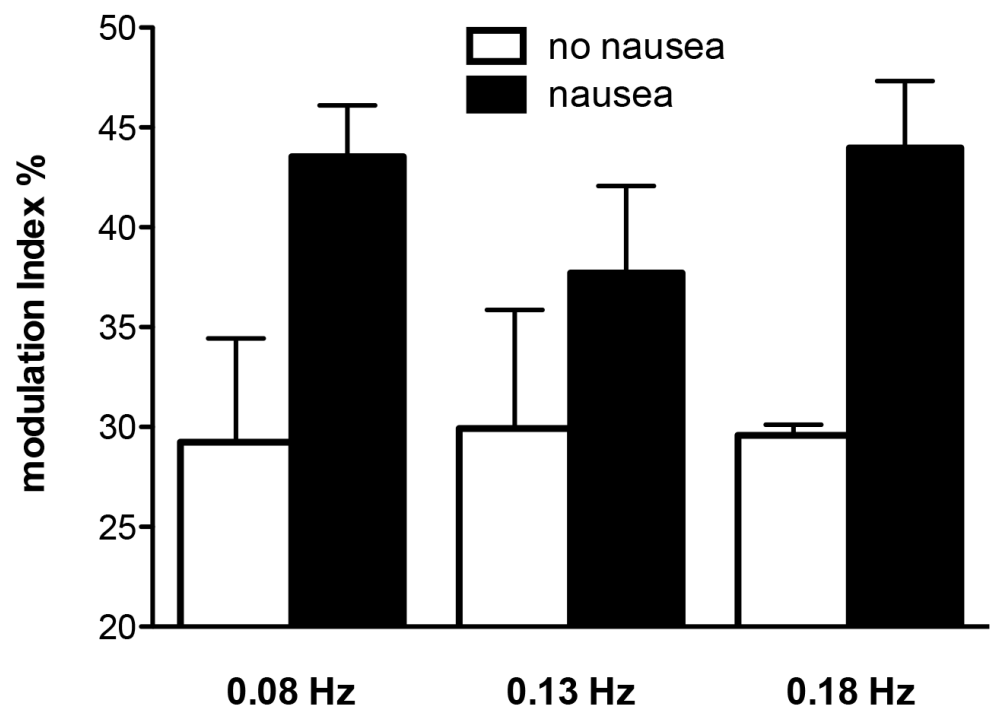

Fig. 16.

Modulation indices of primary peak of skin sympathetic nerve activity (SSNA) during sinusoidal galvanic vestibular stimulation (sGVS) at different frequencies as a function of whether or not subjects reported nausea. It is evident that modulation indices were higher in those subjects who reported nausea. Reproduced from (132), with permission. 

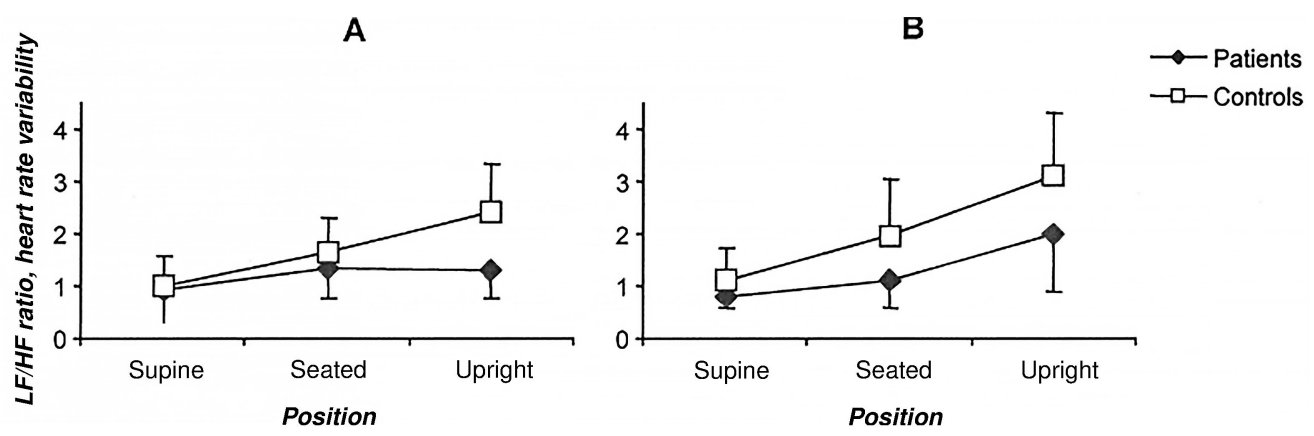

Fig. 17.

Mean and 95\% confidence interval of mean of low frequency/high frequency (LF/HF ratio of heart rate variability during active change in posture, as follows: 5 min supine rest, 5 min back-unsupported sitting, and 5 min upright stance. Data from seven persons with unilateral vestibular failure and seven healthy age/sex matched volunteers at A: day 1, and B: week 2. From (158); used with permission. 

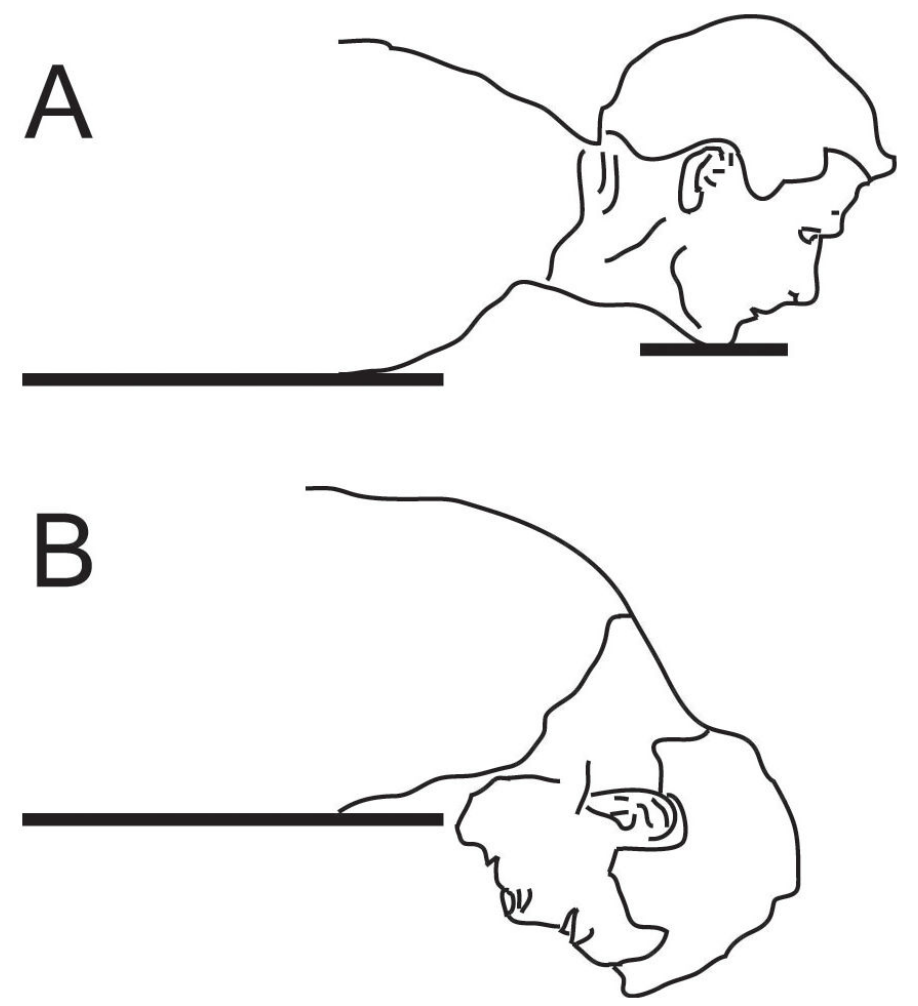

Fig. 18.

Head-down neck flexion posture first used by Essandoh et al (95). A: The subject is prone, with neck slightly extended and the chin resting comfortably on a soft-padded support at the edge of the table. This represents the head-up posture B: chin support is removed, and subject's head is lowered to maximally flex the neck. This represents the head-down neck flexion (HDNF) posture. 
Subject 1
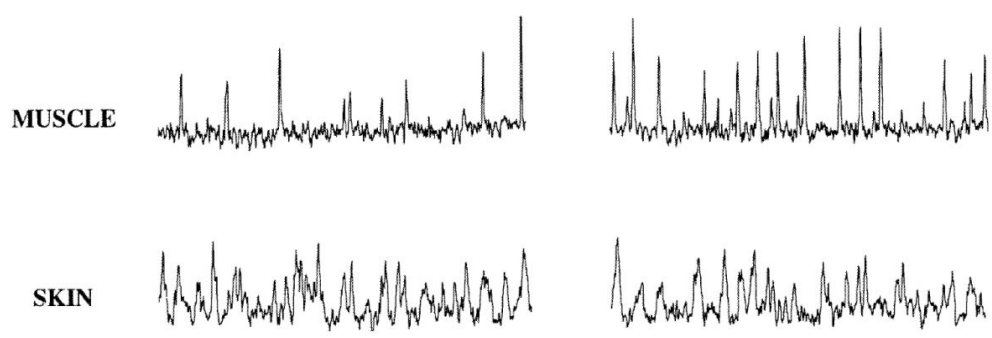

Subject 2

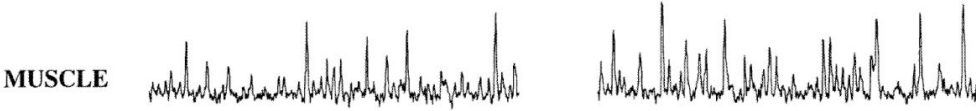
SKIN
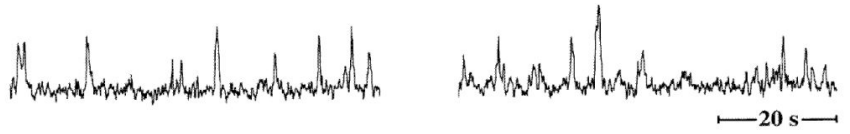

BASELINE

HDNF

Fig. 19.

Recordings of muscle and skin sympathetic nerve activity in two subjects, during baseline and head-down neck flexion (HDNF) conditions. Muscle sympathetic nerve activity was increased during HDNF, whereas skin sympathetic nerve activity was unchanged during HDNF. From (239); used with permission. 

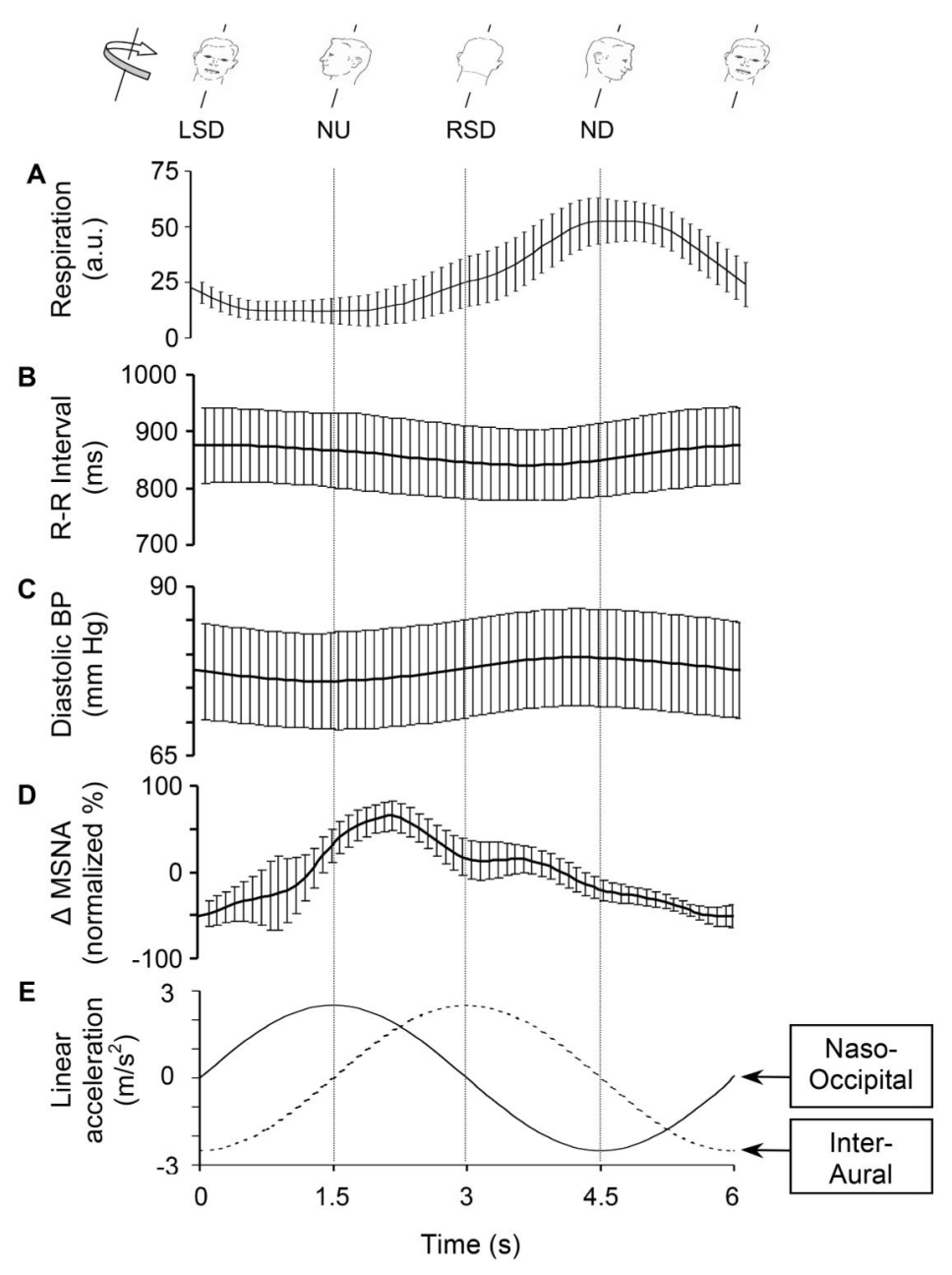

Fig. 20.

Hemodynamic, respiratory, and autonomic modulations during off-vertical axis rotation (OVAR) at $60 \%$. A, Phase of respiratory cycle; B, RR interval; C, diastolic blood pressure; D, change in MSNA; E, changes in the naso-occipital and interaural components of the gravity vector over each cycle of OVAR. Inserts on top indicate the direction of rotation and the position of the head at various phases of the OVAR cycle. Data are the means \pm SE from 10 consecutive cycles of rotation in seven subjects ( $L S D$, left side down; $N U$, nose-up; $R S D$, right side down; $N D$, nose down). From (167); used with permission. 


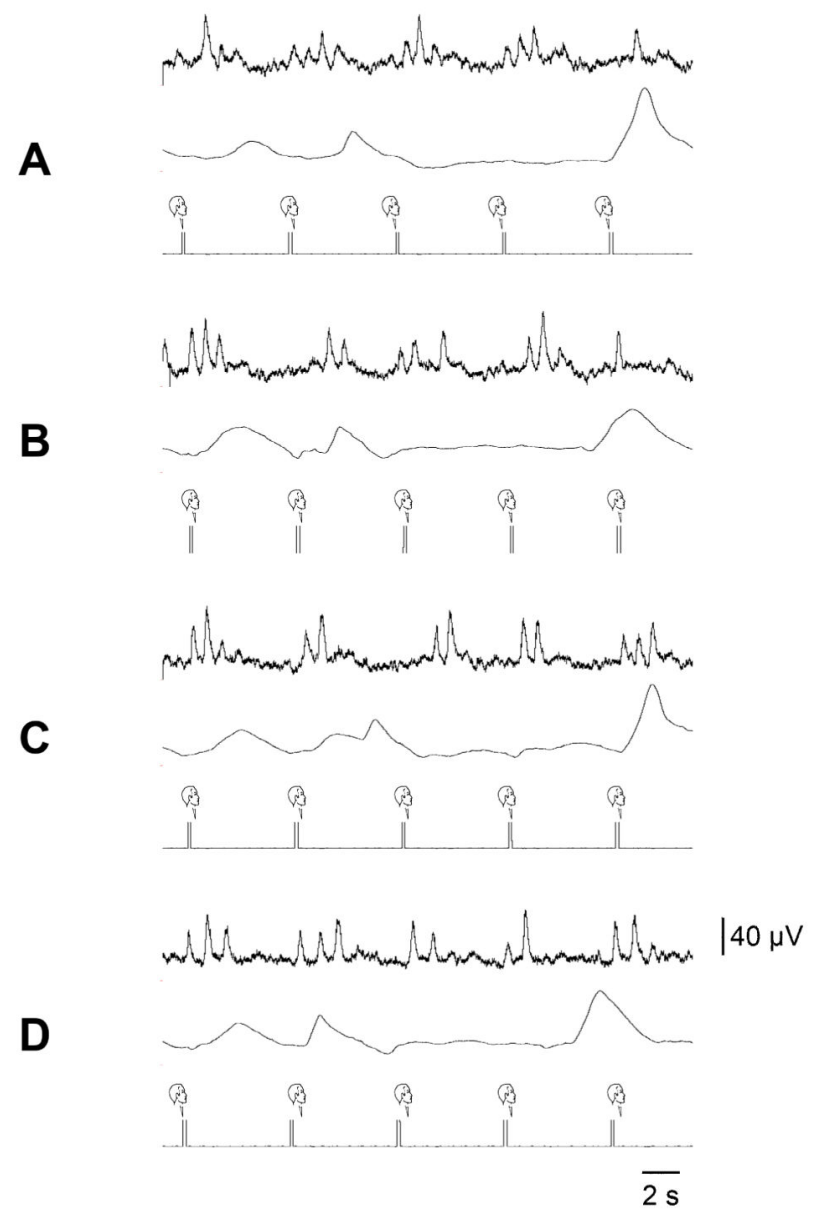

Fig. 21.

Muscle sympathetic nerve activity (MSNA) during earth vertical axis rotation (EVAR) at $60^{\circ} \mathrm{s}$ (A) and off-vertical axis rotation (OVAR) at $24 \%$ s (B) $60^{\circ} / \mathrm{s}$ (C) and $110 \%$ s (D). The axis of rotation was tilted $15^{\circ}$ during OVAR, resulting in a peak acceleration of $0.26 \mathrm{~g}$ along the interaural axis. Upper tracings, MSNA; Lower tracings, signal from the chair holding the subject. The vertical breaks indicate $360^{\circ}$ of rotation and, in B-D, the nose-up position. Inserts over the vertical breaks show the nose-up position of the subject and the axis or rotation. Calibrations are for MSNA voltage and time. From (167); used with permission. 